\title{
Cladistics
}

\section{Phylogeny of the sea spiders (Arthropoda, Pycnogonida) based on direct optimization of six loci and morphology}

\author{
Claudia P. Arango*† and Ward C. Wheeler \\ Division of Invertebrate Zoology, American Museum of Natural History New York, NY 10024-5192, USA
}

Accepted 13 October 2006

\begin{abstract}
Higher-level phylogenetics of Pycnogonida has been discussed for many decades but scarcely studied from a cladistic perspective. Traditional taxonomic classifications are yet to be tested and affinities among families and genera are not well understood. Pycnogonida includes more than 1300 species described, but no systematic revisions at any level are available. Previous attempts to propose a phylogeny of the sea spiders were limited in characters and taxon sampling, therefore not allowing a robust test of relationships among lineages. Herein, we present the first comprehensive phylogenetic analysis of the Pycnogonida based on a total evidence approach and Direct Optimization. Sixty-three pycnogonid species representing all families including fossil taxa were included. For most of the extant taxa more than $6 \mathrm{~kb}$ of nuclear and mitochondrial DNA and 78 morphological characters were scored. The most parsimonious hypotheses obtained in equally weighted total evidence analyses show the two most diverse families Ammotheidae and Callipallenidae to be non-monophyletic. Austrodecidae + Colossendeidae + Pycnogonidae are in the basal most clade, these are morphologically diverse groups of species mostly found in cold waters. The raising of the family Pallenopsidae is supported, while Eurycyde and Ascorhynchus are definitely separated from Ammotheidae. The four fossil taxa are grouped within living Pycnogonida, instead of being an early derived clade. This phylogeny represents a solid framework to work towards the understanding of pycnogonid systematics, providing a data set and a testable hypothesis that indicate those clades that need severe testing, especially some of the deep nodes of the pycnogonid tree and the relationships of ammotheid and callipallenid forms. The inclusion of more rare taxa and additional sources of evidence are necessary for a phylogenetic classification of the Pycnogonida.

(c) The Willi Hennig Society 2007.
\end{abstract}

Pycnogonids or sea spiders (Arthropoda; Pycnogonida) are one of the most extraordinary and intriguing arthropods. A prominent proboscis, the ovigers and the extreme reduction of the abdomen are some of the peculiar characteristics making them easily recognizable and immediately striking. Pycnogonida contains more than 1300 species described, some relatively common at particular habitats and locations, but infrequent and many quite rare. They exhibit a broad range of sizes, forms and habits, from tiny, short-legged intertidal species to large, and long-legged abyssal forms. They

\footnotetext{
*Corresponding author:

E-mail address: claudia.arango@qm.qld.gov.au
}

$†$ Present address: Queensland Museum, PO Box 3300, South Brisbane QLD 4101 Australia inhabit all marine benthic environments worldwide but tend to be cryptic and infrequent thus generally neglected in marine studies. A revision of the biology of sea spiders is in Arnaud and Bamber (1987).

The unresolved phylogenetic affinities of Pycnogonida have been controversial for many years (earlier literature in Hedgpeth, 1947, 1954; Snodgrass, 1952). They are generally regarded as sister group of Euchelicerata or as the sister group to all extant euarthropods (see revision in Dunlop and Arango, 2005; more recent discussion in Giribet et al., 2005; Maxmen et al., 2005; Jager et al., 2006; Manuel et al., 2006). The uncertain origin of the "obscure" sea spiders, is part of, as recently expressed, "one of the most controversial of all zoological topics" (Budd and Telford, 2005). This controversy is continuing and being fueled by a flow of recent data such as phylogenetic data sets (Arango, 2003a), the 
characterization and interpretation of larval anatomy and neurobiology (Vilpoux and Waloszek, 2003; Maxmen et al., 2005), the description of new fossils (Siveter et al., 2004; Poschmann and Dunlop, 2006), and more recently, hox gene expression data (Jager et al., 2006; Manuel et al., 2006). Maxmen et al. (2005) provided an interpretation of novel neuroanatomical data from an Anoplodactylus species (i.e., A. eroticus, see details in Arango and Maxmen, 2006), suggesting chelifores are innervated by the protocerebrum and are not homologous to chelicerae, which are deutocerebral. According to their interpretation, chelifores might be homologous to the "great appendage" of Cambrian stem-arthropods, implying pycnogonids could be the most primitive of all extant arthropods. However, Maxmen et al.'s interpretation has been refuted (Jager et al., 2006; Manuel et al., 2006) with the first data on hox gene expression in sea spiders (Endeis spinosa and Nymphon gracile), which provides strong evidence that chelifores and chelicerae are homologous. Jager et al. (2006) and Manuel et al. (2006) support classical embryological studies showing that chelifores ganglia first appear postorally and then migrate closer to the protocerebrum (Sanchez, 1959 and earlier literature therein). These recent results seem to contribute strongly to a sister group relationship of Pycnogonida and Chelicerata. Such patterns of relationships are yet to be tested in a phylogenetic analysis using an enlarged taxon sampling for Pycnogonida that reflects the variation within the group, and that includes diverse sources of data that can explain the affinities of Pycnogonida in Arthropoda.

On a lower level, there is very little analytical work on the phylogenetic affinities or diversification of sea spiders, and basically no systematic reviews at family or genus level are available. Testable phylogenies of Pycnogonida based on morphological cladistic analysis and molecular data were produced only recently (see References of previous non-cladistic attempts in Arango, 2002, 2003a). These analyses gave a preliminary indication of possible evolutionary patterns in the group such as the parallelism in the reduction and loss of cephalic appendages (chelifores, palps and ovigers) challenging traditional taxonomic classifications (revision in Hedgpeth, 1947; Arnaud and Bamber, 1987; Child, 1998). The inclusion of fragments of ribosomal DNA (18S and 28S) in a first attempt of a total evidence analysis provided some further indications of Austrodecidae as possibly early derived taxon, and the nonmonophyly of Ammotheidae (Arango, 2002). However, too-low variation in the $18 \mathrm{~S}$ fragment and limited taxon sampling reduced the robustness of hypotheses of interfamilial relationships. The need for an improved taxon sampling, the addition of informative characters, and the use of multiple molecular markers analyzed under more exhaustive and consistent analytical procedures was recognized in Arango (2003a).
The aim of the present study was to test the higherlevel phylogeny of the families of Pycnogonida using multiple molecular markers and morphological characters simultaneously. We substantially increase the body of morphological and molecular data from previous studies by (i) the use of six loci adding more than $6 \mathrm{~kb}$; (ii) including 78 morphological characters $[42$ characters added to the previous morphological matrix in Arango (2002)]; (iii) adding four pycnogonid fossils described in the literature to test their affinities to extant taxa; and (iv) adding data of nine non-pycnogonid taxa as outgroup information. This is the largest phylogenetic data set for Pycnogonida available so far, representing all families and taxa from a broad range of latitudes and habitats. Most of the numerous genera are included, except some for which molecular data could not be obtained (e.g., Cilunculus; see Table 1). In Pycnogonida, $22 \%$ of the known genera (18 of 80 ) are monospecific (many of them monotypic), and a similar number have only two or three species described. Generally these taxa are known from deep sea or other remote areas and the chances of collecting fresh material are low. In this study, we were able to include some of the rare or remotely found taxa, such as the Antarctic Decolopoda australis, Pentanymphon antarcticum and Pentapycnon charcoti, and the hydrothermal vents species Sericosura venticola found at more than $1000 \mathrm{~m}$ depth. Thus, although more of the rare taxa are needed for a complete test of affinities, the proposed hypothesis of relationships here constitutes a solid framework for posterior definition of a classification of Pycnogonida, and a revision of the monophyly of the more numerous and complex taxa.

\section{Methods}

\section{Taxon sampling}

An exemplar approach was implemented at least for the ingroup taxa, scoring morphological characters for all the species of pycnogonids for which DNA sequences were obtained, without assuming monophyly at higher levels (Yeates, 1995; Prendini, 2001). Data were compiled for 29 genera and a total of 59 species (Tables 1 and 3). We included species from a wide range of depths and latitudes, as our main aim was to cover as many representative genera from all the families as possible. Most of the species were collected by the first author in a variety of intertidal and subtidal habitats (e.g., coral and rocky reefs, seagrass and algal beds, rocky platforms, fouling docks, low tide sandy beaches) in tropical and subtropical locations (e.g., Caribbean, Pacific USA, east and south-east Australia). Other material was kindly provided by collaborators sampling diverse areas, as remote as 
Table 1

Classification of sea spiders based on Hedgpeth (1954), Stock (1994), Child (1979, 1982, 1998), Arnaud and Bamber (1987), Bamber and El Naga (unpublished data). Number of species in each genera in parentheses. This account indicates a total 1334 species of pycnogonids known. Geographical distribution complemented based on Müller (1993). Genera included in this study marked with *

Phylum ARTHROPODA Siebold, 1848

Class PYCNOGONIDA Latreille, 1810

EXTINCT TAXA

Cambropycnogonon klausmuelleri Waloszek \& Dunlop,

2003 Upper Cambrian Orsten, Sweden

*Haliestes dasos Siveter et al., 2004 Silurian of Herefordshire,

United Kingdom

* Palaeisopus problematicus Broili, 1928 Lower Devonian

Hunsrück Slate, Germany

* Palaeopantopus maucheri Broili, 1929 Lower Devonian

Hunsrück Slate, Germany

* Palaeothea devonica Bergström et al., 1980 Lower Devonian

Hunsrück slate, Germany

Flagellopantopus blocki Poschmann and Dunlop, 2006 Lower

Devonian Hunsrück slate, Germany

LIVING TAXA

AMMOTHEIDAE Dohrn, 1881

* Achelia Hodge, 1864 (70 spp.) tropical and subtropical shallow waters in both hemispheres

Acheliana Arnaud, 1971 (1) Madagascar

* Ammothea Leach, 1814 (41) North and South East Pacific,

Antarctica, Kenya

*Ammothella Verrill, 1900 (45) Tropical East and West Pacific, Caribbean, Africa

*Ascorhynchus Sars, 1877 (77) Africa, Antarctica, West Pacific, North Atlantic, Caribbean, Indian Ocean

Austroraptus Hodgson, 1907 (5) Antarctica

Bathyzetes Stock, 1955 (3) Indonesia, New Caledonia

Boehmia Hoek, 1881(4) South Africa, Antarctica

Calypsopycnon Hedgpeth, 1948 (1) uncertain locality

Chonothea Nakamura \& Child, 1983 (2) Japan

Cilunculus Loman, 1908 (30) Deep-sea; Africa, Antarctica,

West Pacific, Philippines, North Pacific (Japan)

Dromedopycnon Child, 1982 (1) South West Atlantic

Elassorhis Child, 1982 (1) Deep-sea; Brazil

Ephyrogymna Hedgpeth, 1943 (1) Martinique

*Eurycyde Schioedte, 1857 (21) East Atlantic (Cape Verde,

Senegal), Antarctica, Pacific, Caribbean, Norway

Hedgpethius Child, 1974 (3) Caribbean

Hemichela Stock, 1954 (2) Indo-West Pacific, Japan

Heterofragilia Hedgpeth, 1943 (6) New Caledonia, Japan,

St Vincent \& the Grenadines

Megarhethus Child, 1982 (1) Atlantic abyssal, North American Basin

Nymphonella Oshima, 1933 (2) SouthWest Africa, Mediterranean,

Japan

* Nymphopsis Haswell, 1884(13) Africa, Indo-West Pacific,

Caribbean, Mid-Pacific, Japan, Oman

Paranymphon Caullery, 1896 (3) Caribbean, Japan

Proboehmia Stock, 1991 (1) New Caledonia

Prototrygaeus Stock, 1975 (3) Mid Pacific, Guyana

Scipiolus Loman, 1908 (4) South Africa, Indo-west Pacific,

North Pacific (Japan, Russia)

*Sericosura Fry \& Hedgpeth, 1969 (7) Southwest Africa,

Antarctica, Pacific

*Tanystylum Miers, 1879 (46) Africa, Antarctica, Indo-West

Pacific, North Pacific, Caribbean, Japan, Oman

Trygaeus Dohrn, 1881 (1) Mediterranean

AUSTRODECIDAE Stock, 1954
Table 1

Continued

*Austrodecus Hodgson, 1907 (42) Southern Hemisphere

*Pantopipetta Stock, 1963 (15) Antarctica and Northern Atlantic

CALLIPALLENIDAE Hilton, 1942

Anoropallene Stock, 1956 (3) Pacific Ocean

*Austropallene Hodgson, 1915 (11) Antarctica

Bradypallene Kim \& Hong, 1987 (1) Korea

Bango Bamber, 2004 (1) Gabon, Equatorial Guinea

*Callipallene Flynn, 1929 (33) Cosmopolitan

Cheilopallene Stock, 1955 (7) Antarctica, Pacific, Caribbean,

Maldives

Decachela Hilton, 1939 (2) North Pacific

Hannonia Hoek, 1881 (2) Spain, Somalia

Mimipallene Child, 1982 (1) Argentina

Neopallene Dohrn, 1881 (3) New Zealand, Mediterranean

* Oropallene Schimkewitsch, 1930 (5) Pacific

* Parapallene Carpenter, 1892 (21) Madagascar, Australia, Indo-west Pacific, Caribbean

Pigrogromitus Calman, 1927 (1) Pantropical

* Propallene Schimkewitsch, 1909 (12) East Africa, Australia, North Pacific (syn. Metapallene, Staples, 1982).

* Pseudopallene Wilson, 1878 (17) Polar, Australia, Philippines (syn. Spasmopallene, Staples 2005)

Pycnothea Loman, 1920 (2) Madagascar, Western Australia, Chile

Quebus Barnard, 1946 (1) South Africa

Safropallene Arnaud \& Child, 1988 (1) South Africa

Seguapallene Pushkin, 1975 (6) Sub-Antarctic, Indo-west

Pacific, North Australia, Saudi Arabia

* Stylopallene Clark, 1963 (4) Southern Australia

PALLENOPSIDAE Fry, 1978

*Pallenopsis Wilson, 1881 (102) Cosmopolitan

COLOSSENDEIDAE Hoek, 1881

* Colossendeis Jarzinsky, 1870 (67) Cosmopolitan

*Decolopoda Eights, 1835 (1) Antarctica

Dodecolopoda Calman \& Gordon, 1933 (1) Antarctica

*Hedgpethia Turpaeva, 1973 (11) Pacific

Pentacolossendeis Hedgpeth, 1943 (1) Caribbean

Rhopalorhynchus Wood-Mason, 1873 (11) South Africa, Australia,

Caribbean, Indian Ocean, Philippines

NYMPHONIDAE Wilson, 1878

Boreonymphon Sars, 1888 (4) Palearctic region

Heteronymphon Gordon, 1932 (7) Antarctica, Costa Rica,

North West Pacific, North Atlantic

Neonymphon Stock, 1955 (1) Virgin Islands

* Nymphon Fabricius, 1794 (269) Cosmopolitan

*Pentanymphon Hodgson, 1904 (1) Antarctica

Sexanymphon Hedgpeth \& Fry, 1964 (1) Antarctica

PHOXICHILIDIIDAE Sars, 1891

*Anoplodactylus Wilson, 1878 (136) Cosmopolitan

*Phoxichilidium Milne-Edwards, 1840 (11) Subtropical and temperate: South Africa, Australia, North America

Pycnosomia Losina-Losinsky, 1961 (3) Alaska, Russia, Philippines

ENDEIDAE Norman, 1908

*Endeis Philippi, 1843 (17) Cosmopolitan

PYCNOGONIDAE Wilson, 1878

* Pentapycnon Bouvier, 1910 (3) Antarctica, Puerto Rico to

Brazil

*Pycnogonum Brunnich, 1764 (69) Cosmopolitan

RHYNCHOTHORACIDAE

*Rhynchothorax Costa, 1861 (18) Antarctica, Atlantic,

Mediterranean, Australia, Indo-West Pacific, California. 
Antarctic deep-sea and hydrothermal vents fauna among others (list on Table 3).

\section{Outgroups}

Given the uncertain position of pycnogonids in Arthropoda and the uniqueness of their morphology, there is no clear most appropriate sister group, consequently a broad range of taxa was included as outgroups. Nine non-pycnogonid taxa are included as outgroups representing Onychophora, Tardigrada, Chelicerata, Myriapoda and Xiphosura. Pycnogonida have been proposed as sister group to chelicerates or to euarthropods (see Dunlop and Arango, 2005) and this selection of outgroups aims to cover both alternatives. The scoring of outgroups that could test the plesiomorphic state of the pycnogonid characters is not straightforward (Arango, 2002), most of the morphological characters informative for internal pycnogonid phylogeny are not scored in outgroups given the uncertain homologies for most of the key structures (e.g., proboscis, ovigers) of pycnogonids, and in most cases these uncertainties are coded as inapplicable. For some outgroup taxa, a ground-plan approach had to be followed combining DNA data for different species under a supraspecific taxon (see Table 3). Sequences of non-pycnogonid taxa were mostly found in GenBank, unpublished sequences of Scorpiones were kindly made available by L. Prendini.

\section{Fossil taxa}

Fossils described so far as pycnogonids are spare and some of them problematic (Hedgpeth, 1954; Bergström et al., 1980). Morphological characters for Paleoisopus problematicus $\dagger$, Paleopantopus maucheri $\dagger$ and Paleothea devonica $†$ were scored according to the known descriptions based on X-ray images (Bergström et al., 1980). The Silurian sea spider Haliestes dasos $\dagger$ recently described based on three-dimensional imaging (Siveter et al., 2004), was also scored in the morphological matrix (note that the Haliestes male attribution in Siveter et al. is not necessitated by the presence of ovigers; in fact, females of all lineages have ovigers except Phoxichilidiidae including Endeis, and Pycnogonidae). The larval fossil Cambropycnogon klausmuelleri†, from the Upper Cambrian "Orsten" of Sweden (Waloszek and Dunlop, 2002) was not included because only adult characters were considered in this data set, and due to enormous uncertainty when proposing homologies of the larval structures. Molecular data for the extinct species included were entered as missing.

\section{Living taxa}

Our criterion for using ingroup living taxa was to include species from representative genera from all families, of which tissue suitable for DNA analysis could be obtained (see Table 1 for taxonomic classification of the group and the genera included in the analysis). Interestingly, 10-legged Antarctic species Pentapycnon charcoti [only few specimens known (Child, 1995b), the one used in this study recently collected at $3213 \mathrm{~m}$ depth by the German Expedition "Polarsten" 42, ANTXIV/2, Museum für Naturkunde Berlin], Pentanymphon antarcticum and Decolopoda australis were available in this study together with other representatives of Colossendeidae, Nymphonidae and Pycnogonidae, to test for the affinities of these polymerous forms (Hedgpeth, 1954).

Finding and collecting specimens suitable for analysis can be difficult; most of the genera can only be represented by one, two or three species in the analysis, however, speciose, relatively common genera such as Anoplodactylus, Nymphon and Achelia are represented by more species. Our living ingroup taxa resulted in a set of 59 species in 29 living genera scored with morphological characters and six loci in most cases (Table 3).

\section{Character sampling}

\section{Morphology}

Description of some of the morphological characters mostly follows the character evaluation presented in Arango (2002). Modifications and the descriptions of new characters included in this study are shown on the list of characters (Appendix 2). Description of characters and terminology follow general pycnogonid references (e.g., Arnaud and Bamber, 1987; Child, 1998). A total of 78 characters were scored across 72 terminal taxa. Fortytwo characters are added based on additional observations of external morphology including arrangement of eggs and types of larva. Characters were scored from direct observation of the specimens using light microscopy and imaging on a Hitachi S4700 Field Emission Scanning Electron Microscope at the American Museum of Natural History (AMNH). When availability of gender or life stage prevented those observations, literature descriptions were sought. Characters relevant to the relationships among other arthropods and pycnogonids are based on data sets in Giribet et al. (2001) and Edgecombe (2004) as indicated in Appendix 2. Two of these characters are ground-plan coded for Pycnogonida as well as characters related to eye ultrastructure according to $\mathrm{He} \beta$ et al. (1996) (See Appendix 2).

\section{$D N A$}

Molecular work was carried out at the Molecular Systematics Laboratory of the AMNH. Genomic DNA was extracted from absolute ethanol-preserved specimens using the Qiagen Dneasy Tissue Kit: Dneasy Protocol for animal tissues (Qiagen, Valencia, CA). Depending on the size of the specimen a piece of leg was cut off and macerated with a plastic pestle after adding the lysis buffer and proteinase K. For a few small individuals $(\approx 0.6 \mathrm{~mm})$ the whole specimen was used for 
Table 2

Primers used in the amplification and sequencing of Pycnogonida

\begin{tabular}{|c|c|c|}
\hline Locus & $5^{\prime}-3^{\prime}$ & Reference \\
\hline \multirow[t]{2}{*}{$12 \mathrm{~S} \mathrm{mt} \mathrm{rRNA}$} & 12Sai: AAACTAGGATTAGATACCCTATTAT & Kocher et al. (1989) \\
\hline & 12Sbi: AAGAGCGACGGGCGATGTGT & Kocher et al. (1989) \\
\hline \multirow[t]{2}{*}{$16 \mathrm{~S} \mathrm{mt}$ rRNA } & LR-N-13398 (ar): CGCCTGTTTATCAAAAACAT & Simon et al. (1994) \\
\hline & LR-J-12887 (br): CTCCGGTTTGAACTCAGATCA & Simon et al. (1994) \\
\hline \multirow[t]{4}{*}{ Cytochrome $\mathrm{C}$ oxidase I } & LCO1490: GGTCAACAAATCATAAAGATATTGG & Folmer et al. (1994) \\
\hline & HCOOUTOUT: GTAAATATATGRTGDGCTC & AMNH laboratory \\
\hline & HCOEXTERNA: AAGTTTATATTTTAATTTTACCTGG & AMNH laboratory \\
\hline & HCOEXTERNB: CCTATTGAWARAACATARTGAAAATG & AMNH laboratory \\
\hline \multirow[t]{6}{*}{$18 \mathrm{~S}$ nuclear rRNA } & 1F: TACCTGGTTGATCCTGCCAGTAG & Giribet et al. (1996) \\
\hline & 5R: CTTGGCAAATGCTTTCGC & Giribet et al. (1996) \\
\hline & 3F: GTTCGATTCCGGAGAGGGA & Giribet et al. (1996) \\
\hline & Bi: GAGTCTCGTTCGTTATCGGA & Whiting (2002) \\
\hline & A2.0: ATGGTTGCAAAGCTGAAAC & Whiting (2002) \\
\hline & 9R: GATCCTTCCGCAGGTTCACCTAC & Whiting (2002) \\
\hline \multirow[t]{11}{*}{$28 \mathrm{~S}$ nuclear rRNA } & 28SRD1A: CCCSCGTAAYTTAGGCATAT & AMNH laboratory \\
\hline & 28SB: TCGGAAGGAACCAGCTACTA & AMNH laboratory \\
\hline & 28SRD3A: AGTACGTGAAACCGTTCAGG & AMNH laboratory \\
\hline & 28SRD4B: CCTTGGTCCGTGTTTCAAGAC & AMNH laboratory \\
\hline & D3A (28SA): GACCCGTCTTGAAGCAACG & Whiting (2002) \\
\hline & D3B (28SBOUT): CCCACAGCGCCAGTTCTGCTTACC & Nunn et al. (1996) \\
\hline & 28SRD4.5a: AAGTTTCCCTCAGGATAGCTG & Whiting (2002) \\
\hline & 28SRD7B1: GACTTCCCTTACCTACAT & Whiting (2002) \\
\hline & AS6/8: ACAAAGAAAAGACAACTCT & Mallatt and Sullivan (1998) \\
\hline & AS7: GGTCAGTCGGTCCTAAGA & Mallatt and Sullivan (1998) \\
\hline & OP2: CAGACTAGAGTCAAGCTCAACAGG & Mallatt and Sullivan (1998) \\
\hline \multirow{2}{*}{ Histone 3} & H3AF: ATGGCTCGTACCAAGCAGACVGC & Colgan et al. (1998) \\
\hline & H3AR: ATATCCTTRGGCATRATRGTGAC & Colgan et al. (1998) \\
\hline
\end{tabular}

the extraction; in most cases duplicates were kept as vouchers and deposited at corresponding collections (Museum Victoria, Australian Museum, Queensland Museum, and Instituto de Investigaciones Marinas Invemar, Colombia). Certain DNA fragments were obtained for museum specimens (e.g., Pantopipetta sp. at $\mathrm{AMNH}$ ). Extracted DNA aliquots for most of the species used are kept at the Ambrose Monell Cryo Collection at the AMNH (nos 131594-131673).

Double-stranded DNA template suitable for sequencing was prepared by polymerase chain reaction (PCR) using the combination of primers in Table 2. Amplifications were made in a $25-\mu \mathrm{L}$ volume reaction adding $1 \mu \mathrm{L}$ of each $10 \mu \mathrm{m}$ primer, $23 \mu \mathrm{L}$ of $\mathrm{dH}_{2} \mathrm{O}$ and $2 \mu \mathrm{L}$ of template DNA to the Ready-to-Go PCR beads (Amersham Pharmacia Biotech, Pittsburg, PA). The PCR programs ran on DNA Engine Dyad Thermal Cyclers (MJ Research, Waltham, MA) and Eppendorf Mastercyclers $^{\circledR}$ and consisted of an initial denaturing step at $94{ }^{\circ} \mathrm{C}$ for $3 \mathrm{~min}, 40$ amplification cycles $\left(94{ }^{\circ} \mathrm{C}\right.$ for $1 \mathrm{~min}, 48-56{ }^{\circ} \mathrm{C}$ for $1 \mathrm{~min} 15 \mathrm{~s}, 72{ }^{\circ} \mathrm{C}$ for $1 \mathrm{~min}$ ) and a final step at $72{ }^{\circ} \mathrm{C}$ for $5 \mathrm{~min}$. Annealing for $12 \mathrm{~S}$ and Cytochrome Oxidase I (COI) fragments conducted at lower temperatures $\left(44-46{ }^{\circ} \mathrm{C}\right)$. PCR products were checked on a $1 \%$ Agarose/TBE electrophoretic gel and purified using cleaning buffer on the Biomek 2000 Automation Workstation following the manufacturer's protocol. Single-stranded sequencing was conducted using automated Applied Biosystems Inc. Prism 3700 and 3730XL DNA sequencers and the Dye Terminator Sequence Kit (Applied Biosystems, Foster City, CA). Each cycle of sequencing reaction was carried out in a $8 \mu \mathrm{L}$ reaction containing $2 \mu \mathrm{L}$ of BDTmix, $1 \mu \mathrm{L}$ of $3.2 \rho \mathrm{M}$ primer and $10 \mathrm{ng} / \mathrm{mL}$ of PCR product. The products of the cycling sequencing reactions were cleaned by precipitation with isopropanol and ethanol (40 $\mu \mathrm{L} \mathrm{70 \%} \mathrm{isopropanol} \mathrm{added,} \mathrm{centrifuged} \mathrm{at} 2750 \mathrm{~g}$ for $30 \mathrm{~min}$, microplate inverted and spun for $1 \mathrm{~min}$ at $43 \mathrm{~g}$; then repeated procedure but instead of isopropanol used $70 \%$ ethanol), air-dried for $20 \mathrm{~min}$ and resuspended in $10 \mu \mathrm{L}$ formamide to be loaded on to the sequencer.

Sequences were verified by independently producing the complementary strands for each sample for all fragments. Chromatograms were examined and edited using Sequencher ver. 4.1 .4 (Gene Codes Corp., Ann Arbor, MI) and BioEdit (http://www.mbio.ncsu.edu/BioEdit).

A total of 755 final sequences were generated for this study. The nuclear loci used were 18S (1767-1806 bp in sea spiders; 1746-2133 bp in outgroups), 28S (27472860 bp in sea spiders; 2510-2949 bp in outgroups) and Histone 3 (H3) (327 bp in all). The mitochondrial loci were $12 \mathrm{~S}(331-359 \mathrm{bp}$ in sea spiders, 333-351 bp in outgroups), 16S (447-517 bp in sea spiders and 442-522 in outgroups) and COI (1081 bp in all). Some fragments (e.g., H3) could not be sequenced successfully for particular genera (e.g., Austropallene) or for some of 
the species (e.g., 12S for two Anoplodactylus, COI for Hedgpethia dofleini). For specimens of Achelia echinata, Phoxichilidium femoratum, and Rhynchothorax australis only two of six loci were sequenced. Sequences obtained in this study are deposited in GenBank (accession numbers in Table 3).

Given the dynamic nature of the analysis with Direct Optimization (DO), which is quite demanding computationally when dealing with large data sets, $18 \mathrm{~S}, 28 \mathrm{~S}$ and COI were split into smaller, recognizably homologous segments within the matrix. The splitting was guided by conserved areas in which known motifs (primers) are located (segments separated by "\#" according to POY guidelines) (Wheeler et al., 1996-2003; Giribet, 2005). Thus, $28 \mathrm{~S}$ was segmented into 12 fragments, $18 \mathrm{~S}$ into nine fragments and COI into four fragments. Targeted fragments of $12 \mathrm{~S}, \mathrm{H} 3$ and $16 \mathrm{~S}$ were shorter so they were amplified as a single segment and were not split into smaller fragments. The resulting POY-formatted file of the combined data in the form of an implied alignment can be obtained from the authors by request.

\section{Analysis}

Phylogenetic reconstruction was performed with parsimony analysis of a combined data set of DNA sequences and morphological characters, following the idea that a simultaneous analysis of all available evidence maximizes explanatory power (Kluge, 1989; Nixon and Carpenter, 1996). The data were analyzed under DO (Wheeler, 1996) as implemented in the program POY, ver. 3.0.11a. (Wheeler et al., 1996), run on the AMNH parallel computing cluster using $25-50$ processors. POY seeks the cladogram-alignment combination (i.e., the optimal tree alignment) that minimizes the total number of hypothesized transformation events required to explain the data. POY does a one-step minimization (instead of the traditional two-step analysis doing a multiple alignment first and then submitting it as a fixed character matrix to tree searching) of total changes on a trial topology, directly assessing the number of evolutionary events or DNA sequence transformations and taking into account insertion/deletion events (indels, gaps) as historical evidence (Wheeler, 1996, 2002). All data, that is both, morphology and DNA, were treated as non-additive and analyzed all under equal weights (for DNA a cost ratio of indels, transversions and transitions $1: 1: 1)$ providing the simplest minimization of transformations (but see Faivovich et al., 2005).

For the sequence character optimization, we employed two DO algorithms of different degree of exhaustiveness: Optimization Alignment or generally called Direct Optimization (DO; Wheeler, 1996), and Iterative Pass Optimization (Wheeler, 2003b). With the optimization alignment or DO (Wheeler, 1996), hypothetical ancestral sequences are optimized based only on descendant sequences, while Iterative Pass (IP) optimizes hypothetical ancestral sequences based on both descendant and ancestral sequences. IP is based on a three-sequence DO with iterative improvement and it is much more computationally demanding, but it can find more parsimonious cladograms (Wheeler, 2003b). The IP routine is being included as part of the search strategy for final rounds of tree branching and reconnecting (TBR) applied to different types of data sets (see Giannini and Simmons, 2003; Sparks and Smith, 2004; Faivovich et al., 2005; Frost et al., 2006; among others).

For purposes of the analyses, Onychophora was selected as outgroup. A total of 50 random addition sequences were swapped with TBR and altered using ratchet (Nixon, 1999). Resulting topologies were improved by subsequent rounds of ratcheting with different percentages (20 and 40) and severity (2 and 4) and tree fusing (Goloboff, 1999). Based on the resulting 57 most parsimonious topologies, another search using TBR, ratchet and tree fusing was performed under iterative pass optimization (Wheeler, 2003b) and the exact command (De Laet and Wheeler, 2003). For the analysis of only extant taxa, the resulting most parsimonious trees (MPTs) for the complete data set were used as starting point for the search under IP. The implied alignments (Wheeler, 2003a) (see Giribet, 2005) and topologies were visualized and exported from the Winclada platform (Nixon, 2000). Implied alignment was used to calculate support for clades indicated by values from jackknife resampling analyses (1000 replications, 10 random additions per replication) and to generate the list of synapomorphies, all performed in TNT (Goloboff et al., 2000). Morphological synapomorphies are mapped on to the optimal topology in Fig. 8 and molecular synapomorphies for the pycnogonid clades are listed in Appendix 3.

The morphological data were analyzed separately solely for the discussion of differences in the interpretation of character transformations based on a simultaneous analysis and a separate morphological analysis, and for comparison with previous results in Arango (2002). We did heuristic searches in TNT and NONA ver. 2.0 (Goloboff, 1997), performing TBR branch swapping on 100 random addition replicates, holding 10000 trees and 10 starting trees. Additional swapping on 1000 trees that are up to $5 \%$ longer than optimal was run to move between local optima. Finally, these trees were TBR swapped retaining only optimal trees.

\section{Results}

\section{Total evidence analysis}

Simultaneous analysis of morphological and molecular data (10 902 characters based on implied alignment) 
Table 3

Taxa and GenBank accesion numbers for each of the sequences used. Pycnogonid sequences were obtained by the authors at the AMNH laboratory (LP are unpublished outgroup sequences by L. Prendini, AMNH)

\begin{tabular}{|c|c|c|c|c|c|c|c|}
\hline Species & Locality & $28 \mathrm{~S}$ & $18 \mathrm{~S}$ & $\mathrm{H} 3$ & $16 \mathrm{~S}$ & COI & $12 \mathrm{~S}$ \\
\hline \multicolumn{8}{|l|}{ Pycnogonida } \\
\hline \multicolumn{8}{|l|}{ Austrodecidae } \\
\hline Austrodecus glaciale & Palmer S. Antarctica & DQ390100 & DQ389890 & DQ390154 & DQ389994 & DQ390048 & DQ389944 \\
\hline Pantopipetta sp. & Antarctica & DQ390112 & DQ389903 & DQ390167 & DQ390006 & & \\
\hline \multicolumn{8}{|c|}{ 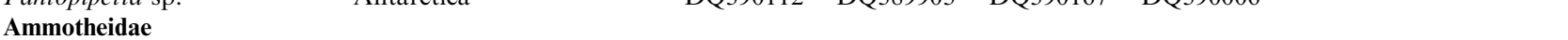 } \\
\hline Achelia assimilis & Victoria, Australia & DQ390143 & DQ389932 & DQ390196 & DQ390036 & DQ390087 & DQ389981 \\
\hline Achelia alaskensis & California, USA & & & DQ390202 & DQ390041 & DQ390093 & DQ389987 \\
\hline Achelia hoekii & Palmer S. Antarctica & DQ390098 & DQ389888 & DQ390152 & DQ389992 & DQ390046 & DQ389942 \\
\hline Achelia spicata & Palmer S. Antarctica & & & DQ390176 & & & DQ389963 \\
\hline Achelia echinata & California, USA & & & DQ390177 & & DQ390096 & \\
\hline Achelia sawayai & Colombian Caribbean & DQ390126 & DQ389916 & DQ390180 & DQ390019 & DQ390070 & DQ389966 \\
\hline Ammothella appendiculata & Colombian Caribbean & DQ390109 & DQ389899 & DQ390163 & DQ390003 & DQ390056 & DQ389953 \\
\hline Ammothella spinifera & Colombian Caribbean & DQ390130 & DQ389919 & DQ390184 & DQ390023 & DQ390074 & DQ389969 \\
\hline Ammothella tuberculata & California, USA & DQ390149 & DQ389938 & DQ390203 & DQ390042 & DQ390094 & DQ389988 \\
\hline Eurycyde raphiaster & Caribbean & DQ390131 & DQ389920 & DQ390185 & DQ390024 & DQ390075 & DQ389970 \\
\hline Eurycyde curvata & Colombian Caribbean & DQ390107 & DQ389897 & DQ390161 & DQ390001 & DQ390055 & DQ389951 \\
\hline Eurycyde spinosa & California, USA & DQ390148 & DQ389937 & DQ390201 & DQ390040 & DQ390092 & DQ389986 \\
\hline Ammothea ovatoides & California, USA & DQ390137 & DQ389926 & DQ390190 & DQ390030 & DQ390081 & DQ389976 \\
\hline Ammothea clausi & Palmer S. Antarctica & DQ390104 & DQ389894 & DQ390158 & DQ389998 & DQ390052 & DQ389948 \\
\hline Ammothea hilgendor $f$ & California, USA & DQ390147 & DQ389936 & DQ390200 & DQ390039 & DQ390091 & DQ389985 \\
\hline Ascorhynchus castelli & Colombian Caribbean & DQ390123 & DQ389913 & & DQ390016 & DQ390067 & \\
\hline Ascorhynchus castellioides & Colombian Caribbean & DQ390114 & DQ389905 & DQ390169 & DQ390008 & DQ390060 & DQ389957 \\
\hline Ascorhynchus japonicum & Brit. Columbia, Canada & & & DQ390151 & DQ389990 & DQ390044 & DQ389940 \\
\hline Nymphopsis duodorsospinosa & Colombian Caribbean & DQ390125 & DQ389915 & DQ390179 & DQ390018 & DQ390069 & DQ389965 \\
\hline Sericosura venticola & North Pacific vents & DQ390136 & DQ389925 & DQ390189 & DQ390029 & DQ390080 & DQ389975 \\
\hline Tanystylum orbiculare & $\begin{array}{l}\text { Mar del Plata, } \\
\text { Argentina, }\end{array}$ & DQ390120 & DQ389910 & DQ390174 & DQ390013 & DQ390064 & DQ389962 \\
\hline \multicolumn{8}{|l|}{ Callipallenidae } \\
\hline Austropallene cornigera & Palmer S. Antarctica & DQ390133 & DQ389922 & & DQ390026 & DQ390077 & DQ389972 \\
\hline Austropallene cristata & Palmer S. Antarctica & DQ390097 & DQ389887 & & DQ389991 & DQ390045 & DQ389941 \\
\hline Callipallene brevisrostris & Colombian Caribbean & DQ390110 & DQ389900 & DQ390164 & DQ390004 & DQ390057 & DQ389954 \\
\hline Callipallene novaezealandiae & Victoria, Australia & DQ390138 & DQ389927 & DQ390191 & DQ390031 & DQ390082 & DQ389977 \\
\hline Oropallene minor & $\begin{array}{l}\text { New South Wales, } \\
\text { Australia }\end{array}$ & DQ390113 & DQ389904 & DQ390168 & DQ390007 & DQ390059 & DQ389956 \\
\hline Parapallene avida & Victoria, Australia & DQ390139 & DQ389928 & DQ390192 & DQ390032 & DQ390083 & DQ389978 \\
\hline Propallene longiceps & Japan & DQ390106 & DQ389896 & DQ390160 & DQ390000 & DQ390054 & DQ389950 \\
\hline Pseudopallene ambigua & Victoria, Australia & DQ390141 & DQ389930 & DQ390194 & DQ390034 & DQ390085 & DQ389979 \\
\hline Stylopallene longicauda & Victoria, Australia & DQ390140 & DQ389929 & DQ390193 & DQ390033 & DQ390084 & \\
\hline Nymphon brevicaudatum & Palmer S. Antarctica & DQ390099 & DQ389889 & DQ390153 & DQ389993 & DQ390047 & DQ389943 \\
\hline Nymphon floridanum & Colombian Caribbean & DQ390129 & & DQ390183 & DQ390022 & DQ390073 & \\
\hline Nymphon hamatum & Antarctica, Polarsten Exp. & DQ390132 & DQ389921 & DQ390186 & DQ390025 & DQ390076 & DQ389971 \\
\hline Nymphon uniunguiculatum & Palmer S. Antarctica & DQ390105 & DQ389895 & DQ390159 & DQ389999 & DQ390053 & DQ389949 \\
\hline Pentanymphon antarcticum & Palmer S. Antarctica & DQ390101 & DQ389891 & DQ390155 & DQ389995 & DQ390049 & DQ389945 \\
\hline \multicolumn{8}{|l|}{ Colossendeidae } \\
\hline Colossendeis stramenti & Antarctica, Polarsten Exp. & DQ390134 & DQ389923 & DQ390187 & DQ390027 & DQ390078 & DQ389973 \\
\hline Colossendeis tenera & North Pacific & DQ390116 & DQ389907 & DQ390171 & DQ390010 & DQ390061 & DQ389959 \\
\hline Decolopoda australis & Livingston, Antarctica & DQ390118 & DQ389909 & DQ390172 & DQ390012 & DQ390063 & DQ389961 \\
\hline Hedgpethia dofleini & Alaska, USA & DQ390108 & DQ389898 & DQ390162 & DQ390002 & & DQ389952 \\
\hline \multicolumn{8}{|l|}{ Phoxichilidiidae } \\
\hline Anoplodactylus batangensis & Colombian Caribbean & DQ390128 & DQ389918 & DQ390182 & DQ390021 & DQ390072 & DQ389968 \\
\hline Anoplodactylus californicus & Colombian Caribbean & DQ390124 & DQ389914 & DQ390178 & DQ390017 & DQ390068 & DQ389964 \\
\hline Anoplodactylus erectus & California, USA & DQ390145 & DQ389934 & DQ390198 & DQ390038 & DQ390089 & DQ389983 \\
\hline Anoplodactylus evansi & $\begin{array}{l}\text { New South Wales, } \\
\text { Australia }\end{array}$ & DQ390115 & DQ389906 & DQ390170 & DQ390009 & & DQ389958 \\
\hline Anoplodactylus lentus & North Atlantic & AF062972 & DQ389912 & DQ390175 & DQ390015 & DQ390066 & DQ389912 \\
\hline Anoplodactylus petiolatus & Mar del Plata, Argentina & DQ390121 & DQ389911 & & DQ390014 & DQ390065 & \\
\hline $\begin{array}{l}\text { Anoplodactylus sp. } \\
\text { (pygmaeus-group) }\end{array}$ & Colombian Caribbean & DQ390127 & DQ389917 & DQ390181 & DQ390020 & DQ390071 & DQ389967 \\
\hline
\end{tabular}


Table 3

Continued

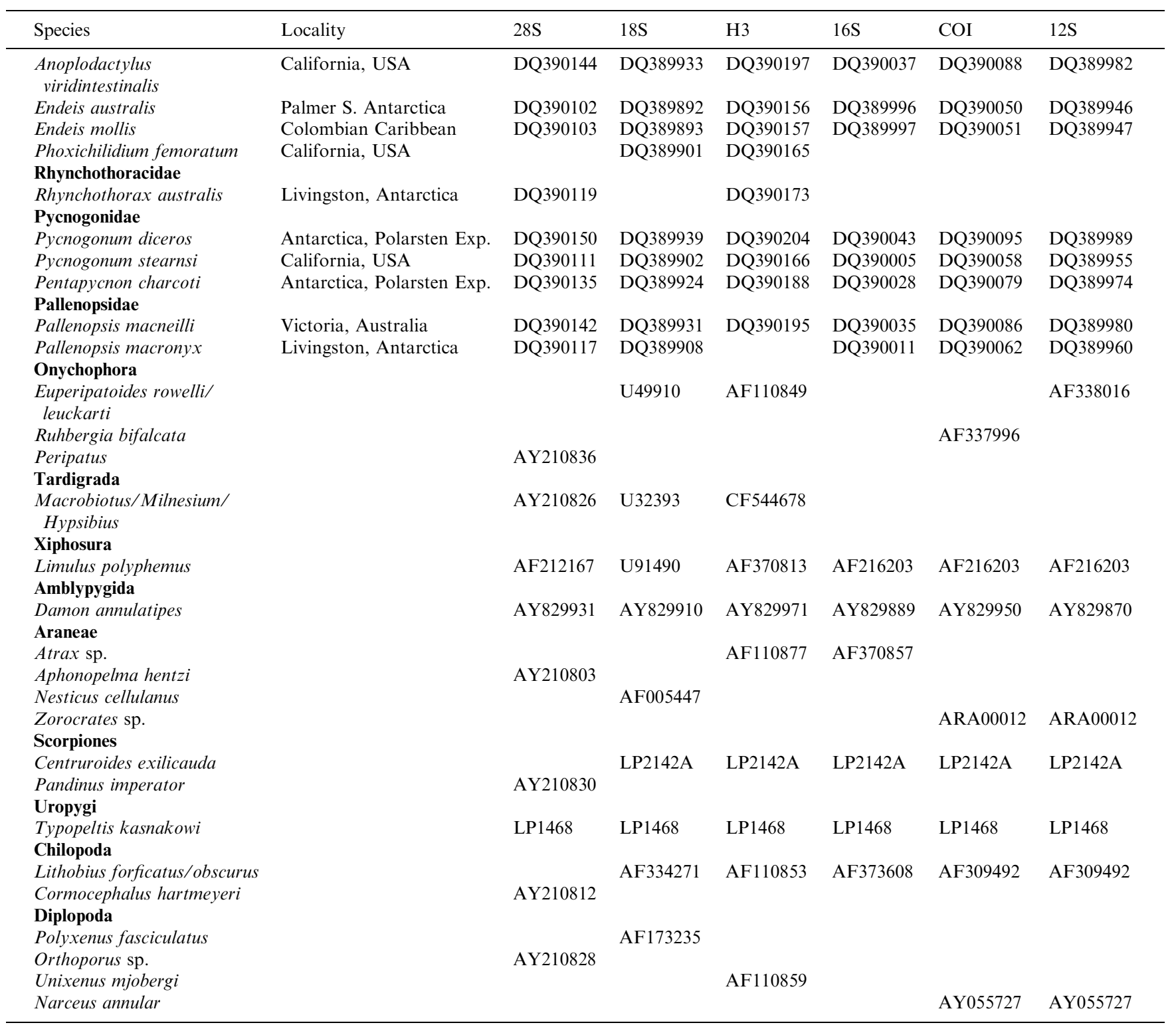

by DO all under equal costs, resulted in 12 MPTs 28726 steps long. The 12 MPTs are due to the unresolved position of the fossil Paleothea devonicat. Paleothea devonicat appears either related to ammotheid taxa, in the callipallenid-nymphonid clade or in the Pycnogonidae clade. The instability of $P$. devonicat causes some deep nodes to collapse (see strict consensus tree Fig. 1). When the fossil taxa were removed from the analysis, a heuristic search and swapping produced a single MPT (Length $=28699)$, which maintains the groupings from the complete data set and the basic topology remained the same showing most of the groups well supported (Fig. 2). Although the position of fossil taxa is not strongly supported or unambiguous, they are apparently related to extant taxa and do not constitute an early derived "fossil clade". $H$ dasos $\dagger, P$. problematicus $\dagger$ and $P$. maucheri $\dagger$ appear related to the segregated ammotheid clade Ascorhynchus + Eurycyde.

A single most-parsimonious polytomous tree obtained with non-additive, equally weighted morphological and molecular characters (one of the 12 trees obtained with the full data set, which is exactly the same topology of the single MPT obtained after the exclusion of fossils) is presented as the basis to describe the phylogeny of Pycnogonida (Fig. 3). This cladogram definitely supports monophyly of the sea spiders as expected. Monophyly of Austrodecidae, Colossendeidae, Phoxichilidiidae (except Phoxichilidum femoratum 


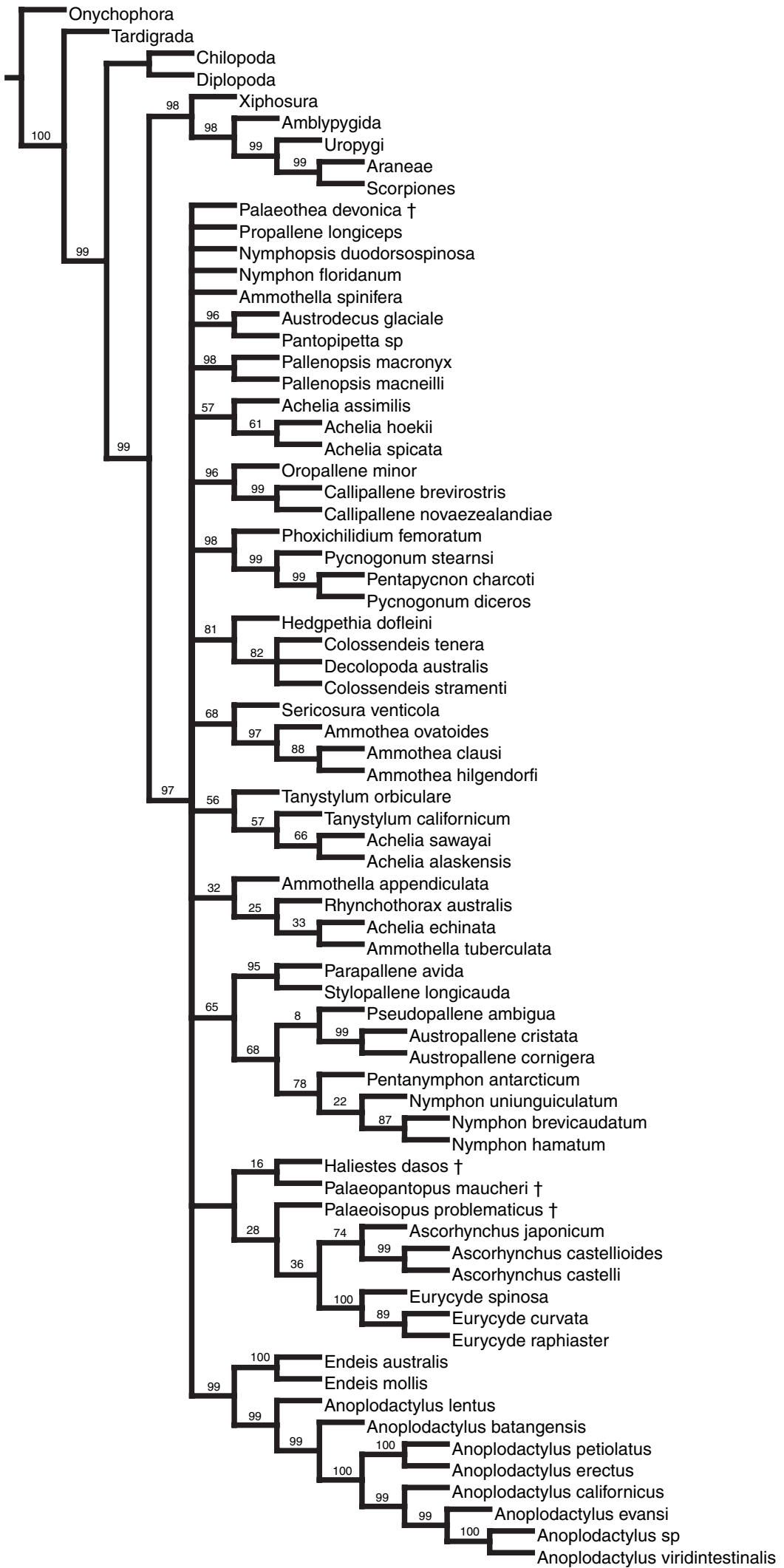

Fig. 1. Strict consensus of 12 most parsimonious trees resulting from total evidence analysis of 10902 aligned nucleotide characters and morphology $(\mathrm{L}=28726)$. Jackknife values $(\mathrm{rep}=1000, P=36)$ on the nodes. 


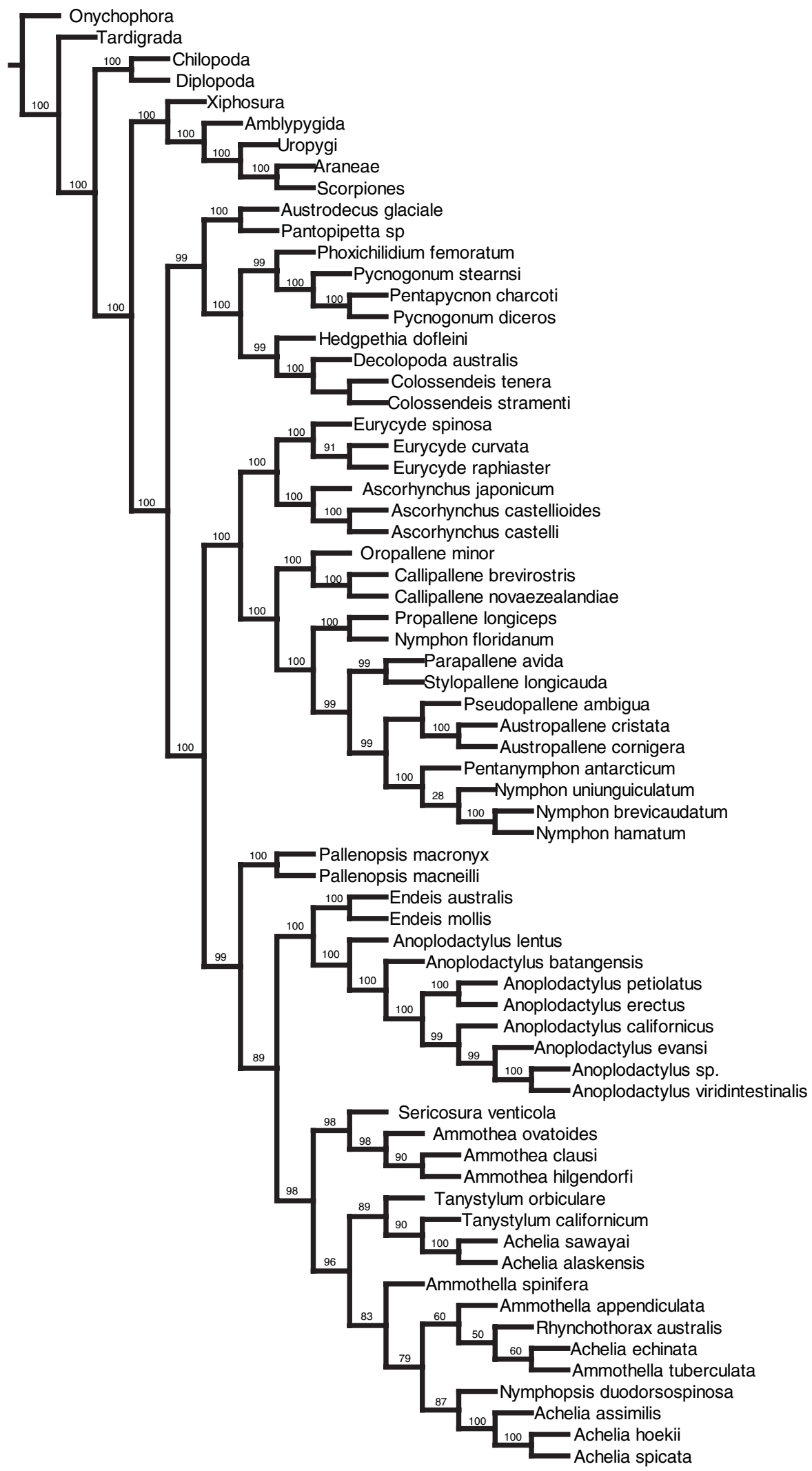

Fig. 2. Single most parsimonious tree resulting from the same total evidence analysis as in Fig. 1 after excluding the four fossil taxa $(\mathrm{L}=28699)$. Jackknife values $(\mathrm{rep}=1000, P=36)$ on the nodes. 


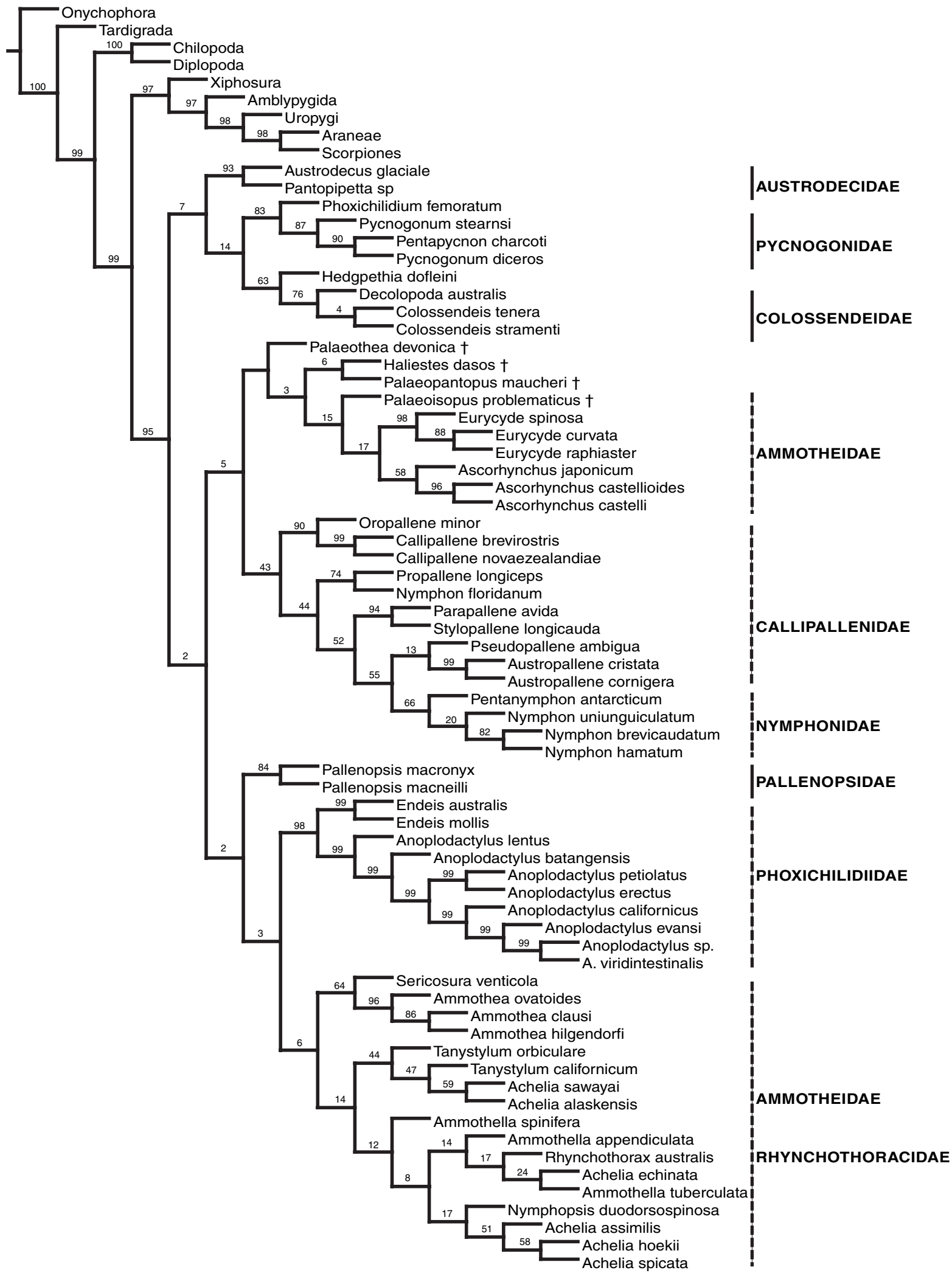

Fig. 3. Most parsimonious tree resulting from total evidence analysis of 10902 aligned nucleotide characters and morphology. $(\mathrm{L}=28726$, $\mathrm{CI}=$ $0.44, \mathrm{RI}=0.58)$. Jackknife values (rep $=1000, P=36$ ) on the nodes. Monophyletic and non-monophyletic groups obtained are indicated by solid and dashed vertical lines, respectively. 
placed outside the Phoxichilidiidae clade) and Pycnogonidae was supported by these data, while Ammotheidae was polyphyletic and Callipallenidae and Nymphonidae were not recovered either, due to a Nymphonidae species grouped with callipallenid genera (Fig. 3).

Three main clades of Pycnogonida are proposed according to this topology:

1 Austrodecidae + Pycnogonidae + Colossendeidae. This early derived clade is a robust clade relating three quite diverse and widespread lineages that tend to be of Antarctic and temperate distribution. It includes Phoxichilidium femoratum basal to the Pycnogonidae, although well supported by resampling and support values (Figs 2 and 3) this node is based on much fewer DNA sequence characters given unavailability of $P$. femoratum sequences.

2 ( $($ Haliestes $\dagger+$ Paleopantopus $\dagger)+($ Paleoisopus $\dagger$ $+($ Eurycyde + Ascorhynchus $))+($ Callipallenidae Nymphonidae). This node shows very low support in the total analysis (according to the 12 MPTs obtained), but when fossil taxa are excluded the clade ((Eurycyde + Ascorhynchus $)+$ (callipallenids + nymphonids)) is well supported according to jackknife values (Fig. 2). Eurycyde and Ascorhynchus two ammotheid genera with strong strigilis and ovigers terminal claw are segregated from Ammotheidae. Their sister group affinities with callipallenids + nymphonids had not been made explicit before.

3 Pallenopsidae + (Phoxichilidiidae + (Ammotheids + Rhynchothoracidae). Pallenopsis is solidly positioned at the base of Phoxichilidiidae and the rest of Ammotheids (species with feeble strigilis) supporting the raising of Pallenopsidae (in Fry, 1978) to family rank. Endeis is strongly supported as the sister taxon of Anoplodactylus. Within the Ammotheidae + Rhynchothoracidae clade, Ammothea was putatively monophyletic but other genera were not, being Achelia one of the most problematic. The position of the Rhynchothoracidae related to Achelia and Ammothella is weakly supported, only few informative characters were available for this rare lineage (less than $800 \mathrm{bp}$ being sequenced).

\section{Analysis of morphological data}

Separate analysis of the 78 morphological characters equally weighted, resulted in 1344 MPTs $(\mathrm{L}=338$, consistency index $=0.36$, retention index $=0.74$ ). The strict consensus tree (Fig. 4) shows only few clades strongly supported (jackknife values $>60$ ), these are mostly shallow nodes relating species within a genus, in the case of Eurycyde and Endeis, and the two genera of Pycnogonidae: Pentapycnon and Pycnogonum. Deeper nodes in the phylogenetic tree are not well supported except the early derived position of $P$. problematicus $\dagger$ (jackknife value $=90$ ). Ammotheidae is shown as polyphyletic again with many of the terminals unplaced (Fig. 4), while Callipallenidae appears monophyletic and sister group to Nymphonidae. Pallenopsis species do not form a group and appear related to Phoxichilidiidae, although weakly supported.

\section{Discussion}

Pycnogonida relationships

Fossil taxa

A good account of the different classification schemes used for pycnogonid fossils is in Waloszek and Dunlop (2002). The controversial Paleoisopus problematicus $\dagger$ defined by a plesiomorphic five-segmented abdomen has been generally regarded as the most primitive known adult form of sea spiders, an earlier form than the Devonian Paleopantopus maucheri with a three-segmented abdomen assumed to be sister taxon of the rest of Pycnogonida (Pantopoda; see Hedgpeth, 1978; Bergström et al., 1980). This scheme assumes the evolutionary trend applied to the classification of sea spiders, implying they have gradually changed from more segmented to less segmented or assuming the absence of body parts as the apomorphic state (Bergström et al., 1980; Stock, 1994; Munilla, 1999; Waloszek and Dunlop, 2002). In the present simultaneous analysis, the four fossil taxa were grouped within the crown group not following a reductive trend for the whole group, thus differing from previous interpretations (Bergström et al., 1980; Munilla, 1999; Waloszek and Dunlop, 2002). Similarly, Siveter et al. (2004) analyzed the position of Haliestes within Pycnogonida by adding it together with other fossil taxa to the matrix in Arango (2002). Their final topologies, although poorly supported, showed Haliestes $\dagger$, Paleopantopus $\dagger$ and Paleothea $\dagger$ in a crown-group position (Siveter et al., 2004). However, in Siveter et al. Paleoisopus $\dagger$ appears as stem lineage of the Pycnogonida, a pattern only obtained here when the present morphological matrix is analyzed separately (Fig. 4).

In general, these results indicate that fossils could be more derived than thought before. Paleothea devonicat is so poorly documented there is no clear indication of its affinities. In this analysis the position of pycnogonid fossils close to the ammotheid Ascorhynchus and Eurycyde is due to characters of the proboscis (characters 64 and 73) and the segmentation of palps (characters 30 and 32) (Fig. 8). Stock (1994) suggested an early condition of these ammotheid taxa because of the twosegmented proboscis in Eurycyde and tripartition marks of the Ascorhynchus proboscis, seen as remains of a primitive condition. Also, the bent abdomen in Eurycyde with similar armature to that of Haliestes dasos $\uparrow$ 


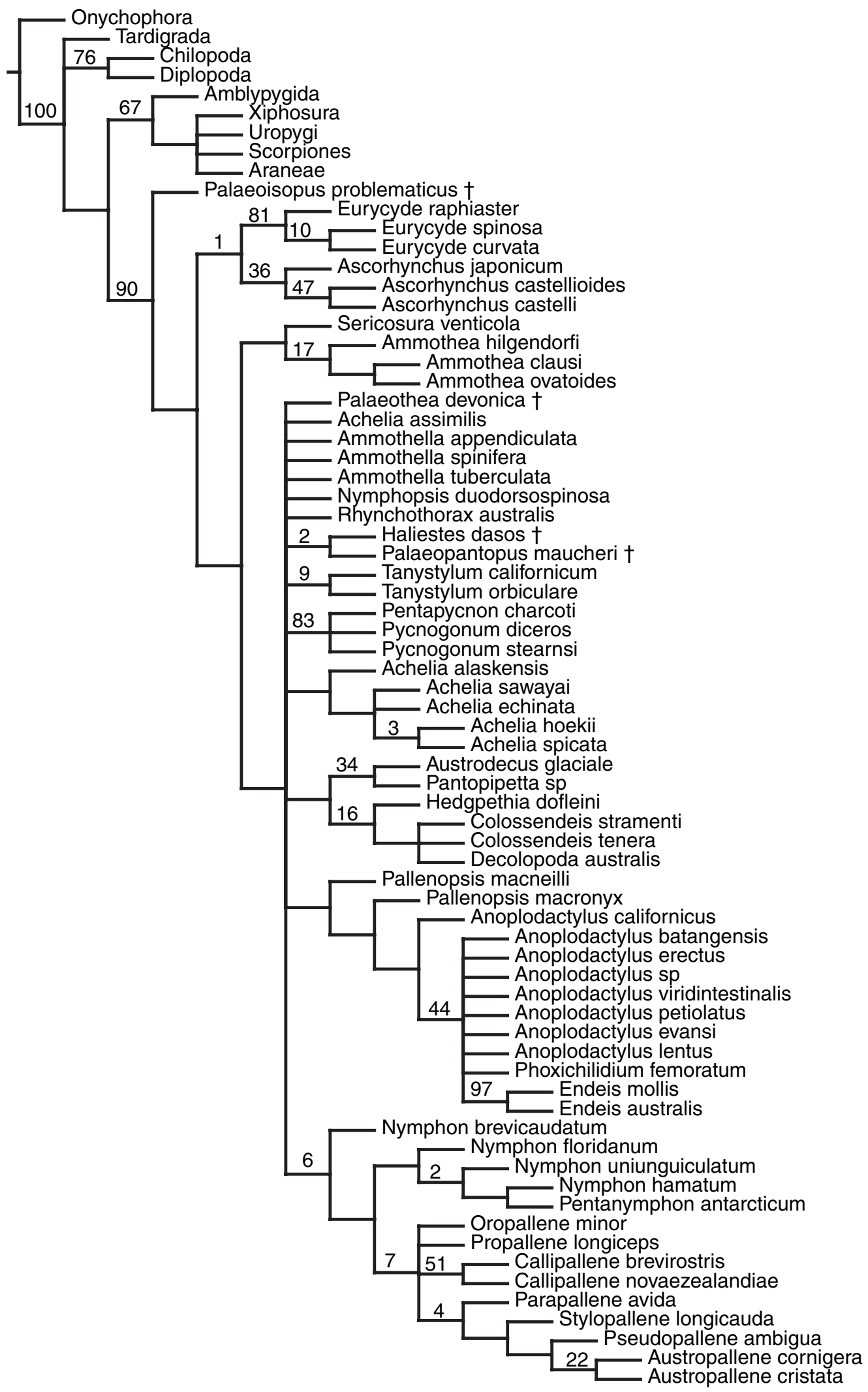

Fig. 4. Strict consensus of 1344 MPTs (Length $=338 ; \mathrm{CI}=0.36 ; \mathrm{RI}=0.74$ ) resulting from the Parsimony analysis of the 78 morphological characters equally weighted and considered non-additive. Jackknife values (rep $=1000, P=36$ ) on the nodes. 
(Siveter et al., 2004) could agree with this pattern of relationships. This total evidence analysis does not agree with the notion of fossil taxa determining plesiomorphic conditions for the whole Pycnogonida, instead, places them within the extant clade close to ammotheid taxa, therefore it does not support fossils to be considered outgroups (as in Arango, 2002). The sister group relationships of fossil pycnogonids with the Ascorhychus + Eurycyde clade are not strongly supported though, thus no definite classification is to be made, but the results suggest the possibility of more plesiomorphic conditions in living taxa compared with the extinct taxa known so far. Pycnogonid fossils known so far and those waiting to be described might be more diverse and of more derived condition than previously recognized (Poschmann and Dunlop, 2006). The inclusion of a recently described Devonian pycnogonid with a flagelliform telson (Poschmann and Dunlop, 2006) in future analyses might challenge this hypothesis and will surely provide alternative hypothesis regarding homologies in abdomen segmentation and the relationship among fossil taxa.

\section{Austrodecidae + Pycnogonidae + Colossendeidae}

Austrodecus and Pantopipetta, the two Austrodecidae genera, form a monophyletic group within an early derived clade, which agrees with previous results of combined analysis (Arango, 2003a) and with a modified version of the matrix in Arango (2002), which places Haliestes $\dagger$ within Pycnogonida (Siveter et al., 2004). Previously, Austrodecidae had been grouped within ammotheids based on morphology (Arango, 2002). Morphologically, Austrodecidae is a special lineage due to the remarkable specialization of the proboscis and mouth. They bear a unique down-curved pipettelike annulated proboscis with a ventrodistal mouth bilaterally symmetrical, not tripartite as in the rest of the taxa (characters 68, 69; Fig. 6A,C). Species of Austrodecidae are extremely small and slender when compared with sister groups Pycnogonidae and Colossendeidae (see Fig. 5B,E,F), but in all three lineages chelifores are completely absent in adults (character 24) (Fig. 5), while palps are present in Austrodecidae and Colossendeidae only (characters 29 and 31). Stock (1994) and Munilla (1999), although not in an explicit analysis, related Colossendeidae to Austrodecidae and Rhynchothoracidae based on the absence of chelifores and presence of palps, while Pycnogonidae had been related to Phoxichilidiidae due to the absence of ovigers in females in both lineages (Stock, 1994; Arango, 2002) but dissolved in the present analysis of an extended morphological matrix (Fig. 4). No males carrying eggs or larvae are known for Colossendeidae or Austrodecidae (Stock, 1957), thus a different mode of reproduction could be suspected, although nothing is known about reproductive traits in these groups (Stock, 1957; Arnaud and
Bamber, 1987). In a previous total evidence analysis (Arango, 2003a) Colossendeidae was related to Nymphonidae, but this grouping is not supported by this extended data set, nor are the Colossendeidae grouped with Ascorhynchus + Eurycyde as proposed before based solely on morphology (Arango, 2002). According to the present topology, the multiple rows of spines on distal segments of ovigers (strigilis; Fig. 7A) have appeared independently in the ammotheids Ascorhynchus and Eurycyde and in Colossendeids. The position of Phoxichilidium femoratum, a phoxichilidiid species has not been debated before. Morphologically, it shares the absence of female ovigers and larval characteristics with Pycnogonidae, but some of these transformations are also found at the Phoxichilidiidae node (Fig. 8); the expected position according to traditional classifications. However, the $18 \mathrm{~S}$ and $16 \mathrm{~S}$ sequences suggest a closer position to Pycnogonidae and Colossendeidae, respectively (cladograms not shown). As all loci could not be made available for $P$. femoratum, the synapomorphies at that node Phoxichilidium + Pycnogonidae are relatively few (see Appendix 3) and its position out of Phoxichilidiidae should be tested further with a more complete molecular data set and other sources of evidence when available.

The clade Austrodecidae + (Colossendeidae + (Phoxichilidium + Pycnogonidae)) has no morphological synapomorphies in the total evidence analysis (Fig. 8), but the list of their molecular synapomorphies is in Appendix 3. From the ecological point of view, the three main lineages are cosmopolitan tending to occur in deep cold waters. Colossendeidae and Austrodecidae have predominantly Antarctic and sub-Antarctic distribution (excepting few species known from North temperate seas), and Pycnogonidae have some more representatives in other shallow and warmer locations. In both, Colossendeidae and Pycnogonidae there is an occurrence of polymeric species, or species with extra trunk somites (here included Decolopoda australis, Colossendeidae and Pentapycnon charcoti, Pycnogonidae), but the phenomenon also occurs in Nymphonidae, an apparently unrelated lineage according to this topology.

\section{(Paleothea $\dagger+$ (Haliestes $\dagger+$ Paleopantopus $\dagger)+$ Paleoisopus $\dagger+$ (Ascorhynchus + Eurycyde $))+$ (Callipallenidae-Nymphonidae)}

The separation of Ascorhynchus and Eurycyde from Ammotheidae is supported by total evidence here and also by morphological data sets (Fig. 4; Arango, 2002). The clade formed by Ascorhynchus, Eurycyde and the fossil taxa except $P$. devonicat is stable among the MPTs obtained. It is supported by strict synapomorphies related to palps and proboscis (see Fig. 8). After excluding the fossil taxa the node for Ascorhynchus + Eurycyde has maximum support as well as in 

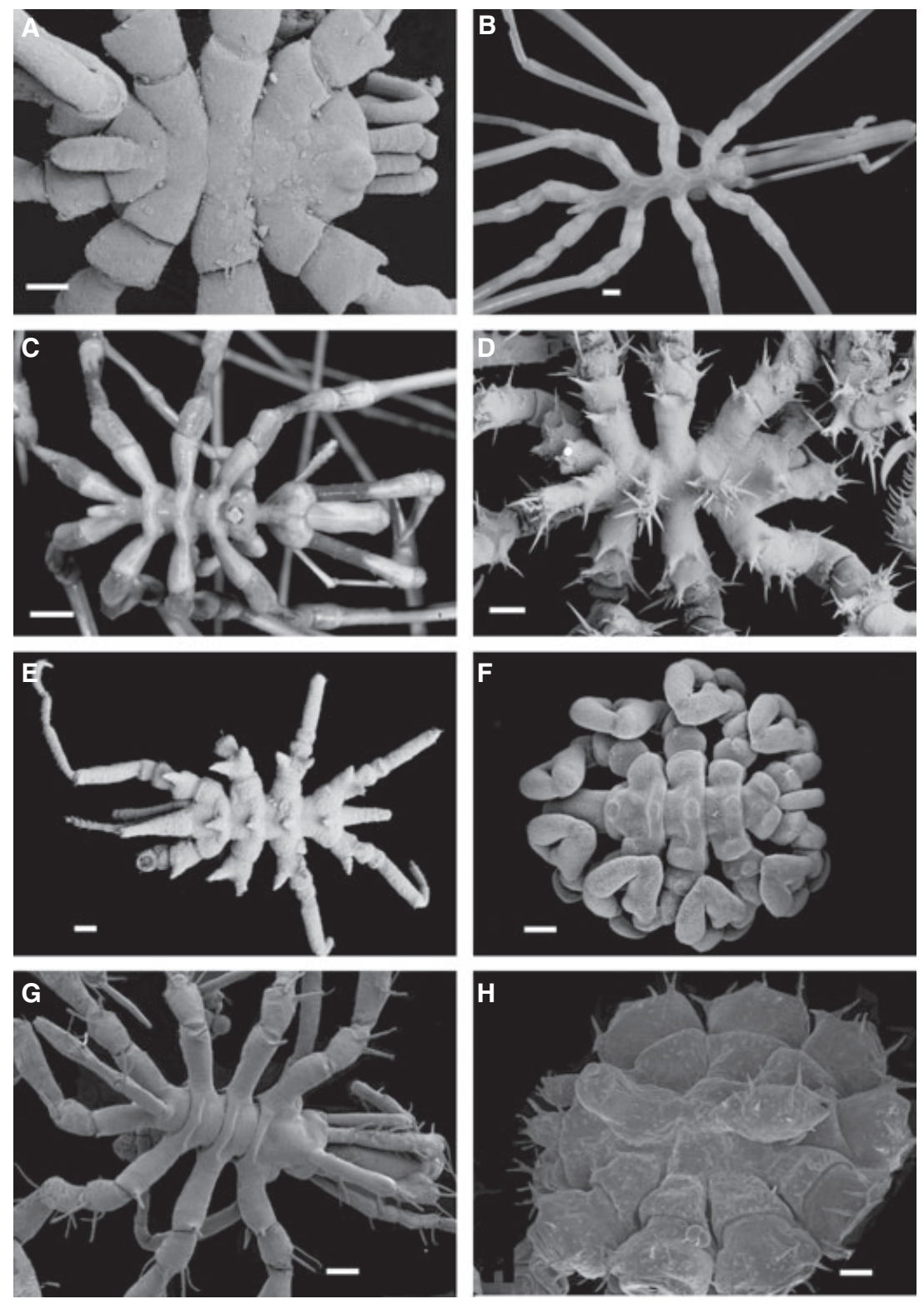

Fig. 5. Dorsal view of the trunk of six different species from different families of Pycnogonida. (A) Achelia hoekii, Ammotheidae, chelifores with atrophied chelae seen on the right hand side margin. Scale $100 \mu \mathrm{m}$. (B) Colossendeis sp., Colossendeidae. Note the complete absence of chelifores. Scale $200 \mu \mathrm{m}$. (C) Nymphon uniuniguiculatum, Nymphonidae. Scale $200 \mu \mathrm{m}$. (D) Nymphopsis duodorsospinosa. Note the two dorsal spinose tubercles flanked by the ocular tubercle on the right, and the abdomen, also with a spination pattern, on the left. Scale $100 \mu \mathrm{m}$. (E) Austrodecus glaciale, Austrodecidae. Ocular tubercle and palps near the left margin. Scale $200 \mu \mathrm{m}$. (F) Pycnogonum stearnsi, Pycnogonidae. Proboscis part covered by the first pair of legs on the left hand side. Note the complete absence of chelifores and palps. Scale $200 \mu \mathrm{m}$. (G) Ammothella appendiculata, Ammotheidae. Long abdomen pointing towards the upper left-hand corner. Scale $80 \mu \mathrm{m}$. (H) Tanystylum orbiculare, Ammotheidae. Chelifores are tiny knobs near the left hand margin (only first coxae of all legs shown). Scale $70 \mu \mathrm{m}$.

the separate morphological analysis, showing $100 \%$ frequency (values not shown) in the resulting MPTs (consensus in Fig. 4). The oviger distal segments or strigilis (character 56), the type of mouth (character 70; Fig. 6B) and the shape of proboscis (character 62; Fig. 6D), are synapomorphies for the group. Eurycyde is notably peculiar due to a clear segmentation of the proboscis, the anterior segment is a unique stalk or pedestal articulating with the pyriform part (Fig. 6D) and in the genotypic data, COI has a deletion of two codons at position 468 in the three species of Eurycyde, appearing as a molecular autapomorphy for the genus. The affinities of other ammotheid genera (rarer forms such as Bathyzetes or Heterofragilia) that could potentially relate to this clade remain to be tested. This result confirms the non-monophyly of Ammotheidae 

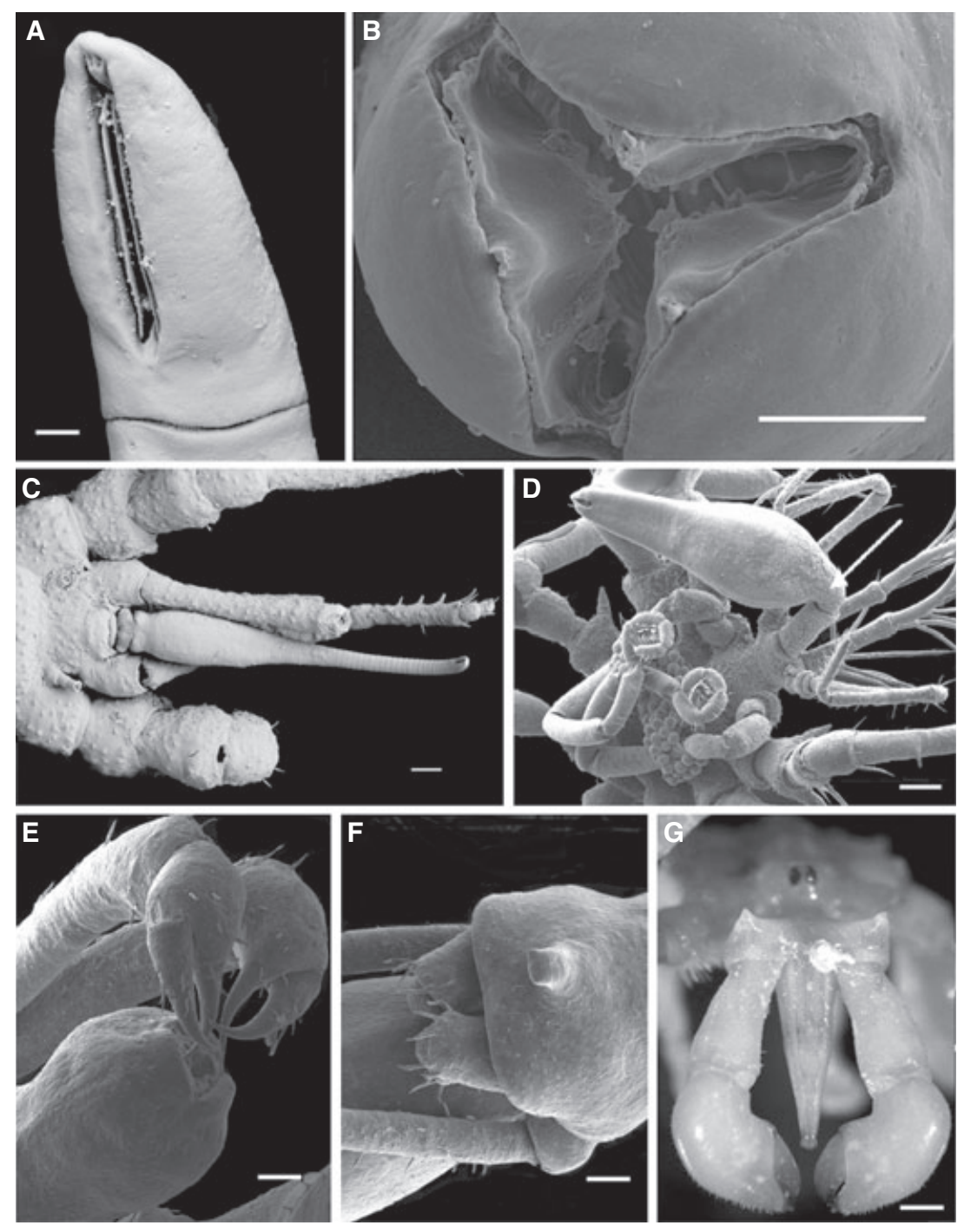

Fig. 6. (A) Mouth of Austrodecus glaciale. Ventral view of the distal part of the proboscis bearing the bilobate mouth, autapomorphy of the Austrodecidae. Note the annulated pattern of the proboscis (also C). Scale $10 \mu \mathrm{m}$. (B) Mouth of Achelia hoekii, frontal view showing a tripartite configuration, characteristic of all pycnogonid families except Austrodecidae. Note the deep incisures of the mouth common to the Ammotheidae. Scale $50 \mu \mathrm{m}$. (C) Ventral view of the cephalic segment of Austrodecus glaciale showing the thin, down-curved proboscis with an annulated or segmented pattern. Scale $100 \mu \mathrm{m}$. (D) Ventrolateral view of Eurycyde raphiaster, Ammotheidae, the arrow indicates the segmentation line of the proboscis, the mouth points towards the upper left corner, the ovigers with strong strigilis carrying eggs, seen at the center of the image. Scale $200 \mu \mathrm{m}$. (E) Mouth and chelae of Anoplodactylus californicus. Scale $100 \mu \mathrm{m}$. (F) Reduced chelifores of Sericosura venticola. Scale $400 \mu \mathrm{m}$. (G) Austropallene cristata frontal view of proboscis and chelifores. Scale $60 \mu \mathrm{m}$.

suggested in Arango (2002) and implies that the reduction or loss of chelae could be a yet unexplained event occurring in unrelated taxa, instead of being one of the main diagnostic characters of the family Ammotheidae as proposed by traditional taxonomy. Characters related to the proboscis and mouth such as the deep incisures (e.g., characters 66 and 70) (Fig. 6B) are also shared by the two groupings of ammotheids. On the other hand, Ascorhynchus and Eurycyde species tend to have a more plain and simple propodus configuration (of the type in Fig. 7E), whereas generally small ammotheid taxa such as Ammothella and Achelia show more complex propodi (Fig. 7D).

With the addition of terminals, and phenotypic and genotypic data, a monophyletic Callipallenidae is not recovered here, similar to Arango (2002) that showed a pectinate pattern of relationships among callipallenid genera. However, the extended morphological data set supports the Callipallenidae node with four synapomorphies, two of them strict (characters 30, 31, 59, 63; Fig. 4). In the total analysis the group formed by callipallenids and nymphonids is the strongest clade 

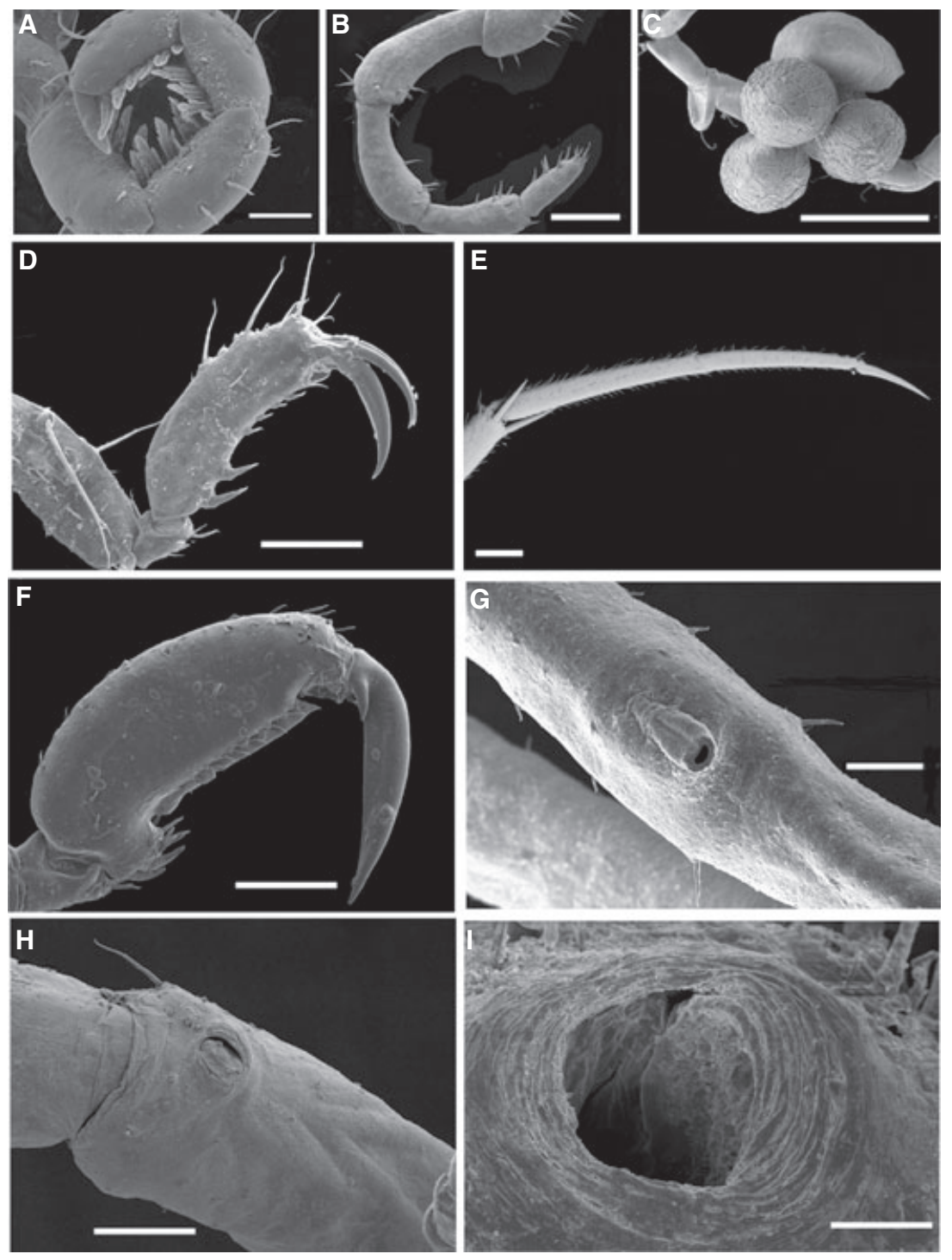

Fig. 7. (A) Detail of the strigilis of Eurycyde raphiaster showing the compound spines and the terminal claw on the distal segment. Scale $60 \mu \mathrm{m}$. (B) Distal segments of the oviger of Pallenopsis macronyx, Pallenopsidae, with no strigilis present. Scale $500 \mu \mathrm{m}$. (C) Fifth segment of the oviger of a male Callipallene californiensis, Callipallenidae with four eggs attached and the apophysis on the distal end of the segment. This type of apophysis occurs in most Callipallenidae and Nymphonidae species. Scale $300 \mu \mathrm{m}$. (D) Lateral view of the distal leg segments of Ammothella spinifera, Ammotheidae showing two propodus heel spines and prominent auxiliary claws dorsal to the main claw. Scale $100 \mu \mathrm{m}$. (E) Lateral view of the distal leg segments of Nymphon australe with tarsus and propodus equally slender, auxiliary claws completely absent. Scale $200 \mu \mathrm{m}$. (F) Propodus of Anoplodactylus viridintestinalis with reduced, endal auxiliary claws, typical of the genus. Scale $100 \mu \mathrm{m} .(\mathrm{G})$ Cement gland tube of Anoplodactylus californicus male, located dorsally on the femora. Scale $100 \mu \mathrm{m}$. (H) Genital pore of an adult female of Ammothella spinifera, located ventrodistally on the second coxae of all legs. Scale $70 \mu \mathrm{m}$. (I) Detail of a genital pore of an adult male of Pallenopsis macronyx. Scale $100 \mu \mathrm{m}$.

supported by a large number of character transformations (see Fig. 7 and Appendix 3). In traditional classifications their morphological similarities have served to consider them relatives (Stock, 1994), although Nymphonidae have also been regarded as primitive due to their "completeness" (see Hedgpeth, 1947 and discussion in Arango, 2002). Morphological synapomorphies for the Callipallenidae-Nymphonidae group include the presence of an apophysis on the male oviger (character 59) illustrated in Fig. 7(C) and the type of larvae (character 77). Internally, Oropallene is sister taxon of Callipallene instead of Propallene (as in Arango, 2002), which unexpectedly joins Nymphon floridanum, the only shallow water, tropical Nymphon included here. The diversity in species $(\approx 300$ species described, Table 1) and morphology patterns in Nymphon needs to be considered further in future studies. For instance, N. floridanum and other species have 
auxiliary claws and heel spines on propodi while other complex of species (e.g., $N$. australe) have the simple type of propodus (Fig. 7E). This, and other combinations of characteristics have been used by taxonomists to define species complexes (for example see Child, 1988). Species-level revision of the cosmopolitan Nymphonidae and the systematic revision of callipallenid genera [21 or 22 depending on synonymies, see Staples, 2005) are essential for further testing of affinities among nymphonid and callipallenid forms. The major clade of Pycnogonida including fossil taxa, Ascorhynchus, Eurycyde and callipallenid-nymphonid taxa is supported in the total evidence analysis (Figs 3 and 8 ) by several synapomorphies from all partitions, but mostly from the $28 \mathrm{~S}$ sequences (see Appendix 3). The morphological characters supporting the clade are the multiple, scattered cement glands (character 45) and the position of chelae opposing to each other (character 61) typical of Callipallenidae and Nymphonidae and here coded for P. problematicus $\dagger$ according to Bergström et al., (1980) description. The sister group relationship between the ammotheid genera and the callipallenid-nymphonids is very low supported according to jackknife resampling in the total analysis (although maximum support was obtained after excluding the fossils, Fig. 2), and the affinities of the Callipallenidae-Nymphonidae group to the other extant pycnogonid taxa remain to be tested by additional sources of non-genotypic evidence.

\section{Pallenopsidae + (Phoxichilidiidae + ammotheids)}

The position of Pallenopsis supports raising the familial rank Pallenopsidae following a numerical taxonomy analysis by Fry (1978) and suggested in taxonomic studies (Child, 1992; see Discussion in Bamber, 2004), and the previous cladistic analyses (Arango, 2002) of morphology, although the combined results placed Pallenopsis as sister taxon to Anoplodactylus (Arango, 2003a). The genus Anoplodactylus is a robust monophyletic group also well supported as sister group to Endeis. The Endeis-Anoplodactylus grouping is supported by the absence of palps (characters 29, 31), simplicity of ovigers in males (character 38 ), complete absence of ovigers in females (character 35) and the lack of developed strigilis (character 56). On the other hand, Endeis shows a remarkable set of morphological autapomorphies (Fig. 7), related to the size and position of proboscis (characters 64, 67, 76), the configuration of cement glands (characters 42-45) and especially the total absence of chelifores in adulthood. The familial rank of Endeidae Norman (Hedgpeth, 1947; Fry, 1978; Endeididae in Child 1992, 1998), although generally used in taxonomy, has been questioned before (Stock, 1965; Arango, 2002). In this study the lack of support for Phoxichilidium within Phoxichilidiidae, and the absence of other Phoxichilidiidae genera (Table 1) makes it difficult to propose a definite position for Endeis within
Phoxichilidiidae. The number of autapomorphies evident for this genus could be taken as support for its familial rank, but Endeidae can only be clarified with better taxon sampling and an increased data set for the Phoxichilidiidae.

Sericosura (Fig. 6F) and Ammothea are at the base of the second ammotheid clade, Ammothea putatively monophyletic. More problematic genera are Tanystylum (Fig. 5H) and Achelia, which are again, not recovered as monophyletic even after the addition of taxa and data to previous data sets (Arango, 2002, 2003a). Rhynchothoracidae appears related to species of Ammothella and Achelia, as obtained before solely with morphological characters (Arango, 2002), although this position is supported by fewer molecular data available and this extended morphological data fails to position $R$. australis unambiguously (see strict consensus Fig. 4). Pallenopsidae + (Phoxichilidiidae + ammotheids) is supported by reduction of palps (characters 30 and 32 ), the absence of oviger terminal claw (character 37) (see Fig. 7) and a number of nuclear transformations mostly in $28 \mathrm{~S}$ and $16 \mathrm{~S}$ sequences (Appendix 3).

\section{Implications and remarks}

Novel relationships proposed in this topology are the deep nodes relating the main lineages. Based on a supposed reductive trend, earlier taxonomists had suggested Ammotheidae or Nymphonidae as primitive taxa from which more derived groups have appeared, showing a gradual reduction of appendages (e.g., Hedgpeth, 1947; Stock, 1994; Munilla, 1999). The hypothesis of the reductive trend is not supported here (nor was it in Arango, 2002, 2003a). The resulting most parsimonious hypothesis of relationships shows nymphonids strongly related to callipallenids in a quite derived position (Fig. 3). Additionally, the occurrence of species with extra trunk somites seems to be an independent event occurring at least in Nymphonidae (the 10-legged Pentanymphon antarcticum included here), unrelated to Colossendeidae and Pycnogonidae. According to this result the polymeric forms cannot be traced as a shared feature between the three different families. The occurrence of the extra segments remains unstudied from genetic, functional or structural perspectives (see discussion in Hedgpeth, 1954).

The phylogeny we present here, implies that chelifores have been lost three times in the Pycnogonida, a more parsimonious hypothesis than previously proposed (five losses) based on smaller data sets of morphology and DNA (Arango, 2002, 2003a). In the present phylogeny the loss of chelifores in Endeis could be a case of parallelism not explained, but also, the process of the loss of chelifores in Endeis could be different to that of Austrodecidae, Colossendeidae and Pycnogonidae (e.g., reduction or loss at a different larval stage). On the other 


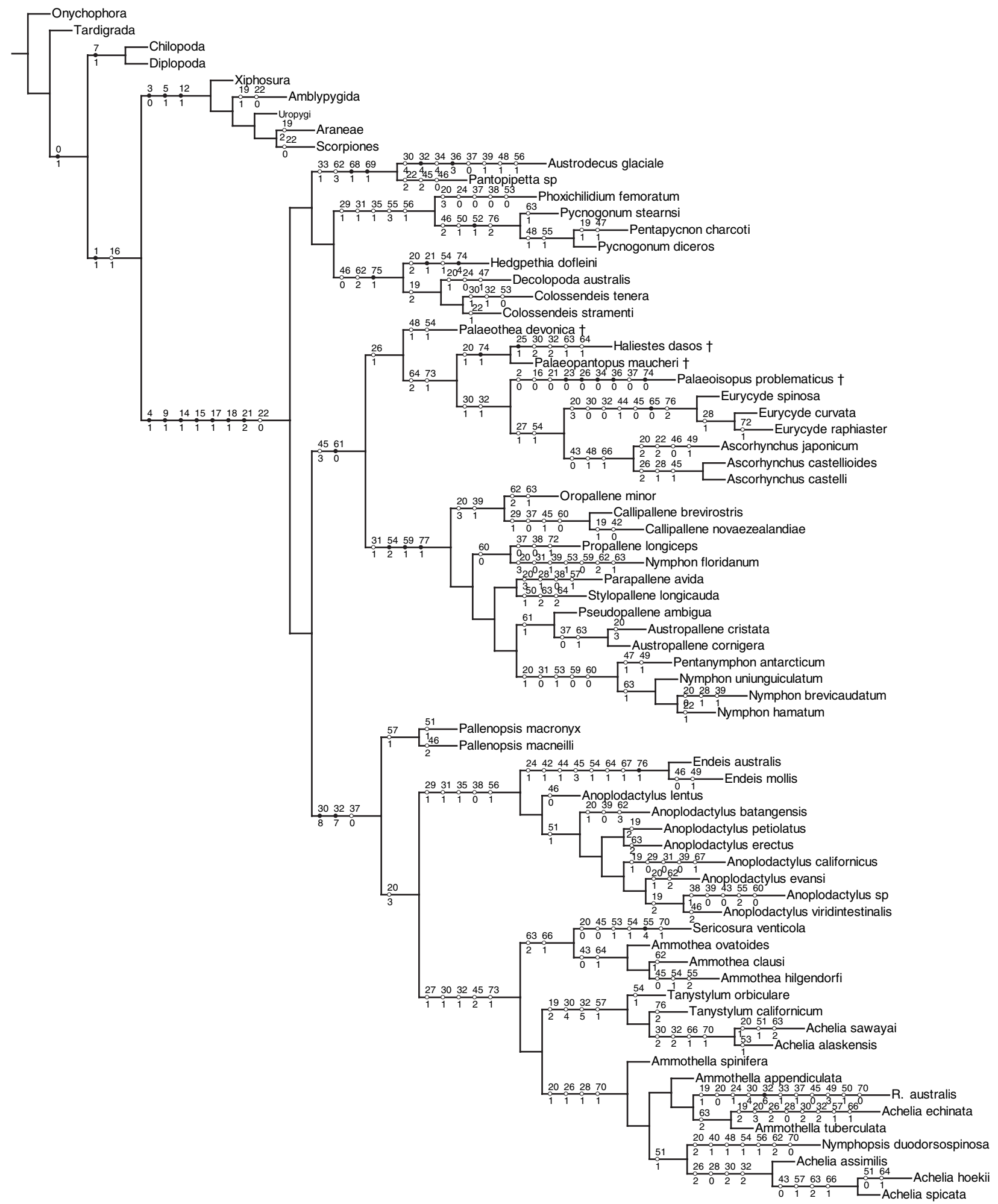

Fig. 8. Morphological characters (Appendix 2) traced onto the optimal topology found (Fig. 3) in an attempt to signal the nodes requiring a stronger test, that are those for which additional evidence is needed from non-genotypic sources, and how the present hypothesis of relationships is supported by morphological information available. The length of this tree with only morphological characters active is 406 steps, 68 longer than the resulting MPTs of the separate analysis of morphological characters in Fig. 4. The mapping of characters on to this tree is complemented by the list of molecular synapomorphies presented in the Appendix 3. 
hand, Rhynchothoracidae, another group characterized by the absence of chelifores is tentatively related to ammotheids, not unexpectedly repeating the pattern obtained with morphology alone in Arango (2002), given the sparse molecular data available (see Methods) for this rare lineage. Affinities between Rhynchothoracidae, Austrodecidae and Pycnogonidae based on body shape, segmentation of palps and ovigers and number of female gonopores are not evident here (see discussion in Arango, 2002).

The strong grouping of ammotheids and phoxichilidiids including Endeis, could be in agreement with the concurrence of similar embryological traits observed in species of these families such as small eggs with complete and symmetrical cleavage (Sanchez, 1959), although similar embryology is described in Pycnogonum litorale (Sanchez, 1959; King, 1973). A peculiar spiral type of cleavage observed in a Callipallene species (Sanchez, 1959; King, 1973) and a different type of total cleavage in Nymphon (Sanchez, 1959; King, 1973) remain to be compared with embryological features in other species. Observations of embryology and larval development are known for species from a few genera, but they would definitely be useful for expanding the range of potentially informative sources.

The deeper nodes of the pycnogonid phylogeny, although strongly supported in a total evidence analysis, are not strongly defended by known morphological synapomorphies. Potentially informative structural characters with known variation within Pycnogonida, such as sperm morphology (van Deurs, 1974a,b) and eye structure (Heß et al., 1996), are to be scored across a much broader range of terminals. The task is to investigate different sources (e.g., internal anatomy, development, gene order, etc.) that could provide additional evidence to test phylogenetic hypotheses in Pycnogonida.

The absence or reduction of appendages in many taxa causes proliferation of missing or inapplicable data as well as homoplasy. In Arango (2002) the use of implied weights allowed the exploration of how homoplastic characters can have more or less influence in the phylogeny of the group, but nodes were not strongly supported. The need for more characters led to a subsequent preliminary molecular approach and combined analysis of nine major taxa, morphology and $\approx 1.2 \mathrm{~kb}$ of nuclear ribosomal DNA. In this work we largely increased the data set available for Pycnogonida, and provided a strong test of the phylogeny using a total evidence approach under iterative pass (IP) optimization, which contributed substantially to the improvement in tree length compared with the initial RAS, TBR and tree fusing rounds (not shown). Similar results and outcomes have been reported before with the use of IP optimization (Giannini and Simmons, 2003; Wheeler, 2003b; Sorhannus, 2004). The analysis presented here constitutes a more consistent approach and more aggressive search for most parsimonious topologies, which should provide a strong, more reliable higherlevel phylogeny testing for monophyly and interfamilial affinities. The progress in non-supraspecific taxon sampling largely depends upon exhaustive fieldwork and wide collaboration with research teams sampling a variety of habitats, in particular those from deeper or remote areas. Although a complete test for monophyly for each of the genera is not attempted here, several species groups representing diversity in morphology can provide more reliable results at a higher level. In future investigations, additional terminals and the inclusion of more non-genotypic characters are needed to test the stability of the clades. Regarding the molecular data, further analyses will focus on the dependence and sensitivity of these results to variation in analytical assumptions (e.g., indel and gap extension costs). Finally, at the level of arthropod evolution studies, the great variation observed among the pycnogonid lineages, and the phylogenetic position of pycnogonid taxa sampled, need to be carefully considered, as they can potentially have large impacts in their results and interpretations.

\section{Acknowledgments}

We are grateful to Chuck Amsler, Shane Anderson, Roger Bamber, Monica Barg, Jim Bouitillier, Gabriel Genzano, Dan Kamikawa, Tripp McDonald, Katsumi Miyazaki, Tomás Munilla, Tom Shirley, Susan Thornton-DeVictor and Jennifer Wolf for kindly providing specimens. Thanks to Juan Cruz, Guillermo DiazPulido, Richard Tinsman, Jane Watson for help in the field and especially to David Staples for his field support in Victoria, Australia. To the California Academy of Sciences, Instituto de Investigaciones Marinas y Costeras (Invemar) Colombia, Museum für Naturkunde Berlin, Museum Victoria (Melbourne Museum), Australian Museum (AM), Field Museum Chicago, Northern Territory Art Gallery and Museum and Santa Barbara Museum of Natural History, for loans and collecting permit arrangements. Thanks to David Staples and Franz Krapp for taxonomic expertise and discussion and for sharing unpublished accounts of genera and species. To Tarang Sharmat for assistance in the molecular laboratory and Sue Lindsay for SEM work. Thanks to Lorenzo Prendini for making unpublished sequences available and to Don Colgan for helpful comments to an earlier version of the manuscript. Thanks to the editors and the reviewers Stefan Richter and Tomás Munilla for useful comments that improved the manuscript. This work was funded by a Lerner-Gray Fellowship at AMNH and Australian Biological Resource Study (ABRS) grant (no. 204-61) 
to C.P.A., and the Fundamental Space Biology Program of NASA supporting W.C.W.

\section{References}

Arango, C.P., 2002. Morphological phylogenetics of the sea spiders (Arthropoda: Pycnogonida). Org. Div. Evol. 2, 107-125.

Arango, C.P., 2003a. Molecular approach to the phylogenetics of sea spiders (Pycnogonida, Arthropoda) using nuclear ribosomal DNA and morphology. Mol. Phylogenet. Evol. 28, 588-600.

Arango, C.P., 2003b. Sea spiders from the Great Barrier Reef: New species, new records and ecological annotations. J. Nat. Hist. 37, $2723-2772$.

Arango, C.P., Maxmen, A., 2006. Proboscis ornamentation as diagnostic character for the Anoplodactylus californicus-digitatus complex (Arthropoda: Pycnogonida) with an example from the Anoplodactylus eroticus female. Zootaxa, 1311, 51-64.

Arnaud, F., Bamber, R.N., 1987. The biology of Pycnogonida. Adv. Mar. Biol. 24, 1-95.

Bain, B., 2003. Larval types and a summary of postembryonic development within the pycnogonids. Invertebr. Reprod. Dev. 43, 193-222.

Bamber, R.N., 2004. Pycnogonids (Arthropods: Pycnogonida) from French Cruises to Melanesia. Zootaxa, 551, 1-27.

Bergström, J., Stürmer, W., Winter, G., 1980. Palaeoisopus, Palaeopantopus and Palaeothea, pycnogonid arthropods from the Lower Devonian Hunsrück Slate, West Germany. Paläontol. Z. 54, 7-54.

Bogomolova, E.V., Malakhov, V.V., 2003. Larvae of sea spiders (Arthropoda, Pycnogonida) from the White Sea. Entomol. Rev. 83, 222-236.

Budd, G.E., Telford, M.J., 2005. Along came a sea spider. Nature, 437, 1099-1102.

Child, A.C., 1978. Gynandromorphs of the pycnogonid Anoplodactylus portus. Zool. J. Linn. Soc. (London), 63, 133-134.

Child, A.C., 1979. Shallow water Pycnogonida of the Isthmus of Panama and the coasts of Middle America. Smithson. Contrib. Zool. 23, 1-86.

Child, A.C., 1982. Pycnogonida from Carrie Bow Cay, Belize. Smithson. Contrib. Mar. Sci. 12, 1-539.

Child, A.C., 1988. Pycnogonida from Aldabra Atoll. Biol. Soc. Wash. Bull. 8, 45-78.

Child, A.C., 1992. Shallow water Pycnogonida of the Gulf of Mexico. Mem. Hourglass Cruises, 9, 1-86.

Child, A.C., 1995a. Antarctic and Subantarctic Pycnogonida IV. The families Colossendeidae and Rhynchothoracidae. In: Cairns, S. (Ed.), Antarctic and Subantarctic Pycnogonida: Nymphonidae, Colossendeidae, Rhynchothoracidae, Pycnogonidae, Endeididae, and Callipallenidae. American Geophysical Union, Washington, DC, pp. 69-111.

Child, A.C., 1995b. Antarctic and Subantarctic Pycnogonida V. The families Pycnogonidae, Phoxichilidiidae, Endeididae and Callipallenidae, including the genus Pallenopsis. In: Cairns, S. (Ed.), Antarctic and Subantarctic Pycnogonida: Nymphonidae, Colossendeidae, Rhynchothoracidae, Pycnogonidae, Endeididae, and Callipallenidae. American Geophysical Union, Washington, DC, pp. $112-165$.

Child, A.C., 1998. The marine fauna of New Zealand: Pycnogonida (sea spiders). NIWA Biodiversity Mem. 109, 1-46.

Colgan, D.J., McLauchlan, A., Wilson, G.D.F., Livingston, S.P., Edgecombe, G.D., Macaranas, J., Cassis, G., Gray, M.R., 1998. Histone H3 and U2 snRNA DNA sequences and arthropod molecular evolution. Aust. J. Zool. 46, 419-437.

De Laet, J., Wheeler, W.C., 2003. POY version 3.0.11 (Wheeler, Gladstein and De Laet, May 6 2003). Command line documentation. ftp://ftp.amnh.org/pub/molecular/poy/ van Deurs, B., 1974a. Pycnogonid sperm. An example of intra-specific axonemal variation. Cell Tissue Res. 149, 105-111.

van Deurs, B., 1974b. Spermatology of some Pycnogonida (Arthropoda), with special reference to a microtubule-nuclear envelope complex. Acta Zool. 55, 151-162.

Dunlop, J.A., Arango, C.P., 2005. Pycnogonid affinities: a review. J. Zool. Syst. Evol Res. 43, 8-21.

Edgecombe, G.D., 2004. Morphological data, extant Myriapoda and the myriapod stem-group. Contrib. Zool. 73, 207-252.

Fahrenbach, H., Arango, C., in press. Microscopic anatomy of Pycnogonida. II. Digestive system. III. Excretory system. J. Morphol.

Faivovich, J., Hadadd, C., Garcia, P., Frost, D., Campbell, J., Wheeler, W.C., 2005. Systematic review of the frog family Hylidae, with special reference to Hylinae: Phylogenetic analysis and taxonomic revision. Bull. Am. Mus. Nat. Hist. 294, 1-240.

Folmer, O., Black, M., Hoeh, W., Lutz, R., Vrijenhoek, R., 1994. DNA primers for amplification of mitochondrial cytochrome $\mathrm{c}$ oxidase subunit I from diverse metazoan invertebrates. Mol. Mar. Biol. Biotechnol. 3, 294-299.

Frost, D., Grant, T., Faivovich, J., Bain, R., Haas, A., Haddad, C.F.B., De Sá, R., Channing, A., Wilkinson, M., Donellan, S.C., Raxworthy, C.J., Campbell, J.A., Blotto, B.L., Moler, P., Drewes, R.C., Nussbaum, R.A., Lynch, J.D., Green, D.M., Wheeler, W.C., 2006. The Amphibian tree of life. Bull. Am. Mus. Nat. Hist. 297, 1-370.

Fry, W.G., 1978. A classification within the pycnogonids. Zool. J. Linn. Soc. (London), 63, 35-38.

Fry, W.G., Hedgpeth, J.W., 1969. Pycnogonida. Colossendeidae, Pycnogonidae, Endeidae, Ammotheidae. NZ Dept. Sci. Indust. Res. Bull. Part, 7, 1-139.

Giannini, N.P., Simmons, N.B., 2003. A phylogeny of megachiropteran bats (Mammalia: Chiroptera: Pteropodidae) based on direct optimization analysis of one nuclear and four mitochondrial genes. Cladistics, 19, 496-511.

Giribet, G., 2005. Generating implied alignments under Direct Optimization using POY. Cladistics, 21, 396-402.

Giribet, G., Carranza, S., Baguña, J., Riutort, M., Ribera, C., 1996. First molecular evidence for the existence of a Tardigrada + Arthropoda clade. Mol. Biol. Evol. 13, 76-84.

Giribet, G., Edgecombe, G.D., Wheeler, W.C., 2001. Arthropod phylogeny based on eight molecular loci and morphology. Nature, $413,157-161$.

Giribet, G., Richter, S., Edgecombe, G.D., Wheeler, W.C., 2005. The position of crustaceans within Arthropoda-evidence from nine molecular loci and morphology. In: Koeneman, S., Jenner, R.A. (Eds.), Crustacea and Arthropod Relationships. Taylor \& Francis, Boca Raton, FL, pp. 307-352.

Goloboff, P.A., 1997. NONA. 2.0. Computer Software and Documentation. Distributed by the American Museum of Natural History, New York.

Goloboff, P.A., 1999. Analyzing large data sets in reasonable times. Solutions for Composite Optima. Cladistics, 15, 415-428.

Goloboff, P.A., Farris, J.S., Nixon, K.C., 2000. T.N.T. Tree Analysis using New Technology. 1.0. Program and documentation available from the authors, and at http://www.zmuck.dk/public/phylogeny

Hedgpeth, J.W., 1947. On the evolutionary significance of the Pycnogonida. Smithson. Misc. Coll. 106, 1-53.

Hedgpeth, J.W., 1954. On the phylogeny of the Pycnogonida. Acta Zool. 35, 193-213.

Hedgpeth, J.W., 1978. A reappraisal of the Palaeopantopoda with description of species from the Jurassic. Zool. J. Linn. Soc. (London), 63, 23-34.

Heß, M., Melzer, R.R., Smola, U., 1996. The eyes of a nobody, Anoplodactylus petiolatus (Pantopoda, Anoplodactylidae). Helgol. Meeresunters. 50, 25-36.

Jager, M., Murienne, J., Clabaut, C., Deutsch, J., Le Guyader, H., Manuel, M., 2006. Homology of arthropod anterior appendages 
revealed by Hox gene expression in a sea spider. Nature, 441, 506508.

King, P.E., 1973. Pycnogonids. Hutchinson, London.

Kluge, A., 1989. A concern for evidence and a phylogenetic hypothesis of relationships among Epicrates (Boidae, Serpentes). Syst. Zool. $38,7-25$.

Kocher, T.D., Thomas, W.K., Meyer, A., Edwards, S.V., Paabo, S., Villablanca, F.X., Wilson, A.C., 1989. Dynamics of mitochondrial DNA evolution in animals: Amplification and sequencing with conserved primers. Proc. Natl Acad. Sci. USA, 86, 6196-6200.

Mallatt, J.M., Sullivan, J., 1998. 28S and 18S rDNA sequences support the monophyly of lampreys and hagfishes. Mol. Biol. Evol. 15, $1706-1718$.

Manuel, M., Jager, M., Murienne, J., Clabaut, C., Le Guyader, H., 2006. Hox genes in sea spiders (Pycnogonida) and the homology of arthropod head segments. Dev. Genes Evol. 10.1007/s00427-0060095-2.

Maxmen, A., Browne, W.E., Martindale, M.Q., Giribet, G., 2005. Neuroanatomy of sea spiders implies an appendicular origin of the protocerebral segment. Nature, 437, 1144-1148.

Müller, H.-G., 1993. World Catalogue and bibliography of the Recent Pycnogonida. Wissenschaftlicher Verlag, Laboratory for Tropical Ecosystems, Research \& Information Service, Wetzlar, Germany.

Munilla, T., 1999. Evolución Y Filogenia de Los Picnogónidos. In: Melic, A., De Haro, J., J., Mendez, M., Ribera, I. (Eds.), Evolución y Filogenia de Arthropoda. Sociedad Entomológica Aragonesa (SEA), Zaragoza, pp. 273-279.

Nixon, K.C., 1999. The parsimony ratchet, a new method for rapid parsimony analysis. Cladistics, 15, 407-414.

Nixon, K.C., 2000. WINCLADA. 0.9.99m24 Beta. Cornell University, Ithaca, NY.

Nixon, K.C., Carpenter, G.H., 1996. On simultaneous analysis. Cladistics, 12, 221-241.

Nunn, G.B., Theisen, B.F., Christensen, B., Arctander, P., 1996. Simplicity-correlated size growth of the Nuclear 28S Ribosomal RNA D3 expansion segment in the Crustacean Order Isopoda. J. Mol. Evol. 242, 211-223.

Poschmann, M., Dunlop, J.A., 2006. A new sea spider (Pycnogonida) with a flagelliform telson from the lower Devonian Hunsruck Slate, Germany. J. Palaeontol. 49, 1-7.

Prendini, L., 2001. Species or supraspecific taxa as terminals in cladistic analysis? Groundplans versus exemplars revisited. Syst. Biol. 50, 290-300.

Sanchez, S., 1959. Le development des pycnogonides et leurs affinites avec les arachnides. Arch. Zool. Exp. Gen. 98, 1-102.

Simon, C., Frati, F., Beckenbach, A., Crespi, B., Liu, H., Flook, P.K., 1994. Evolution, weighting, and phylogenetic utility of mitochondrial gene sequences and a compilation of conserved polymerase chain reaction primers. Ann. Entomol. Soc. Am. 87, 651-700.
Siveter, D.J., Sutton, M.D., Briggs, D.E.G., Siveter, D.J., 2004. A Silurian sea spider. Nature, 431, 978-980.

Snodgrass, R.E., 1952. A Textbook of Arthropod Anatomy. Cornell University, New York.

Sorhannus, U., 2004. Diatom phylogenetics based on direct optimization of nuclear encoded SSU rRNA sequences. Cladistics, 20, 487-497.

Sparks, J., Smith, W.L., 2004. Phylogeny and biogeography of cichlid fishes. Cladistics, 20, 501-517.

Staples, D.A., 1982. Pycnogonida of the Calliope River and Auckland Creek, Queensland. Mem. Qld. Mus. 20, 455-471.

Staples, D.A., 2005. Pycnogonida from the Althorpe Islands, South Australia. Trans. R. Soc. South Aust. 129, 158-169.

Stock, J.H., 1957. The pycnogonid family Austrodecidae. Beaufortia, $6,1-81$.

Stock, J.H., 1965. Pycnogonida from the southwestern Indian Ocean. Beaufortia, 13, 13-33.

Stock, J.H., 1994. Indo-west pacific Pycnogonida collected by some major oceanographic expeditions. Beaufortia, 44, 17-77.

Vilpoux, K., Waloszek, D., 2003. Larval development and morphogenesis of the sea spider Pycnogonum litorale (Strom, 1762) and the tagmosis of the body of Pantopoda. Arthropod Struct. Dev. 32, 349-383.

Waloszek, D., Dunlop, J.A., 2002. A larval sea spider (Arthropoda: Pycnogonida) from the upper Cambrian 'Orsten' of Sweden, and the phylogenetic position of pycnogonids. Palaeontology, 45, 421446.

Wheeler, W.C., 1996. Optimization alignment: the end of multiple sequence alignment in phylogenetics? Cladistics, 12, 1-9.

Wheeler, W.C., 2002. Optimization alignment: down, up, error, and improvements. In: Desalle, R., Giribet, G., Wheeler, W. (Eds.), Techniques in Molecular Systematics and Evolution. BirkhäuserVerlag, Switzerland, pp. 55-69.

Wheeler, W.C., 2003a. Implied alignment: a synapomorphy-based multiple-sequence alignment method and its use in cladogram search. Cladistics, 19, 261-268.

Wheeler, W.C., 2003b. Iterative Pass Optimization. Cladistics, 19, 254 260.

Wheeler, W.C., Hayashi, C., 1998. The phylogeny of extant chelicerate orders. Cladistics, 14, 173-192.

Wheeler, W.C., Gladstein, D.S., De Laet, J., 1996-2006. POY, Version 3.0.11. Available from ftp.amnh.org/pub/molecular/poy

Whiting, M.F., 2002. Mecoptera is paraphyletic. multiple genes and phylogeny of Mecoptera and Siphonaptera. Zool. Scr. 31, 93-104.

Yeates, D.K., 1995. Groundplans and exemplars: paths to the tree of life. Cladistics, 11, 343-357. 


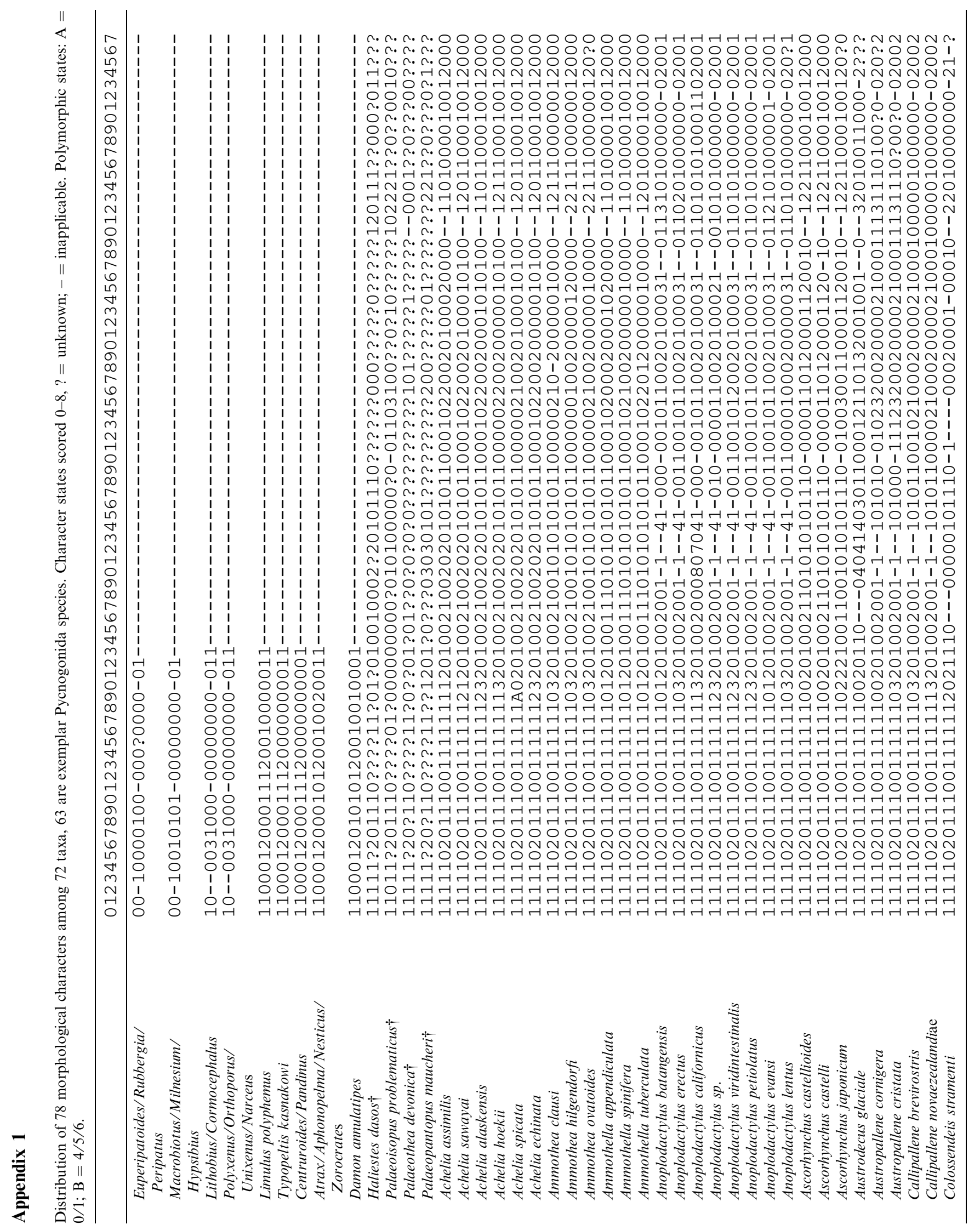




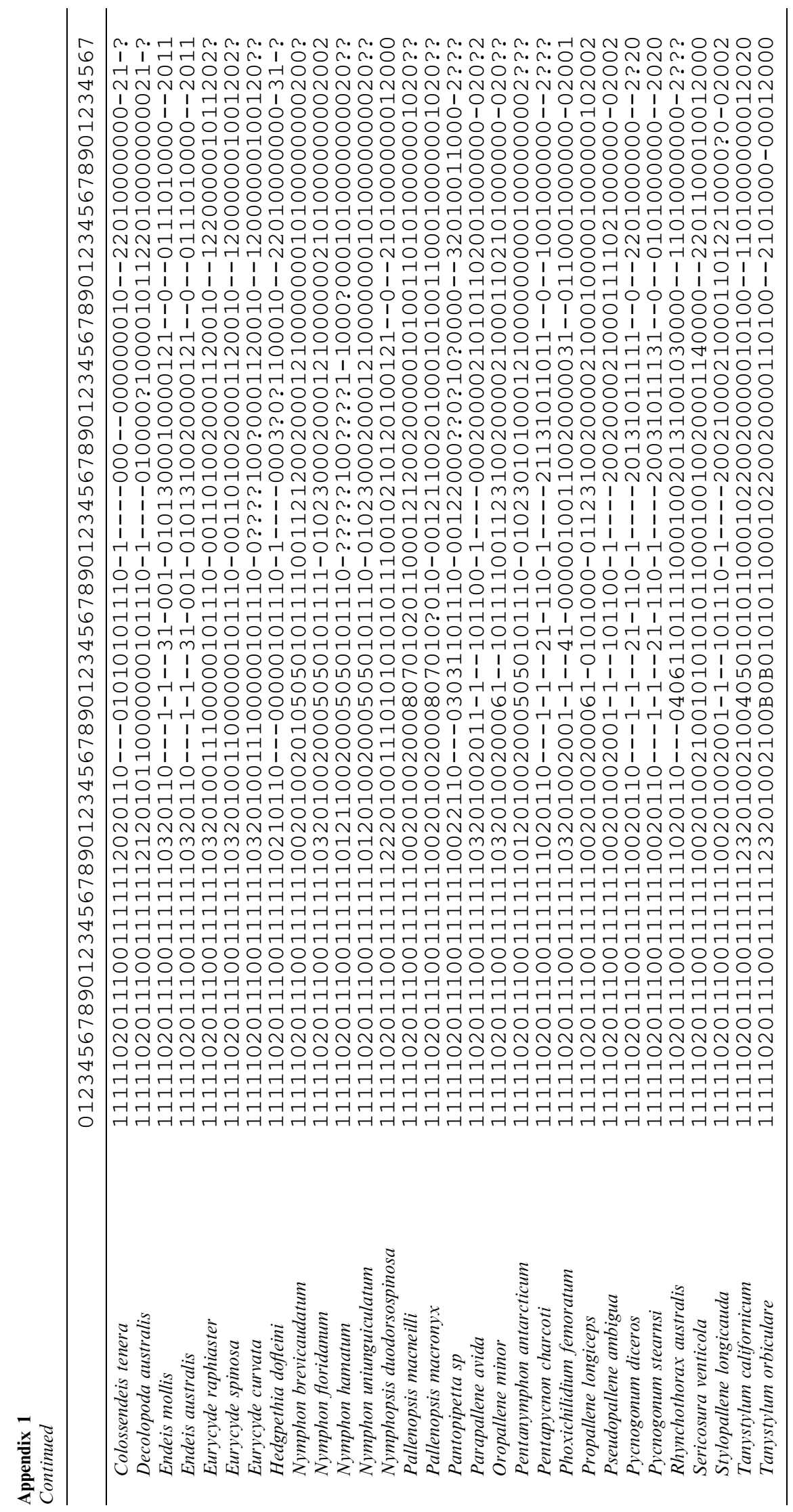




\section{Appendix 2}

List of 78 morphological characters used in this study. Description and earlier references of previously used characters are signaled in bold with initial and number of character in that study. A\# in Arango (2002); E\# in Edgecombe (2004); WH\# in Wheeler and Hayashi (1998). 0 Sclerotization of cuticle into hard, articulated exoskeleton: (0) absent; (1) present (E17).

1 Tagmosis into prosoma-opisthosoma: (0) absent; (1) present (E190). 2 Opisthosoma greatly reduced forming a slender tube emerging from the last pair of legs: (0) absent; (1) present (E193).

3 Body carapace or shield: (0) present; (1) absent.

4 Body extending in lateral processes: (0) absent; (1) present.

5 Endosternum (ventral tendons fused into prosomal endosternum): (0) absent; (1) present. (E207).

6 Appendage of deutocerebral segment: (0) jaw; (1) walking leg; (2) Chelicera/Chelifore; (3) antenna. (E103). This is a crucial character to resolve pycnogonids position in arthropod data sets. Segmental correspondence recently discussed in Edgecombe (2004), Maxmen et al. (2005), Manuel et al. (2006), Jager et al. (2006), and others cited therein. In this particular data set we are favoring the hypothesis that chelicerae of chelicerates and chelifores of pycnogonids are homologous (see Discussion in Vilpoux and Waloszek, 2003; Manuel et al., 2006; Jager et al., 2006), in opposition to the argument by Maxmen et al. (2005) suggesting they are convergent structures innervated from different segmental neuromeres. If pycnogonids are at the base of the arthropod tree and not related to euchelicerates as suggested by Maxmen et al. then chelifores/chelicerae are a plesiomorphy of Arthropoda or a product of convergence. In this study, the chelifore $=$ chelicerae hypothesis follows the scoring from previous arthropod data sets based on classical embryological studies (e.g., Sanchez, 1959) and now on novel hox gene expression data.

7 Mandible: (0) absent; (1) present (E119).

8 Triradiate pharyngeal lumen: (0) absent; (1) present. (E99)

9 Enlarged external fixed proboscis with terminal triangular mouth (internally observed in Austrodecidae): (0) absent; (1) present (WH4). 10 Post oral antenna: (0) present; (1) absent (WH1).

11 Pedipalps chelate: (0) absent; (1) present.

12 Ganglia of post oral appendages fused into a single nerve mass: (0) absent; (1) present. (E51).

13 Number of median eyes: (0) none; (1) four; (2) two. (E77).

14 Orientation of retinula cells: (0) eversely oriented; (1) inversely oriented. Supraspecific Pycnogonida have been coded with retinula cells inversely oriented according to results in Heß et al. (1996) (E79). 15 Eyes Tapetum lucidum: (0) absent; (1) present. The presence of Tapetum lucidum is coded as an apomorphy of the supraspecific terminal Pycnogonida according to $\mathrm{He} ß$ et al. (1996).

16 Telson: (0) present; (1) absent (E261).

17 Ovigers: (0) absent; (1) present. (E141)

18 Genital pores location: (0) on body segment; (1) on coxae of legs (E275, 276).

19 Trunk segmentation: (0) fully segmented; (1) partially segmented; (2) trunk not segmented (A19).

20 Abdomen position: (0) horizontal; (1) diagonal to body; (2) bent or pointing ventrally; (3) erect (A30). One state has been added to code for the bending of the abdomen pointing downwards in Ascorhynchus and Nymphopsis, or the extreme ventral position observed in Hedgpethia.

21 Anus position: (0) ventral on last segment of abdomen; (1) ventral on reduced abdomen; (2) apically on abdomen. Generally all pycnogonid taxa have the anus at the tip of the abdomen and can be seen dorsally. Hedgpethia, is the only genus included here in which the anus is positioned ventrally on a extremely reduced abdomen. Another
Colossendeid genus, Rhopalorhynchus, shares this state (illustration in Arango, 2003b). No description of the anus is available for the fossils $H$. dasos and P. devonica.

22 Ocular tubercle: (0) present; (1) absent; (2) reduced (E85).

23 Leg shape: (0) flattened, laterally compressed; (1) tubular. This character codes for the unique flattened shape of the legs described in P. problematicus (Bergström et al., 1980).

24 Loss of chelifores when adulthood reached in pycnogonids: (0) absent; (1) present. (see Fig. 5). The loss of chelifores with the last molt when they convert to adulthood in many genera of sea spiders is coded as an apomorphic event. This is the same as character 0 in Arango (2002) just re-stated so the process of losing the chelifores is the character used (A0).

25 Chelae with finger reversal: (0) absent; (1) present. In most known pycnogonid genera the movable finger of each chela is placed ventrally to the immovable finger and articulates downward. In Decolopoda and Dodecolopoda (not included here) two of the polymerous taxa of Colossendeidae the movable finger is placed dorsally and articulated upward (see in Child, 1995a).

26 Chelifore scape number of segments: (0) three; (1) two; (2) one. When chelifores are absent coded as inapplicable (A1 but unordered). 27 Loss of chelae when adulthood reached: (0) absent; (1) present (see Fig. 5E,F,G) (A2).

28 Chelifores dorsal spines on scape: (0) absent; (1) present (A3).

29 Palps males: (0) present; (1) absent (A4).

30 Palps number of segments in male pycnogonids: (0) 10; (1) nine; (2) eight; (3) seven; (4) six; (5) five; (6) four; (7) two; (8) one (A5).

31 Palps female: (0) present; (1) absent (A6).

32 Palps number of segments in female pycnogonids: (0) 10; (1) nine; (2) eight; (3) seven; (4) six; (5) five; (6) four; (7) one (A7).

33 Segmentation line at base of palp: (0) present; (1) absent. In most pycnogonids the palps are visibly segmented from the body. In Austrodecidae and Rhnchothoracidae the first segment of the palp does not articulate (no segmentation line visible) but appears as a lateral process.

34 Ovigers number of segments in male: (0) 11; (1) 10; (2) nine; (3) seven; (4) six; (5) five; (6) four (A8).

35 Oviger female: (0) present; (1) absent (A9).

36 Oviger female number of segments: (0) 11; (1) 10; (2) nine; (3) six (A10).

37 Ovigers terminal claw (in both sexes when present in females otherwise in males, same applies to characters 55-58): (0) absent; (1) present (A11) (Fig. 6A,B).

38 Propodus heel: (0) present; (1) absent. The heel is especially conspicuous in Phoxichilidiidae and some Callipallenids.

39 Auxiliary claws: (0) absent; (1) present (A12) (Fig. 7D,E).

40 Auxiliary claws position: (0) ectal dorsally from main claw; (1) lateral to main claw. The tiny auxiliary claws in Anoplodactylus when present, are found laterally, implanted on the main claw, not arising dorsally from the base of the main claw as in other sea spiders (Fig. 7F).

41 Cement glands on femora and/or other leg segments: (0) present; (1) absent (A13).

42 Cement glands number: (0) one; (1) multiple (A14).

43 Cement glands type: (0) pore or slit; (1) tube (Fig. 7G) (A15).

44 Cement gland position on a transverse axis on femora: (0) dorsal (Fig. 7G); (1) lateral; (2) ventral (A16).

45 Cement gland position on a longitudinal axis on femora: (0) proximal; (1) at or near midpoint (Fig. 7G); (2) distal; (3) distributed or scattered (A17).

46 Trunk shape: (0) elongate; (1) medium; (2) compact (A18) (Fig. 5). 47 Trunk segments number: (0) four; (1) five. The significance of the polymery in some families of pycnogonids has not been investigated. Pentanymphon antarcticum, Pentapycnon charcoti and Decolopoda australis (fig. 3e in Dunlop and Arango, 2005) show five-segmented body, instead of the usual four. Six-segmented trunk species such as 
Dodecolopoda mawsoni or Sexanymphon mirabilis were not available for this study.

48 Dorsomedian trunk tubercles: (0) absent; (1) present. Conspicuous tubercles dorsally are coded as apomorphic, e.g., Nymphopsis (Fig. 4D,E).

49 Genital pores position in males: (0) all pairs of legs; (1) second, third and fourth pairs of legs; (2) third and fourth pair of legs; (3) fourth pair of legs (A20). Detail of a male genital pore in Fig. 7(I).

50 Pair of legs having genital pores in female: (0) all pairs of legs; (1) fourth pair of legs; (2) first, second and third pair of legs (A21).

51 Genital spurs ventrally on second coxae of males: (0) absent; (1) present. Mature males of Anoplodactylus and some ammotheids show prominent spurs ventrally on second coxae of the third and fourth pair of legs. These spurs bear a small genital pore at the tip.

52 Genital pores position in females: (0) Ventrally on second coxae (Fig. 7H); (1) Dorsally on second coxae. Dorsal genital pores in females appear as an autapomorphy of Pycnogonidae. The location of female gonopore could not be observed nor was available from material or descriptions for the extinct taxa, Decolopoda australis, Hedgpethia dofleini Nymphon hamatum and Pantopipetta sp.

53 Heel spines: (0) present; (1) absent (A22).

54 Ocular tubercle position: (0) anterior; (1) at or near midpoint; (2) posterior (as in Nymphon, Fig. 5C) (A23).

55 Oviger longest segment: (0) sixth; (1) fifth; (2) fourth; (3) third; (4) one (A24).

56 Oviger spines (developed strigilis): (0) present; (1) absent (A25) (Fig. 6E,F).

57 Oviger spines type: (0) compound; (1) simple (A26).

58 Oviger number of rows of spines: (0) one; (1) multiple (A27).

59 Oviger apophysis in males: (0) absent; (1) present. Only present in species of Callipallenidae and Nymphonidae, in which mature males show a distal apophysis on the fifth segment of the ovigers (Fig. 7C). 60 Chelae teeth: (0) present; (1) absent (A28).

61 Chelae orientation: (0) opposing each other; (1) pointing down; (2) pointing upwards. A third state is included to code the state described from reconstructions of the Silurian $H$. dasos showing the chelae pointing upwards (see supplementary information in Siveter et al., 2004) (A29).

62 Proboscis shape: (0) A; (1) B; (2) C; (3) D (Fry and Hedgpeth, 1969; Arango, 2002) (A31).

63 Proboscis relative length: (0) less than half the trunk length; (1) half or near half the trunk length (45-55\%); (2) more than half the trunk length (larger than $55 \%$ of trunk length). The description of states (1) and (2) has been modified as in Siveter et al. (2004) (A33).

64 Proboscis position: (0) frontal; (1) diagonal with respect to body axis; (2) ventral (A34).

65 Proboscis segmentation: (0) present; (1) absent. A unique basal segment in form of pedestal is observed in Eurycyde species (Fig. 6D). It is considered to be a primitive character by Stock (1994). The plesiomorphic state cannot be defended until there is a clear hypothesis of homology regarding the anterior segmentation of pycnogonids and other arthropods.

66 Proboscis articulated by basal unsclerotized arthrodial membrane for mobility (Arnaud and Bamber, 1987): (0) absent, not as evident; (1) present. A flexible articulation at the base of the proboscis gives vertical and some lateral movement to the proboscis observed in ammotheid taxa. In species with a short, apparently fixed proboscis like the nymphonids or callipallenids, this articulation is not observed.

67 Mouth surrounded by sensory setae: (0) absent; (1) present.

68 Proboscis annulation: (0) absent; (1) present. A pipette-like, thin, curved proboscis as autapomorphic of the Austrodecidae (Fig. 6C).

69 Mouth configuration in pycnogonids: (0) Trilobate, terminally opening at front of proboscis (Fig. 6B); (1) Bilobate, ventrodistally on proboscis (Fig. 6A). It distinguishes the specialized bilobate mouth configuration of Austrodecidae; however, the triradiate structure of the proboscis is observed internally (Fahrenbach and Arango, in press).

70 Proboscis wall incisures shaping the mouth: (0) absent; (1) present (Figs 6B.D). The evolutionary or functional significance of these deep incisures are unknown but can be related to food specialization in the ammotheid taxa.

71 Proboscis ventral protuberances in females: (0) absent; (1) present. Conspicuous ventral bumps occur in mature females of Anoplodactylus californicus, A. evansi and 12 other species not included in this study. This dimorphism seems to have some intraspecific variation in A. californicus and has been related to gynandromorphy (Child, 1978). Its variation with age or any other factors, or the functional significance of these outgrowths is yet unknown (Arango and Maxmen, 2006).

72 Palps size proportional to proboscis: (0) longer, distal segments can touch the mouth; (1) shorter, not in contact with mouth.

73 Chelifores size proportional to proboscis: (0) as long or longer than proboscis, in contact with mouth; (1) shorter, not in contact with mouth (Fig. 6E,G).

74 Abdominal segmentation in pycnogonids: (0) five-segmented; (1) three-segmented; (2) one segment peg-shaped; (3) reduced, not visible dorsally. This refers only to the part of pycnogonid body referred to the abdomen, and is coded inapplicable in the other arthropods.

75 Eggs found attached to ovigers of males: (0) present (see Fig. 6D); (1) absent. Eggs attached to male ovigers have not been found in any Colossendeidae or Austrodecidae species and is highly unlikely it could due to sampling effort considering the large numbers of individuals collected of these taxa in old and recent expeditions. It is possible these two families have a different mode of reproduction involving hosts as has been suggested before (for Austrodecidae see Stock, 1957; Arnaud and Bamber, 1987; Child, 1995a).

76 Egg masses configuration attached to ovigers: (0) Separate balls or bracelets on each oviger (Fig. 6D); (1) layers or sheaths held by the two ovigers; (2) single mass attached to both ovigers. The form of masses of eggs attached to ovigers seems to represent a consistent character at genus level. The separate balls or bracelets is the most general form, sheaths or layers observed in Endeis and a single mass held by both ovigers seen in Eurycyde but also in Pycnogonum (in King, 1973). 77 Larval type; (0) typical protonymphon; (1) almost square body, flattened dorsoventrally, thin, long, lash like third segments of second and third appendages, "free swimming larva" (as in Bogomolova and Malakhov, 2003) [named "encysted larva" in the summary by Bain (2003)]; (2) no protonymphon stage after hatching, earliest larva with rudiments of first pair of walking legs. In most cases, the coding based on supraspecific terminals according to literature (Bogomolova and Malakhov, 2003 and earlier literature cited therein).

\section{Appendix 3}

Synapomorphies involving DNA sequences diagnosing major clades of Pycnogonida. Only non-ambiguous transformations included. This list complements the morphological evidence presented in Fig. 8.

\section{Pycnogonida}

$28 S$
Char. 164: $-\rightarrow \mathrm{A}$
Char. 165: T $\rightarrow \mathrm{C}$
Char. 175: $-\rightarrow \mathrm{G}$
Char. 180: $\rightarrow \mathrm{C}$
Char. 186: $-\rightarrow \mathrm{G}$
Char. 187: $-\rightarrow \mathrm{G}$
Char. 189: $\rightarrow \mathrm{T}$
Char. 228: $\mathrm{G} \rightarrow \mathrm{A}$
Char. 232: $\mathrm{C} \rightarrow \mathrm{G}$
Char. 236: T $\rightarrow \mathrm{G}$ 
Char. 243: $\mathrm{T} \rightarrow-$

Char. 264: $\mathrm{G} \rightarrow \mathrm{C}$

Char. 267: $\mathrm{C} \rightarrow \mathrm{T}$

Char. 269: $\mathrm{A} \rightarrow \mathrm{G}$

Char. 275: $\mathrm{C} \rightarrow \mathrm{T}$

Char. 289: $\mathrm{T} \rightarrow-$

Char. 293: $-\rightarrow \mathrm{T}$

Char. 311: $\mathrm{A} \rightarrow \mathrm{T}$

Char. 322: $\mathrm{G} \rightarrow \mathrm{T}$

Char. 338: $\mathrm{C} \rightarrow \mathrm{A}$

Char. 387: $\mathrm{G} \rightarrow \mathrm{T}$

Char. 419: $\mathrm{G} \rightarrow \mathrm{T}$

Char. 429: $\mathrm{A} \rightarrow \mathrm{G}$

Char. 447: $\mathrm{A} \rightarrow \mathrm{G}$

Char. 546: $\mathrm{T} \rightarrow \mathrm{C}$

Char. 605: $\mathrm{T} \rightarrow \mathrm{C}$

Char. 766: $-\rightarrow$ A

Char. 786: $-\rightarrow$ A

Char. 891: $-\rightarrow$ T

Char. 909: $-\rightarrow$ G

Char. 915: $-\rightarrow$ C

Char. 916: $-\rightarrow$ A

Char. 946: AG $\rightarrow$ C

Char. 977: $\mathrm{C} \rightarrow \mathrm{G}$

Char. 987: $\mathrm{T} \rightarrow \mathrm{G}$

Char. 992: $\rightarrow \mathrm{T}$

Char. 997: $\mathrm{A} \rightarrow \mathrm{G}$

Char. 1001: $\mathrm{A} \rightarrow \mathrm{T}$

Char. 1014: $\mathrm{G} \rightarrow-$

Char. 1021: $\mathrm{G} \rightarrow \mathrm{C}$

Char. 1032: $\mathrm{T} \rightarrow-$

Char. 1048: $\mathrm{T} \rightarrow-$

Char. 1116: $\mathrm{A} \rightarrow \mathrm{T}$

Char. 1122: $\mathrm{G} \rightarrow \mathrm{T}$

Char. 1146: $\mathrm{C} \rightarrow \mathrm{G}$

Char. 1150: $\mathrm{G} \rightarrow \mathrm{C}$

Char. 1153: $\mathrm{G} \rightarrow \mathrm{A}$

Char. 1179: $\mathrm{T} \rightarrow \mathrm{C}$

Char. 1189: - $\rightarrow$ G

Char. 1196: - $\rightarrow$ A

Char. 1231: $\mathrm{G} \rightarrow \mathrm{C}$

Char. 1291: $-\rightarrow \mathrm{G}$

Char. 1318: $-\rightarrow \mathrm{T}$

Char. 1343: $-\rightarrow$ G

Char. 1348: - $\rightarrow$ G

Char. 1357: $\mathrm{G} \rightarrow \mathrm{T}$

Char. 1372: $\mathrm{G} \rightarrow \mathrm{T}$

Char. 1427: $\mathrm{T} \rightarrow-$

Char. 1449: $\mathrm{T} \rightarrow-$

Char. 1457: $\mathrm{G} \rightarrow \mathrm{T}$

Char. 1488: C $\rightarrow-$

Char. 1521: $\mathrm{T} \rightarrow \mathrm{A}$

Char. 1571: $\mathrm{G} \rightarrow \mathrm{T}$

Char. 1593: $\mathrm{G} \rightarrow \mathrm{C}$

Char. 1603: $-\rightarrow \mathrm{G}$

Char. 1684: $\mathrm{C} \rightarrow-$

Char. 1714: $\mathrm{G} \rightarrow \mathrm{C}$

Char. 1749: $\mathrm{A} \rightarrow \mathrm{T}$

Char. 1760: $\mathrm{C} \rightarrow \mathrm{A}$

Char. 1763: $\mathrm{G} \rightarrow \mathrm{A}$

Char. 1773: $\mathrm{C} \rightarrow-$

Char. 1785: $\mathrm{G} \rightarrow \mathrm{T}$

Char. 1901: $-\rightarrow$ G

Char. 1938: $\mathrm{C} \rightarrow \mathrm{T}$

Char. 2019: $-\rightarrow \mathrm{C}$

Char. 2091: $\mathrm{A} \rightarrow \mathrm{G}$

Char. 2106: $\mathrm{T} \rightarrow \mathrm{C}$
Char. 2113: $\mathrm{G} \rightarrow \mathrm{C}$

Char. 2146: $\mathrm{A} \rightarrow \mathrm{T}$

Char. 2155: - $\rightarrow$ G

Char. 2167: $\mathrm{G} \rightarrow \mathrm{A}$

Char. 2170: $A \rightarrow G$

Char. 2184: $\mathrm{A} \rightarrow \mathrm{T}$

Char. 2239: $-\rightarrow \mathrm{T}$

Char. 2397: $\mathrm{G} \rightarrow \mathrm{C}$

Char. 2399: $\mathrm{C} \rightarrow \mathrm{T}$

Char. 2404: $\mathrm{T} \rightarrow \mathrm{C}$

Char. 2413: $\mathrm{C} \rightarrow \mathrm{A}$

Char. 2426: $\mathrm{C} \rightarrow \mathrm{T}$

Char. 2436: $-\rightarrow \mathrm{T}$

Char. 2453: $\mathrm{G} \rightarrow \mathrm{A}$

Char. 2457: $\mathrm{A} \rightarrow \mathrm{T}$

Char. 2473: $\mathrm{T} \rightarrow \mathrm{C}$

Char. 2490: $\mathrm{A} \rightarrow \mathrm{G}$

Char. 2631: $\mathrm{T} \rightarrow \mathrm{C}$

Char. 2648: $\mathrm{T} \rightarrow \mathrm{C}$

Char. 2685: $-\rightarrow$ T

Char. 2701: $-\rightarrow$ C

Char. 2928: $\mathrm{T} \rightarrow-$

Char. 2954: $\mathrm{C} \rightarrow \mathrm{T}$

Char. 3011: $\mathrm{G} \rightarrow \mathrm{A}$

Char. 3068: $\mathrm{T} \rightarrow \mathrm{C}$

Char. 3118: $\mathrm{T} \rightarrow \mathrm{C}$

Char. 3195: $\mathrm{C} \rightarrow \mathrm{T}$

Char. 3199: $\mathrm{C} \rightarrow \mathrm{T}$

Char. 3211: $\mathrm{G} \rightarrow \mathrm{A}$

Char. 3235: $-\rightarrow \mathrm{G}$

Char. 3244: $-\rightarrow$ C

Char. 3248: $-\rightarrow$ G

Char. 3346: $-\rightarrow$ C

Char. 3363: $-\rightarrow \mathrm{C}$

Char. 3376: $\mathrm{A} \rightarrow \mathrm{G}$

Char. 3422: $\mathrm{T} \rightarrow \mathrm{C}$

Char. 3426: $\mathrm{T} \rightarrow \mathrm{G}$

Char. 3428: $\mathrm{C} \rightarrow \mathrm{T}$

Char. 3443: $\mathrm{A} \rightarrow \mathrm{G}$

Char. 3464: $\mathrm{T} \rightarrow \mathrm{C}$

Char. 3483: $\mathrm{T} \rightarrow \mathrm{C}$

Char. 3556: $\mathrm{A} \rightarrow \mathrm{G}$

Char. 3664: $A \rightarrow G$

Char. 3755: $\mathrm{G} \rightarrow \mathrm{T}$

Char. 3843: $\mathrm{G} \rightarrow \mathrm{T}$

Char. 3916: $\mathrm{T} \rightarrow \mathrm{C}$

Char. 3950: $\mathrm{T} \rightarrow \mathrm{C}$

Char. 3958: $\mathrm{G} \rightarrow \mathrm{A}$

Char. 4003: $\mathrm{T} \rightarrow \mathrm{C}$

Char. 4004: $\mathrm{A} \rightarrow \mathrm{G}$

Char. 4013: $\mathrm{G} \rightarrow \mathrm{C}$

Char. 4014: $\mathrm{A} \rightarrow \mathrm{G}$

Char. 4034: $\mathrm{G} \rightarrow \mathrm{A}$

Char. 4066: $\mathrm{T} \rightarrow \mathrm{C}$

Char. 4081: $\mathrm{G} \rightarrow \mathrm{T}$

Char. 4102: $\mathrm{C} \rightarrow \mathrm{T}$

Char. 4120: $-\rightarrow$ G

Char. 4121: $-\rightarrow$ A

Char. 4123: - $\rightarrow$ G

Char. 4127: $-\rightarrow \mathrm{T}$

Char. 4134: $\mathrm{G} \rightarrow \mathrm{C}$

Char. 4138: $\mathrm{T} \rightarrow \mathrm{A}$

Char. 4187: $\mathrm{G} \rightarrow \mathrm{A}$

Char. 4190: $\mathrm{T} \rightarrow \mathrm{C}$

Char. 4193: $\mathrm{C} \rightarrow \mathrm{T}$

Char. 4219: $-\rightarrow$ C

Char. 4225: $\mathrm{G} \rightarrow-$ 
Char. 4227: $\mathrm{A} \rightarrow \mathrm{C}$

Char. 4234: $-\rightarrow$ C

Char. 4362: $\mathrm{C} \rightarrow \mathrm{A}$

Char. 4380: $\mathrm{G} \rightarrow \mathrm{A}$

Char. 4385: $\mathrm{G} \rightarrow \mathrm{A}$

Char. 4421: $\mathrm{C} \rightarrow \mathrm{A}$

Char. 4432: $\mathrm{T} \rightarrow \mathrm{C}$

Char. 4433: $\mathrm{G} \rightarrow \mathrm{C}$

Char. 4476: $\mathrm{G} \rightarrow \mathrm{A}$

Char. 4541: $\mathrm{C} \rightarrow-$

Char. 4545: $\mathrm{T} \rightarrow-$

Char. 4594: $\mathrm{G} \rightarrow \mathrm{C}$

Char. 4599: $\mathrm{A} \rightarrow \mathrm{G}$

Char. 4624: $\mathrm{G} \rightarrow \mathrm{T}$

Char. 4670: $-\rightarrow$ C

Char. 4744: $\mathrm{C} \rightarrow \mathrm{A}$

Char. 4792: $-\rightarrow$ A

Char. 4805: $\mathrm{C} \rightarrow \mathrm{T}$

Char. 4810: $\mathrm{A} \rightarrow \mathrm{C}$

Char. 4841: $\mathrm{T} \rightarrow \mathrm{C}$

Char. 4849: $\mathrm{G} \rightarrow \mathrm{A}$

Char. 4904: $\mathrm{T} \rightarrow \mathrm{C}$

Char. 4906: $\mathrm{C} \rightarrow \mathrm{A}$

Char. 4919: $\mathrm{T} \rightarrow \mathrm{G}$

Char. 4935: $\mathrm{G} \rightarrow \mathrm{T}$

Char. 4937: $\mathrm{A} \rightarrow \mathrm{G}$

Char. 5103: $\mathrm{T} \rightarrow \mathrm{C}$

Char. 5196: $\mathrm{C} \rightarrow \mathrm{T}$

\section{$18 S$}

Char. 5259: $\mathrm{C} \rightarrow \mathrm{G}$

Char. 5279: $\mathrm{A} \rightarrow \mathrm{T}$

Char. 5337: $-\rightarrow$ A

Char. 5352: $\mathrm{T} \rightarrow \mathrm{C}$

Char. 5398: $\mathrm{G} \rightarrow \mathrm{C}$

Char. 5400: $\mathrm{C} \rightarrow \mathrm{G}$

Char. 5429: $-\rightarrow \mathrm{C}$

Char. 5488: $-\rightarrow$ C

Char. 5506: $-\rightarrow$ A

Char. 5608: - $\rightarrow$ G

Char. 5695: $-\rightarrow$ C

Char. 5731: $\mathrm{C} \rightarrow \mathrm{T}$

Char. 5733: $\mathrm{A} \rightarrow \mathrm{G}$

Char. 6116: $\mathrm{G} \rightarrow \mathrm{A}$

Char. 6138: $\mathrm{T} \rightarrow \mathrm{G}$

Char. 6143: $\mathrm{C} \rightarrow \mathrm{T}$

Char. 6145: $\mathrm{G} \rightarrow \mathrm{A}$

Char. 6169: $\mathrm{C} \rightarrow \mathrm{T}$

Char. 6178: $-\rightarrow \mathrm{T}$

Char. 6183: $-\rightarrow \mathrm{T}$

Char. 6189: $-\rightarrow$ C

Char. 6192: $-\rightarrow \mathrm{T}$

Char. 6215: $-\rightarrow \mathrm{T}$

Char. 6250: $\mathrm{C} \rightarrow \mathrm{G}$

Char. 6265: $\mathrm{T} \rightarrow \mathrm{G}$

Char. 6266: $\mathrm{T} \rightarrow \mathrm{C}$

Char. 6271: $\mathrm{T} \rightarrow \mathrm{A}$

Char. 6280: $\mathrm{C} \rightarrow \mathrm{A}$

Char. 6353: $\mathrm{C} \rightarrow-$

Char. 6377: $\mathrm{A} \rightarrow \mathrm{G}$

Char. 6417: $\mathrm{G} \rightarrow \mathrm{C}$

Char. 6674: $\mathrm{G} \rightarrow \mathrm{C}$

Char. 7050: $\mathrm{C} \rightarrow \mathrm{T}$

Char. 7069: A $\rightarrow-$

Char. 7122: $\mathrm{T} \rightarrow \mathrm{C}$

Char. 7144: $\mathrm{T} \rightarrow \mathrm{C}$

Char. 7226: $\mathrm{C} \rightarrow \mathrm{T}$
Char. 7232: $\mathrm{G} \rightarrow \mathrm{C}$

Char. 7415: $\mathrm{A} \rightarrow \mathrm{G}$

Char. 7601: $\mathrm{G} \rightarrow \mathrm{T}$

Char. 7617: $\mathrm{C} \rightarrow-$

Char. 7642: $-\rightarrow \mathrm{T}$

Char. 7647: $\mathrm{G} \rightarrow \mathrm{A}$

Char. 7655: $\mathrm{C} \rightarrow \mathrm{A}$

Char. 7673: $\mathrm{G} \rightarrow \mathrm{T}$

Char. 7679: $\mathrm{C} \rightarrow \mathrm{G}$

COI

Char. 7826: $\mathrm{C} \rightarrow \mathrm{T}$

Char. 7831: $\mathrm{C} \rightarrow \mathrm{A}$

Char. 7832: $\mathrm{C} \rightarrow \mathrm{A}$

Char. 7833: $\mathrm{A} \rightarrow \mathrm{C}$

Char. 7884: $\mathrm{G} \rightarrow \mathrm{T}$

Char. 7946: $\mathrm{C} \rightarrow \mathrm{T}$

Char. 7966: $\mathrm{T} \rightarrow \mathrm{A}$

Char. 7968: $\mathrm{A} \rightarrow \mathrm{T}$

Char. 8035: $\mathrm{C} \rightarrow \mathrm{T}$

Char. 8052: $-\rightarrow \mathrm{T}$

Char. 8190: $\mathrm{G} \rightarrow \mathrm{A}$

Char. 8267: $\mathrm{T} \rightarrow \mathrm{A}$

Char. 8296: $\mathrm{T} \rightarrow \mathrm{A}$

Char. 8297: $\mathrm{C} \rightarrow \mathrm{G}$

Char. 8302: $\mathrm{A} \rightarrow \mathrm{T}$

Char. 8303: $\mathrm{A} \rightarrow \mathrm{T}$

Char. 8394: $\mathrm{A} \rightarrow \mathrm{T}$

Char. 8460: $\mathrm{G} \rightarrow \mathrm{T}$

Char. 8468: $\mathrm{T} \rightarrow \mathrm{A}$

Char. 8528: $\mathrm{C} \rightarrow \mathrm{T}$

Char. 8550: $\mathrm{C} \rightarrow \mathrm{A}$

Char. 8600: $\mathrm{C} \rightarrow \mathrm{T}$

Char. 8658: $\mathrm{A} \rightarrow \mathrm{T}$

Char. 8667: $\mathrm{C} \rightarrow \mathrm{T}$

Char. 8730: $\mathrm{C} \rightarrow \mathrm{A}$

Char. 8734: $\mathrm{C} \rightarrow \mathrm{T}$

Char. 8749: $-\rightarrow$ A

Char. 8755: $\mathrm{T} \rightarrow \mathrm{A}$

Char. 8756: $\mathrm{C} \rightarrow \mathrm{A}$

Char. 8775: $\mathrm{C} \rightarrow \mathrm{A}$

Char. 8789: $\mathrm{C} \rightarrow$ AT

Char. 8790: $\mathrm{C} \rightarrow \mathrm{A}$

Char. 8850: $\mathrm{C} \rightarrow \mathrm{T}$

Char. 8908: $-\rightarrow \mathrm{T}$

$12 S$

Char. 8997: $\mathrm{A} \rightarrow \mathrm{T}$

Char. 9096: $\mathrm{C} \rightarrow \mathrm{T}$

Char. 9261: $\mathrm{T} \rightarrow \mathrm{A}$

Char. 9264: $\mathrm{T} \rightarrow \mathrm{A}$

Char. 9300: $\mathrm{A} \rightarrow \mathrm{G}$

Char. 9500: $-\rightarrow$ A

Char. 9505: $\mathrm{A} \rightarrow \mathrm{T}$

Char. 9539: $\mathrm{G} \rightarrow \mathrm{A}$

$16 S$

Char. 9605: $\mathrm{A} \rightarrow \mathrm{G}$

Char. 9653: $-\rightarrow$ T

Char. 9774: $\mathrm{T} \rightarrow \mathrm{C}$

Char. 9788: $\mathrm{A} \rightarrow \mathrm{T}$

Char. 9909: $\mathrm{T} \rightarrow \mathrm{C}$

Char. 9926: $\mathrm{T} \rightarrow-$

Char. 10000: $\mathrm{T} \rightarrow-$

Char. 10005: $\mathrm{A} \rightarrow$

Char. 10137: $\mathrm{A} \rightarrow \mathrm{T}$ 
Char. 10148: $\mathrm{A} \rightarrow \mathrm{T}$ Char. 10398: $\mathrm{T} \rightarrow \mathrm{A}$ Char. 10436: $\mathrm{G} \rightarrow \mathrm{A}$ Char. 10439: $\mathrm{A} \rightarrow \mathrm{T}$ Char. 10444: $\mathrm{A} \rightarrow \mathrm{T}$

\section{H3}

Char. 10635: $\mathrm{G} \rightarrow \mathrm{C}$ Char. 10739: $\mathrm{G} \rightarrow \mathrm{A}$ Char. 10765: G $\rightarrow$ A Char. 10825: $\mathrm{G} \rightarrow \mathrm{A}$

\section{Pycnogonidae}

$18 S$

Char. 7362: $\mathrm{G} \rightarrow \mathrm{T}$

COI

Char. 7647: $\mathrm{A} \rightarrow \mathrm{G}$

H3

Char. 10656: $\mathrm{G} \rightarrow \mathrm{A}$ Char. 10712: $\mathrm{C} \rightarrow \mathrm{T}$ Char. 10714: $\mathrm{T} \rightarrow \mathrm{G}$ Char. 10739: $\mathrm{A} \rightarrow \mathrm{G}$ Char. 10744: $\mathrm{T} \rightarrow \mathrm{G}$ Char. 10778: $\mathrm{C} \rightarrow \mathrm{A}$ Char. 10782: $-\rightarrow \mathrm{T}$ Char. 10786: $\mathrm{G} \rightarrow-$ Char. 10789: A $\rightarrow$ C Char. 10791: $\mathrm{A} \rightarrow \mathrm{T}$ Char. 10818: $\mathrm{T} \rightarrow \mathrm{C}$ Char. 10825: $\mathrm{A} \rightarrow \mathrm{G}$ Char. 10835: $\mathrm{C} \rightarrow \mathrm{T}$

Nymphonidae (exc. N. floridanum)

\section{$28 S$}

Char. 190: $\mathrm{C} \rightarrow \mathrm{T}$

Char. 255: $\mathrm{T} \rightarrow \mathrm{G}$

Char. 910: $\mathrm{C} \rightarrow \mathrm{T}$

Char. 944: $\mathrm{T} \rightarrow \mathrm{C}$

Char. 946: $\mathrm{C} \rightarrow \mathrm{T}$

Char. 1094: $\mathrm{C} \rightarrow \mathrm{T}$

Char. 1151: $\mathrm{C} \rightarrow \mathrm{T}$

Char. 1153: $\mathrm{A} \rightarrow \mathrm{T}$

Char. 1162: $\mathrm{A} \rightarrow \mathrm{T}$

Char. 1170: $\mathrm{C} \rightarrow \mathrm{T}$

Char. 1207: $\mathrm{T} \rightarrow-$

Char. 1220: $\mathrm{T} \rightarrow \mathrm{C}$

Char. 1226: $\mathrm{T} \rightarrow \mathrm{C}$

Char. 1231: $\mathrm{C} \rightarrow \mathrm{G}$

Char. 1247: $-\rightarrow \mathrm{T}$

Char. 1348: $\mathrm{G} \rightarrow \mathrm{A}$

Char. 1370: $\mathrm{C} \rightarrow \mathrm{T}$

Char. 1395: $\mathrm{T} \rightarrow \mathrm{C}$

Char. 1431: $\mathrm{G} \rightarrow \mathrm{A}$

Char. 1538: $\mathrm{T} \rightarrow \mathrm{A}$

Char. 1554: $\mathrm{T} \rightarrow \mathrm{A}$

Char. 1639: $\mathrm{T} \rightarrow-$

Char. 1666: $\mathrm{C} \rightarrow \mathrm{T}$

Char. 1676: $-\rightarrow$ C

Char. 1679: $-\rightarrow$ G

Char. 1821: $\mathrm{C} \rightarrow \mathrm{G}$
Char. 1831: $\mathrm{T} \rightarrow \mathrm{A}$

Char. 1846: $\mathrm{G} \rightarrow \mathrm{T}$

Char. 2135: $\mathrm{G} \rightarrow \mathrm{T}$

Char. 2285: $-\rightarrow$ A

Char. 2288: $\mathrm{G} \rightarrow \mathrm{A}$

Char. 2342: $-\rightarrow \mathrm{T}$

Char. 3253: $\mathrm{G} \rightarrow \mathrm{T}$

Char. 3307: $\mathrm{G} \rightarrow-$

Char. 3363: $\mathrm{C} \rightarrow \mathrm{G}$

Char. 3417: $\mathrm{A} \rightarrow \mathrm{T}$

Char. 3770: $\mathrm{G} \rightarrow-$

Char. 3858: $\mathrm{A} \rightarrow-$

Char. 4773: $\mathrm{G} \rightarrow \mathrm{T}$

$18 S$

Char. 5539: $\mathrm{A} \rightarrow \mathrm{G}$

\section{COI}

Char. 7877: $\mathrm{A} \rightarrow \mathrm{T}$ Char. 7954: $\mathrm{T} \rightarrow \mathrm{C}$ Char. 8049: $\mathrm{A} \rightarrow \mathrm{T}$ Char. 8186: $\mathrm{A} \rightarrow \mathrm{T}$ Char. 8198: $\mathrm{A} \rightarrow \mathrm{T}$ Char. 8256: $\mathrm{A} \rightarrow \mathrm{T}$ Char. 8283: $\mathrm{A} \rightarrow \mathrm{T}$

$12 S$

Char. 8953: $\mathrm{T} \rightarrow \mathrm{A}$ Char. 9091: $\mathrm{T} \rightarrow \mathrm{C}$ Char. 9116: $-\rightarrow$ A Char. 9117: - $\rightarrow$ A Char. 9133: $\mathrm{A} \rightarrow \mathrm{G}$ Char. 9153: $\mathrm{T} \rightarrow \mathrm{A}$ Char. 9258: $\mathrm{T} \rightarrow \mathrm{A}$ Char. 9290: $\mathrm{A} \rightarrow-$ Char. 9361: $-\rightarrow$ C Char. 9434: $\mathrm{T} \rightarrow \mathrm{A}$ Char. 9436: $\mathrm{T} \rightarrow \mathrm{A}$ Char. 9525: $\mathrm{A} \rightarrow-$

$16 S$

Char. 9657: $\mathrm{A} \rightarrow \mathrm{T}$ Char. 9696: $\mathrm{T} \rightarrow \mathrm{G}$ Char. 9710: $\mathrm{A} \rightarrow \mathrm{C}$ Char. 9778: $\mathrm{A} \rightarrow \mathrm{T}$ Char. 9787: $\mathrm{T} \rightarrow \mathrm{A}$ Char. 9984: $\mathrm{T} \rightarrow \mathrm{A}$ Char. 10121: $-\rightarrow \mathrm{C}$ Char. 10170: $\mathrm{T} \rightarrow \mathrm{A}$ Char. 10219: $-\rightarrow$ A Char. 10250: $\mathrm{T} \rightarrow-$ Char. 10444: $\mathrm{T} \rightarrow \mathrm{A}$ Char. 10452: $\mathrm{T} \rightarrow \mathrm{C}$

H3

Char. 10675: $\mathrm{T} \rightarrow \mathrm{C}$ Char. 10711: $\mathrm{G} \rightarrow \mathrm{A}$ Char. 10818: $\mathrm{T} \rightarrow \mathrm{C}$

\section{Austrodecidae}

$28 S$

Char. 115: $\mathrm{A} \rightarrow \mathrm{T}$

Char. 173: $\mathrm{C} \rightarrow \mathrm{T}$ 
Char. 199: AGT $\rightarrow$ C

Char. 230: $\mathrm{A} \rightarrow \mathrm{G}$

Char. 232: $\mathrm{G} \rightarrow \mathrm{A}$

Char. 254: $\mathrm{T} \rightarrow \mathrm{C}$

Char. 259: $\mathrm{C} \rightarrow \mathrm{T}$

Char. 260: $\mathrm{G} \rightarrow \mathrm{C}$

Char. 335: $\mathrm{T} \rightarrow-$

Char. 339: $-\rightarrow \mathrm{T}$

Char. 367: $\mathrm{T} \rightarrow \mathrm{C}$

Char. 374: $\mathrm{G} \rightarrow \mathrm{C}$

Char. 402: $\mathrm{G} \rightarrow \mathrm{A}$

Char. 416: $\mathrm{T} \rightarrow \mathrm{C}$

Char. 550: $\mathrm{G} \rightarrow \mathrm{T}$

Char. 561: $\mathrm{G} \rightarrow \mathrm{C}$

Char. 577: $-\rightarrow$ A

Char. 582: $\mathrm{T} \rightarrow \mathrm{C}$

Char. 611: $\mathrm{A} \rightarrow \mathrm{G}$

Char. 613: $\mathrm{C} \rightarrow \mathrm{T}$

Char. 633: $-\rightarrow \mathrm{C}$

Char. 638: $\mathrm{T} \rightarrow \mathrm{G}$

Char. 660: $\mathrm{G} \rightarrow \mathrm{T}$

Char. 694: $\mathrm{G} \rightarrow \mathrm{T}$

Char. 700: $-\rightarrow \mathrm{G}$

Char. 806: $\mathrm{C} \rightarrow-$

Char. 826: $\mathrm{C} \rightarrow \mathrm{T}$

Char. 832: $\mathrm{G} \rightarrow \mathrm{C}$

Char. 874: $\mathrm{C} \rightarrow-$

Char. 899: - $\rightarrow$ C

Char. 910: $\mathrm{G} \rightarrow \mathrm{A}$

Char. 911: $\mathrm{G} \rightarrow \mathrm{A}$

Char. 974: $\mathrm{C} \rightarrow-$

Char. 1017: $\mathrm{G} \rightarrow \mathrm{A}$

Char. 1019: $\mathrm{T} \rightarrow \mathrm{C}$

Char. 1128: $-\rightarrow \mathrm{G}$

Char. 1133: $-\rightarrow$ A

Char. 1134: $-\rightarrow$ C

Char. 1135: $-\rightarrow \mathrm{G}$

Char. 1184: $\mathrm{G} \rightarrow-$

Char. 1186: $\mathrm{C} \rightarrow-$

Char. 1207: $\mathrm{T} \rightarrow-$

Char. 1226: $\mathrm{T} \rightarrow-$

Char. 1283: - $\rightarrow$ A

Char. 1284: $-\rightarrow$ A

Char. 1301: $\mathrm{C} \rightarrow \mathrm{T}$

Char. 1349: $-\rightarrow \mathrm{T}$

Char. 1359: $\mathrm{C} \rightarrow \mathrm{A}$

Char. 1365: $\mathrm{T} \rightarrow \mathrm{C}$

Char. 1370: $\mathrm{T} \rightarrow \mathrm{G}$

Char. 1423: $\mathrm{A} \rightarrow \mathrm{T}$

Char. 1452: $\mathrm{C} \rightarrow \mathrm{T}$

Char. 1457: $\mathrm{T} \rightarrow-$

Char. 1572: $\mathrm{C} \rightarrow \mathrm{T}$

Char. 1602: $\mathrm{C} \rightarrow \mathrm{G}$

Char. 1620: $\mathrm{C} \rightarrow \mathrm{G}$

Char. 1655: $\mathrm{C} \rightarrow \mathrm{T}$

Char. 1668: $\mathrm{C} \rightarrow \mathrm{T}$

Char. 1674: A $\rightarrow$ C

Char. 1709: $-\rightarrow$ T

Char. 1730: $-\rightarrow$ A

Char. 1731: $\mathrm{T} \rightarrow \mathrm{A}$

Char. 1736: $-\rightarrow$ A

Char. 1763: $\mathrm{A} \rightarrow \mathrm{T}$

Char. 1791: $-\rightarrow \mathrm{G}$

Char. 1796: $-\rightarrow \mathrm{T}$

Char. 1813: $-\rightarrow \mathrm{C}$

Char. 1831: $\mathrm{T} \rightarrow \mathrm{G}$

Char. 1841: $-\rightarrow \mathrm{C}$
Char. 1900: $-\rightarrow$ A

Char. 1901: $\mathrm{G} \rightarrow \mathrm{A}$

Char. 1970: $\mathrm{G} \rightarrow \mathrm{T}$

Char. 2020: $-\rightarrow$ T

Char. 2027: $\mathrm{G} \rightarrow \mathrm{A}$

Char. 2038: $\mathrm{C} \rightarrow \mathrm{A}$

Char. 2048: $\mathrm{C} \rightarrow \mathrm{G}$

Char. 2195: $-\rightarrow$ A

Char. 2224: $\mathrm{C} \rightarrow \mathrm{T}$

Char. 2350: $\mathrm{G} \rightarrow \mathrm{T}$

Char. 2407: $-\rightarrow$ T

Char. 2410: $-\rightarrow$ G

Char. 2413: $\mathrm{A} \rightarrow \mathrm{T}$

Char. 2421: $\mathrm{C} \rightarrow \mathrm{T}$

Char. 2427: $\mathrm{A} \rightarrow \mathrm{T}$

Char. 2430: $\mathrm{C} \rightarrow \mathrm{T}$

Char. 2457: $\mathrm{T} \rightarrow \mathrm{C}$

Char. 2705: A $\rightarrow-$

Char. 2707: $\mathrm{G} \rightarrow \mathrm{T}$

Char. 2708: $\mathrm{A} \rightarrow \mathrm{T}$

Char. 2711: A $\rightarrow-$

Char. 2712: $\mathrm{A} \rightarrow \mathrm{T}$

Char. 2840: $\mathrm{C} \rightarrow \mathrm{T}$

Char. 2866: $-\rightarrow \mathrm{T}$

Char. 2867: $\mathrm{C} \rightarrow \mathrm{T}$

Char. 3056: $\mathrm{C} \rightarrow \mathrm{T}$

Char. 3061: $\mathrm{T} \rightarrow \mathrm{G}$

Char. 3062: $\mathrm{G} \rightarrow \mathrm{A}$

Char. 3232: $\mathrm{A} \rightarrow \mathrm{C}$

Char. 3244: $\mathrm{C} \rightarrow \mathrm{T}$

Char. 3307: $\mathrm{G} \rightarrow-$

Char. 3363: C $\rightarrow$ A

Char. 3369: $\mathrm{G} \rightarrow \mathrm{C}$

Char. 3399: $\mathrm{G} \rightarrow \mathrm{T}$

Char. 3406: $\mathrm{A} \rightarrow \mathrm{C}$

Char. 3417: $\mathrm{G} \rightarrow \mathrm{T}$

Char. 3709: $-\rightarrow \mathrm{T}$

Char. 3723: $\mathrm{G} \rightarrow \mathrm{A}$

Char. 3755: $\mathrm{T} \rightarrow \mathrm{A}$

Char. 3800: $\mathrm{C} \rightarrow \mathrm{G}$

Char. 3840: $\mathrm{T} \rightarrow \mathrm{A}$

Char. 3966: - $\rightarrow$ A

Char. 3981: $-\rightarrow \mathrm{T}$

Char. 3993: $\mathrm{T} \rightarrow \mathrm{A}$

Char. 3997: $\mathrm{T} \rightarrow \mathrm{A}$

Char. 4227: $\mathrm{C} \rightarrow \mathrm{G}$

$18 S$

Char. 4249: $\mathrm{G} \rightarrow \mathrm{A}$

Char. 5284: $\mathrm{A} \rightarrow \mathrm{C}$

Char. 5332: $\mathrm{T} \rightarrow \mathrm{C}$

Char. 5355: $\mathrm{T} \rightarrow \mathrm{G}$

Char. 5398: $\mathrm{C} \rightarrow \mathrm{A}$

Char. 5402: $\mathrm{A} \rightarrow \mathrm{T}$

Char. 5416: $\mathrm{C} \rightarrow \mathrm{G}$

Char. 5512: $\mathrm{C} \rightarrow \mathrm{A}$

Char. 5570: $\mathrm{T}-\rightarrow \mathrm{A}$

Char. 5580: $-\rightarrow \mathrm{T}$

Char. 5641: $\mathrm{T} \rightarrow \mathrm{C}$

Char. 5701: $\mathrm{C} \rightarrow \mathrm{A}$

Char. 5729: $\mathrm{G} \rightarrow \mathrm{A}$

Char. 5856: $\mathrm{A} \rightarrow \mathrm{T}$

Char. 6098: $\mathrm{T} \rightarrow \mathrm{C}$

Char. 6099: $\mathrm{C} \rightarrow \mathrm{T}$

Char. 6125: $\mathrm{C} \rightarrow \mathrm{T}$

Char. 6154: $\mathrm{A} \rightarrow \mathrm{G}$

Char. 6189: $\mathrm{C} \rightarrow \mathrm{A}$ 
Char. 6240: $\mathrm{G} \rightarrow \mathrm{A}$

Char. 6314: $A \rightarrow$ G

Char. 6439: $\mathrm{G} \rightarrow \mathrm{A}$

Char. 6610: $\mathrm{C} \rightarrow \mathrm{G}$

Char. 6629: $\mathrm{A} \rightarrow \mathrm{T}$

Char. 6708: $\mathrm{A} \rightarrow \mathrm{G}$

Char. 6713: $A \rightarrow G$

$16 S$

Char. 9599: $\mathrm{A} \rightarrow \mathrm{T}$

Char. 9603: $A \rightarrow G$

Char. 9608: $\mathrm{G} \rightarrow \mathrm{T}$

Char. 9741: $\mathrm{T} \rightarrow \mathrm{G}$

Char. 9754: $A \rightarrow G$

Char. 9757: $A \rightarrow G$

Char. 9759: $\mathrm{T} \rightarrow-$

Char. 9821: $\mathrm{T} \rightarrow \mathrm{A}$

Char. 9870: $\mathrm{A} \rightarrow \mathrm{T}$

Char. 9959: $\mathrm{T} \rightarrow \mathrm{G}$

Char. 9970: $\mathrm{T} \rightarrow-$

Char. 10014: $\mathrm{T} \rightarrow-$

Char. 10017: $\mathrm{T} \rightarrow \mathrm{G}$

Char. 10142: $\mathrm{A} \rightarrow \mathrm{T}$

Char. 10170: $\mathrm{T} \rightarrow \mathrm{A}$

Char. 10198: A $\rightarrow$ -

Char. 10228: $-\rightarrow \mathrm{G}$

Char. 10369: $\mathrm{T} \rightarrow \mathrm{C}$

Char. 10393: A $\rightarrow$ G

Char. 10449: $\mathrm{C} \rightarrow \mathrm{G}$

Char. 10499: $\mathrm{T} \rightarrow-$

Char. 10507: $\mathrm{A} \rightarrow \mathrm{T}$

Char. 10513: $-\rightarrow \mathrm{G}$

H3

Char. 10564: $\mathrm{A} \rightarrow \mathrm{T}$

Char. 10648: C $\rightarrow$ A

Char. 10650: $\mathrm{T} \rightarrow \mathrm{A}$

Char. 10724: $\mathrm{A} \rightarrow \mathrm{G}$

Char. 10747: $\mathrm{G} \rightarrow \mathrm{C}$

Char. 10759: $\mathrm{C} \rightarrow \mathrm{T}$

Austrodecidae + Colossendeidae + (P. femoratum + Pycnogonidae)

28S

Char. 349: $\mathrm{G} \rightarrow \mathrm{C}$

Char. 450: $\mathrm{T} \rightarrow \mathrm{C}$

Char. 696: $\mathrm{G} \rightarrow \mathrm{CT}$

Char. 747: $\rightarrow$ A

Char. 796: $-\rightarrow \mathrm{G}$

Char. 797: $-\rightarrow \mathrm{G}$

Char. 855: $\mathrm{G} \rightarrow \mathrm{T}$

Char. 973: $\mathrm{C} \rightarrow \mathrm{A}$

Char. 1210: $\mathrm{C} \rightarrow-$

Char. 1235: $\mathrm{G} \rightarrow \mathrm{C}$

Char. 1241: $\mathrm{C} \rightarrow \mathrm{T}$

Char. 1309: $\mathrm{C} \rightarrow \mathrm{G}$

Char. 1486: $\mathrm{G} \rightarrow-$

Char. 1504: $\mathrm{G} \rightarrow-$

Char. 1512: $\mathrm{G} \rightarrow-$

Char. 1556: $\mathrm{C} \rightarrow-$

Char. 1557: $\mathrm{G} \rightarrow \mathrm{T}$

Char. 1650: $\mathrm{T} \rightarrow \mathrm{C}$

Char. 1663: $-\rightarrow \mathrm{T}$

Char. 1728: $-\rightarrow$ C
Char. 1757: $\mathrm{G} \rightarrow-$

Char. 1809: $-\rightarrow \mathrm{C}$

Char. 1839: $\mathrm{T} \rightarrow \mathrm{G}$

Char. 1922: $\mathrm{T} \rightarrow \mathrm{C}$

Char. 2002: $\mathrm{C} \rightarrow \mathrm{T}$

Char. 2005: $\mathrm{T} \rightarrow \mathrm{A}$

Char. 2205: $\mathrm{C} \rightarrow \mathrm{T}$

Char. 2216: $\mathrm{G} \rightarrow-$

Char. 2296: $\mathrm{C} \rightarrow \mathrm{T}$

Char. 2333: $-\rightarrow \mathrm{T}$

Char. 3217: $\mathrm{A} \rightarrow \mathrm{G}$

Char. 3264: - $\rightarrow$ A

Char. 3364: $-\rightarrow \mathrm{T}$

Char. 3660: $\mathrm{G} \rightarrow \mathrm{T}$

Char. 3790: $\mathrm{A} \rightarrow \mathrm{G}$

Char. 4760: $-\rightarrow$ C

Char. 4776: $\mathrm{G} \rightarrow \mathrm{C}$

Char. 5225: $\mathrm{G} \rightarrow \mathrm{A}$

$18 S$

Char. 7068: $\mathrm{C} \rightarrow-$

Char. 7097: $\mathrm{A} \rightarrow \mathrm{C}$

Char. 7634: $\mathrm{G} \rightarrow-$

Char. 7771: $\mathrm{A} \rightarrow \mathrm{G}$

Char. 7797: $\mathrm{G} \rightarrow \mathrm{T}$

Char. 7800: $\mathrm{T} \rightarrow \mathrm{A}$

Char. 8177: $\mathrm{A} \rightarrow \mathrm{T}$

Char. 8314: $\mathrm{A} \rightarrow \mathrm{G}$

Char. 8765: $\mathrm{C} \rightarrow \mathrm{A}$

Char. 8780: $\mathrm{T} \rightarrow \mathrm{C}$

$12 S$

Char. 9104: $\mathrm{C} \rightarrow \mathrm{T}$

Char. 9108: $\mathrm{T} \rightarrow-$

Char. 9142: $\mathrm{T} \rightarrow \mathrm{A}$

Char. 9156: $\mathrm{A} \rightarrow \mathrm{T}$

Char. 9158: - $\rightarrow$ A

Char. 9271: $\mathrm{G} \rightarrow \mathrm{A}$

Char. 9330: $\mathrm{A} \rightarrow \mathrm{T}$

Char. 9342: $\mathrm{A} \rightarrow \mathrm{T}$

Char. 9476: $\mathrm{T} \rightarrow \mathrm{A}$

Char. 9509: $\mathrm{A} \rightarrow \mathrm{T}$

$16 S$

Char. 9624: $-\rightarrow$ A

Char. 9683: $\mathrm{A} \rightarrow \mathrm{T}$

Char. 9769: $\mathrm{C} \rightarrow \mathrm{T}$

Char. 9787: $\mathrm{T} \rightarrow \mathrm{A}$

Char. 9811: $\mathrm{T} \rightarrow \mathrm{A}$

Char. 9885: $\mathrm{A} \rightarrow \mathrm{T}$

Char. 10158: $\mathrm{T} \rightarrow-$

Char. 10220: $-\rightarrow$ G

Char. 10305: $-\rightarrow \mathrm{T}$

Char. 10482: $\mathrm{A} \rightarrow \mathrm{T}$

Char. 10487: $\mathrm{A} \rightarrow \mathrm{T}$

H3

Char. 10849: $\mathrm{G} \rightarrow \mathrm{C}$

Char. 10862: $\mathrm{T} \rightarrow \mathrm{C}$

Phoxichilidiidae (Inc. Endeis, exc. P. femoratum)

$28 S$

Char. 165: $\mathrm{C} \rightarrow \mathrm{T}$

Char. 648: $\mathrm{A} \rightarrow \mathrm{T}$ 
Char. 686: $\mathrm{T} \rightarrow \mathrm{A}$ Char. 823: $\mathrm{C} \rightarrow \mathrm{T}$

Char. 880: $\rightarrow$ C

Char. 1094: $\mathrm{C} \rightarrow \mathrm{A}$

Char. 1122: $\mathrm{T} \rightarrow \mathrm{C}$

Char. 1164: $\mathrm{T} \rightarrow \mathrm{G}$

Char. 1248: $-\rightarrow \mathrm{T}$

Char. 1263: $\mathrm{T} \rightarrow \mathrm{G}$

Char. 1303: - $\rightarrow$ G

Char. 1350: $-\rightarrow$ C

Char. 1355: $-\rightarrow$ A

Char. 1512: $\mathrm{G} \rightarrow-$

Char. 1523: $\mathrm{C} \rightarrow \mathrm{T}$

Char. 1524: $\mathrm{C} \rightarrow \mathrm{G}$

Char. 1615: $\mathrm{T} \rightarrow \mathrm{G}$

Char. 1810: $\mathrm{C} \rightarrow-$

Char. 1891: $-\rightarrow \mathrm{T}$

Char. 1938: $\mathrm{T} \rightarrow-$

Char. 1960: $\mathrm{C} \rightarrow \mathrm{G}$

Char. 1970: $\mathrm{G} \rightarrow \mathrm{C}$

Char. 1982: $\mathrm{T} \rightarrow \mathrm{G}$

Char. 2414: $-\rightarrow \mathrm{T}$

Char. 2418: $\mathrm{T} \rightarrow \mathrm{G}$

Char. 3240: $-\rightarrow \mathrm{T}$

Char. 3307: $\mathrm{C} \rightarrow \mathrm{T}$

Char. 3346: $\mathrm{C} \rightarrow \mathrm{G}$

Char. 3363: $\mathrm{C} \rightarrow \mathrm{A}$

Char. 3422: $\mathrm{C} \rightarrow \mathrm{T}$

Char. 3475: $\mathrm{C} \rightarrow \mathrm{T}$

Char. 3493: $\mathrm{C} \rightarrow \mathrm{T}$

Char. 3708: $\mathrm{A} \rightarrow \mathrm{C}$

Char. 3800: $\mathrm{G} \rightarrow-$

Char. 4689: $-\rightarrow \mathrm{G}$

Char. 4699: $-\rightarrow \mathrm{C}$

Char. 4766: $-\rightarrow \mathrm{G}$

Char. 5243: - $\rightarrow$ G

Char. 5247: A $\rightarrow$ C

$18 S$

Char. 5441: $\mathrm{C} \rightarrow \mathrm{T}$

Char. 6203: $\mathrm{A} \rightarrow \mathrm{C}$

Char. 6208: $\mathrm{A} \rightarrow \mathrm{T}$

\section{COI}

Char. 7829: $\mathrm{G} \rightarrow \mathrm{A}$

Char. 8198: $\mathrm{A} \rightarrow \mathrm{T}$

Char. 8275: $\mathrm{C} \rightarrow \mathrm{A}$

Char. 8528: $\mathrm{T} \rightarrow \mathrm{A}$

\section{$12 S$}

Char. 8937: $\mathrm{A} \rightarrow \mathrm{G}$

Char. 8962: $\mathrm{T} \rightarrow \mathrm{A}$

Char. 8977: $\mathrm{T} \rightarrow \mathrm{A}$

Char. 8992: $\mathrm{T} \rightarrow \mathrm{A}$

Char. 9104: $\mathrm{C} \rightarrow \mathrm{T}$

Char. 9295: $\mathrm{T} \rightarrow \mathrm{A}$

Char. 9312: $\mathrm{A} \rightarrow \mathrm{T}$

Char. 9314: $\mathrm{A} \rightarrow \mathrm{T}$

Char. 9362: A $\rightarrow-$

Char. 9364: A $\rightarrow-$

Char. 9500: $\mathrm{A} \rightarrow \mathrm{T}$

Char. 9542: $\mathrm{T} \rightarrow-$

\section{$16 S$}

Char. 9599: $\mathrm{A} \rightarrow \mathrm{T}$

Char. 9683: $\mathrm{A} \rightarrow \mathrm{T}$
Char. 9741: $\mathrm{T} \rightarrow \mathrm{A}$

Char. 9759: $\mathrm{T} \rightarrow \mathrm{G}$

Char. 9796: $\mathrm{A} \rightarrow \mathrm{T}$

Char. 9823: $\mathrm{A} \rightarrow \mathrm{T}$

Char. 9935: $\mathrm{A} \rightarrow \mathrm{T}$

Char. 10046: A $\rightarrow-$

Char. 10061: $\mathrm{T} \rightarrow-$

Char. 10127: $-\rightarrow \mathrm{T}$

Char. 10128: $\mathrm{A} \rightarrow \mathrm{T}$

Char. 10325: $\mathrm{T} \rightarrow-$

Char. 10333: $\mathrm{G} \rightarrow \mathrm{T}$

Char. 10470: $\mathrm{T} \rightarrow \mathrm{A}$

Char. 10490: $\mathrm{A} \rightarrow \mathrm{T}$

H3

Char. 10871: $\mathrm{C} \rightarrow \mathrm{T}$

\section{Colossendeidae}

\section{$28 S$}

Char. 180: $\mathrm{C} \rightarrow \mathrm{T}$

Char. 206: C $\rightarrow$ A

Char. 253: $-\rightarrow \mathrm{T}$

Char. 403: $\mathrm{G} \rightarrow \mathrm{A}$

Char. 545: $\mathrm{C} \rightarrow \mathrm{T}$

Char. 598: A $\rightarrow$ G

Char. 864: $-\rightarrow \mathrm{C}$

Char. 868: $\mathrm{G} \rightarrow \mathrm{A}$

Char. 873: $-\rightarrow \mathrm{T}$

Char. 886: $\mathrm{G} \rightarrow \mathrm{A}$

Char. 1164: $\mathrm{C} \rightarrow \mathrm{G}$

Char. 1165: $\mathrm{G} \rightarrow \mathrm{C}$

Char. 1231: $\mathrm{C} \rightarrow \mathrm{G}$

Char. 1296: $\mathrm{T} \rightarrow \mathrm{C}$

Char. 1310: $-\rightarrow \mathrm{T}$

Char. 1352: $\mathrm{C} \rightarrow \mathrm{T}$

Char. 1431: $\mathrm{AC} \rightarrow \mathrm{T}$

Char. 1513: $\mathrm{C} \rightarrow \mathrm{T}$

Char. 1516: $\mathrm{G} \rightarrow \mathrm{T}$

Char. 1544: $\mathrm{T} \rightarrow \mathrm{G}$

Char. 1590: $\mathrm{C} \rightarrow-$

Char. 1601: G $\rightarrow$ A

Char. 1603: $\mathrm{G} \rightarrow-$

Char. 1644: $\mathrm{C} \rightarrow-$

Char. 1691: $-\rightarrow$ C

Char. 1695: $\mathrm{G} \rightarrow \mathrm{C}$

Char. 1714: $\mathrm{C} \rightarrow-$

Char. 1725: $\mathrm{T} \rightarrow-$

Char. 1753: $-\rightarrow$ A

Char. 1765: $\mathrm{C} \rightarrow \mathrm{G}$

Char. 1781: $\mathrm{G} \rightarrow \mathrm{A}$

Char. 1785: $\mathrm{T} \rightarrow \mathrm{C}$

Char. 1787: $\mathrm{T} \rightarrow \mathrm{G}$

Char. 1814: $\mathrm{C} \rightarrow \mathrm{A}$

Char. 1914: $\mathrm{G} \rightarrow-$

Char. 1930: $\mathrm{C} \rightarrow \mathrm{G}$

Char. 1966: $\mathrm{G} \rightarrow \mathrm{C}$

Char. 2040: $\mathrm{G} \rightarrow \mathrm{A}$

Char. 2288: $\mathrm{G} \rightarrow \mathrm{A}$

Char. 2331: $\mathrm{A} \rightarrow \mathrm{C}$

Char. 2368: $\mathrm{C} \rightarrow-$

Char. 2469: $\mathrm{C} \rightarrow \mathrm{T}$

Char. 2647: $\mathrm{C} \rightarrow \mathrm{T}$

Char. 2708: $\mathrm{A} \rightarrow \mathrm{G}$

Char. 2902: $\mathrm{T} \rightarrow \mathrm{C}$

Char. 3216: $-\rightarrow$ A 
Char. 3221: $-\rightarrow$ A Char. 3417: $\mathrm{G} \rightarrow \mathrm{C}$ Char. 3444: $\mathrm{G} \rightarrow \mathrm{A}$ Char. 3493: $\mathrm{T} \rightarrow \mathrm{C}$ Char. 3548: $\mathrm{C} \rightarrow \mathrm{T}$ Char. 3750: $\mathrm{C} \rightarrow \mathrm{G}$ Char. 3826: $\mathrm{G} \rightarrow \mathrm{T}$ Char. 4199: $\mathrm{G} \rightarrow \mathrm{T}$ Char. 4466: $\mathrm{G} \rightarrow \mathrm{A}$ Char. 4504: $\mathrm{T} \rightarrow-$ Char. 4623: $\mathrm{A} \rightarrow \mathrm{G}$ Char. 4706: $\mathrm{C} \rightarrow \mathrm{G}$ Char. 5232: $\mathrm{A} \rightarrow \mathrm{G}$

Char. 5235: $\mathrm{G} \rightarrow-$

$18 S$

Char. 5554: $-\rightarrow \mathrm{G}$ Char. 5666: $\mathrm{G} \rightarrow \mathrm{T}$ Char. 5940: $\mathrm{T} \rightarrow \mathrm{A}$ Char. 6210: $-\rightarrow$ A Char. 6212: $-\rightarrow$ C Char. 6213: $-\rightarrow$ C Char. 7081: $-\rightarrow$ C Char. 7639: $\mathrm{T} \rightarrow \mathrm{C}$ Char. 7640: $\mathrm{C} \rightarrow \mathrm{T}$

\section{$12 S$}

Char. 8903: $\mathrm{A} \rightarrow \mathrm{T}$ Char. 8913: $\mathrm{T} \rightarrow \mathrm{A}$ Char. 8922: $\mathrm{T} \rightarrow \mathrm{A}$ Char. 8960: $\mathrm{T} \rightarrow \mathrm{A}$ Char. 8962: $\mathrm{T} \rightarrow \mathrm{A}$ Char. 9076: $\mathrm{T} \rightarrow \mathrm{A}$ Char. 9129: - $\rightarrow$ A Char. 9429: $\mathrm{A} \rightarrow \mathrm{T}$ Char. 9433: $-\rightarrow$ A Char. 9442: $\mathrm{T} \rightarrow \mathrm{A}$ Char. 9470: $-\rightarrow$ T Char. 9514: $\mathrm{T} \rightarrow-$ Char. 9537: $-\rightarrow$ A

$16 S$

Char. 9659: $\mathrm{T} \rightarrow \mathrm{A}$ Char. 9717: $\mathrm{C} \rightarrow \mathrm{T}$ Char. 9767: $\mathrm{G} \rightarrow \mathrm{T}$ Char. 9769: $\mathrm{T} \rightarrow \mathrm{A}$ Char. 9774: $\mathrm{C} \rightarrow \mathrm{T}$ Char. 9777: $\mathrm{T} \rightarrow \mathrm{A}$ Char. 9805: $\mathrm{G} \rightarrow \mathrm{A}$ Char. 9808: $\mathrm{T} \rightarrow \mathrm{A}$ Char. 9906: $\mathrm{T} \rightarrow \mathrm{C}$ Char. 9928: $-\rightarrow \mathrm{T}$ Char. 9942: $-\rightarrow$ A Char. 10004: $\mathrm{T} \rightarrow-$ Char. 10037: $-\rightarrow \mathrm{T}$ Char. 10249: $\mathrm{A} \rightarrow \mathrm{T}$ Char. 10275: $\mathrm{G} \rightarrow-$ Char. 10325: $\mathrm{T} \rightarrow \mathrm{A}$ Char. 10333: $\mathrm{G} \rightarrow-$ Char. 10350: $\mathrm{A} \rightarrow \mathrm{G}$ Char. 10354: $A \rightarrow G$ Char. 10436: $\mathrm{A} \rightarrow \mathrm{T}$ Char. 10447: $\mathrm{A} \rightarrow \mathrm{G}$ Char. 10470: T $\rightarrow$ A Char. 10511: $\mathrm{A} \rightarrow \mathrm{T}$ Char. 10532: $\mathrm{T} \rightarrow \mathrm{A}$
Char. 10540: $\mathrm{T} \rightarrow \mathrm{A}$

H3

Char. 10662: A $\rightarrow$ T

Eurycyde + Ascorhynchus + (Callipallenid Nymphonids) group

$28 S$

Char. 180: $\mathrm{C} \rightarrow \mathrm{G}$

Char. 660: $\mathrm{G} \rightarrow \mathrm{T}$

Char. 686: $\mathrm{T} \rightarrow \mathrm{A}$

Char. 856: $-\rightarrow \mathrm{T}$

Char. 903: $\mathrm{T} \rightarrow \mathrm{C}$

Char. 1263: $\mathrm{T} \rightarrow \mathrm{G}$

Char. 1319: $\mathrm{C} \rightarrow \mathrm{T}$

Char. 1510: A $\rightarrow$ G

Char. 1590: $\mathrm{C} \rightarrow-$

Char. 1605: $\mathrm{C} \rightarrow-$

Char. 1714: $\mathrm{C} \rightarrow-$

Char. 1737: $\mathrm{C} \rightarrow \mathrm{T}$

Char. 1804: $-\rightarrow$ C

Char. 1834: $\mathrm{C} \rightarrow-$

Char. 1867: $-\rightarrow \mathrm{T}$

Char. 1880: $\mathrm{C} \rightarrow \mathrm{G}$

Char. 2180: $\mathrm{G} \rightarrow \mathrm{A}$

Char. 2290: $-\rightarrow$ A

Char. 2356: $-\rightarrow \mathrm{T}$

Char. 2371: $\mathrm{C} \rightarrow \mathrm{A}$

Char. 3039: $\mathrm{G} \rightarrow \mathrm{A}$

Char. 3375: $\mathrm{C} \rightarrow \mathrm{A}$

Char. 3806: $\mathrm{A} \rightarrow \mathrm{G}$

Char. 3826: $\mathrm{G} \rightarrow \mathrm{A}$

Char. 4797: $\mathrm{C} \rightarrow-$

$18 S$

Char. 5450: $\mathrm{T} \rightarrow \mathrm{C}$

Char. 7074: $\mathrm{C} \rightarrow \mathrm{A}$

Char. 7602: A $\rightarrow$ C

\section{COI}

Char. 8076: $\mathrm{T} \rightarrow \mathrm{A}$

Char. 8243: A $\rightarrow-$

Char. 8275: $\mathrm{C} \rightarrow \mathrm{A}$

Char. 8489: $\mathrm{C} \rightarrow \mathrm{T}$

Char. 8528: $\mathrm{T} \rightarrow \mathrm{A}$

Char. 8550: $\mathrm{A} \rightarrow \mathrm{G}$

Char. 8559: $\mathrm{A} \rightarrow \mathrm{T}$

Char. 8850: $\mathrm{T} \rightarrow \mathrm{A}$

$12 S$

Char. 9076: $\mathrm{T} \rightarrow-$ Char. 9225: $-\rightarrow \mathrm{T}$ Char. 9350: $\mathrm{T} \rightarrow \mathrm{A}$ Char. 9380: $\mathrm{A} \rightarrow \mathrm{T}$ Char. 9405: $\mathrm{A} \rightarrow \mathrm{T}$

$16 S$

Char. 9585: $\mathrm{A} \rightarrow \mathrm{T}$ Char. 9639: $\mathrm{T} \rightarrow-$ Char. 9781: $\mathrm{T} \rightarrow \mathrm{A}$ Char. 9826: $\mathrm{G} \rightarrow \mathrm{A}$ Char. 9889: $\mathrm{A} \rightarrow \mathrm{G}$ Char. 10106: $\mathrm{T} \rightarrow \mathrm{A}$ 
Char. 10128: $\mathrm{A} \rightarrow \mathrm{T}$

Char. 10314: $\mathrm{A} \rightarrow \mathrm{T}$

\section{H3}

Char. 10714: $\mathrm{T} \rightarrow \mathrm{G}$

Char. 10821: $\mathrm{T} \rightarrow \mathrm{G}$

\section{Pycnogonida except Austrodecidae + Colossendeidae + (P. femoratum + Pycnogonidae)}

\section{$28 S$}

Char. 246: $\mathrm{G} \rightarrow \mathrm{C}$

Char. 248: $\mathrm{T} \rightarrow \mathrm{G}$

Char. 718: $\mathrm{A} \rightarrow \mathrm{C}$

Char. 761: C $\rightarrow$ A

Char. 823: $\mathrm{G} \rightarrow \mathrm{C}$

Char. 852: $-\rightarrow$ C

Char. 862: $-\rightarrow$ C

Char. 868: $\mathrm{G} \rightarrow \mathrm{T}$

Char. 871: $\mathrm{A} \rightarrow \mathrm{T}$

Char. 965: $-\rightarrow$ A

Char. 969: $-\rightarrow \mathrm{T}$

Char. 1091: $\rightarrow \mathrm{T}$

Char. 1168: A $\rightarrow-$

Char. 1282: $-\rightarrow \mathrm{G}$

Char. 1460: $\mathrm{T} \rightarrow \mathrm{A}$

Char. 1484: $-\rightarrow$ A

Char. 1493: $\mathrm{T} \rightarrow \mathrm{A}$

Char. 1511: $-\rightarrow \mathrm{T}$

Char. 1551: $-\rightarrow$ C

Char. 1619: $-\rightarrow$ T

Char. 1674: A $\rightarrow-$

Char. 1695: $\mathrm{G} \rightarrow \mathrm{C}$

Char. 1751: $\mathrm{G} \rightarrow-$

Char. 1765: $\mathrm{C} \rightarrow \mathrm{A}$

Char. 1787: $\mathrm{T} \rightarrow \mathrm{G}$

Char. 1821: $-\rightarrow \mathrm{C}$

Char. 1914: $\mathrm{G} \rightarrow \mathrm{T}$

Char. 1928: $\mathrm{C} \rightarrow \mathrm{T}$

Char. 1952: $-\rightarrow$ C

Char. 2218: $\mathrm{A} \rightarrow \mathrm{T}$

Char. 2336: $\mathrm{C} \rightarrow \mathrm{G}$

Char. 2357: $-\rightarrow \mathrm{C}$

Char. 2417: $\mathrm{T} \rightarrow \mathrm{C}$

Char. 2418: $\mathrm{G} \rightarrow \mathrm{T}$

Char. 2630: $\mathrm{A} \rightarrow \mathrm{T}$

Char. 2686: $-\rightarrow$ C

Char. 2705: $\mathrm{A} \rightarrow \mathrm{G}$

Char. 3192: $\mathrm{T} \rightarrow \mathrm{C}$

Char. 3204: $\mathrm{C} \rightarrow \mathrm{T}$

Char. 3313: $-\rightarrow \mathrm{C}$

Char. 3323: $-\rightarrow \mathrm{T}$

Char. 3359: $\mathrm{A} \rightarrow \mathrm{G}$

Char. 3403: $-\rightarrow \mathrm{C}$

Char. 3424: $-\rightarrow \mathrm{G}$

Char. 3432: $\mathrm{G} \rightarrow \mathrm{A}$

Char. 3493: $\mathrm{T} \rightarrow \mathrm{C}$

Char. 3548: $\mathrm{C} \rightarrow \mathrm{T}$

Char. 3743: $\mathrm{C} \rightarrow \mathrm{T}$

Char. 3750: $\mathrm{C} \rightarrow \mathrm{T}$

Char. 3858: $-\rightarrow$ A

Char. 3865: - $\rightarrow$ A

Char. 4532: $\mathrm{C} \rightarrow \mathrm{G}$

Char. 4547: $\mathrm{C} \rightarrow \mathrm{T}$

Char. 4731: $-\rightarrow$ G

Char. 4738: $-\rightarrow$ C
Char. 4740: $-\rightarrow$ A

Char. 4741: $\mathrm{T} \rightarrow \mathrm{A}$

Char. 4773: $\mathrm{C} \rightarrow \mathrm{G}$

\section{$18 S$}

Char. 5497: $-\rightarrow \mathrm{G}$

Char. 5539: $\mathrm{G} \rightarrow \mathrm{A}$

Char. 5553: $-\rightarrow \mathrm{G}$

Char. 5594: $\mathrm{T} \rightarrow \mathrm{C}$

Char. 5666: $\mathrm{G} \rightarrow \mathrm{C}$

Char. 5696: $\mathrm{C} \rightarrow \mathrm{T}$

Char. 6194: $-\rightarrow$ A

Char. 6203: $-\rightarrow$ A

Char. 6205: $-\rightarrow$ C

Char. 6208: $-\rightarrow$ A

Char. 7635: $\mathrm{G} \rightarrow \mathrm{T}$

Char. 7639: $\mathrm{T} \rightarrow \mathrm{C}$

\section{COI}

Char. 7987: $\mathrm{T} \rightarrow \mathrm{A}$

Char. 8021: $-\rightarrow$ A

Char. 8049: $\mathrm{C} \rightarrow \mathrm{A}$

Char. 8135: $\mathrm{A} \rightarrow \mathrm{T}$

Char. 8234: $\mathrm{T} \rightarrow \mathrm{A}$

Char. 8322: $\mathrm{C} \rightarrow \mathrm{T}$

Char. 8324: $\mathrm{T} \rightarrow \mathrm{A}$

Char. 8345: $\mathrm{T} \rightarrow \mathrm{A}$

Char. 8551: $\mathrm{C} \rightarrow \mathrm{T}$

Char. 8562: $\mathrm{C} \rightarrow \mathrm{T}$

Char. 8769: $\mathrm{A} \rightarrow \mathrm{G}$

Char. 8771: $\mathrm{C} \rightarrow \mathrm{T}$

Char. 8795: T $\rightarrow$ A

Char. 8836: $\mathrm{A} \rightarrow \mathrm{G}$

Char. 8853: $\mathrm{T} \rightarrow \mathrm{A}$

$12 S$

Char. 8897: $\mathrm{T} \rightarrow \mathrm{A}$

Char. 8910: $-\rightarrow$ A

Char. 8936: A $\rightarrow$ G

Char. 9009: $\mathrm{A} \rightarrow \mathrm{T}$

Char. 9012: $\mathrm{T} \rightarrow \mathrm{C}$

Char. 9214: $-\rightarrow$ A

Char. 9347: $\mathrm{A} \rightarrow \mathrm{T}$

Char. 9403: $\mathrm{T} \rightarrow \mathrm{A}$

\section{$16 S$}

Char. 10010: $\mathrm{A} \rightarrow \mathrm{T}$

Char. 10057: $\mathrm{G} \rightarrow \mathrm{A}$

Char. 10227: $\mathrm{T} \rightarrow \mathrm{A}$

Char. 10229: $\mathrm{A} \rightarrow \mathrm{T}$

Char. 10265: $\mathrm{A} \rightarrow \mathrm{T}$

H3

Char. 10604: $\mathrm{T} \rightarrow \mathrm{C}$

Char. 10605: $\mathrm{C} \rightarrow \mathrm{A}$

Char. 10608: $\mathrm{T} \rightarrow \mathrm{A}$

Char. 10629: $\mathrm{A} \rightarrow \mathrm{T}$

Callipallenids + Nymphonids group

$28 S$

Char. 254: $\mathrm{T} \rightarrow \mathrm{C}$

Char. 255: $\mathrm{C} \rightarrow \mathrm{T}$

Char. 343: $\mathrm{G} \rightarrow \mathrm{T}$ 
Char. 359: $\mathrm{G} \rightarrow \mathrm{T}$

Char. 369: $\mathrm{T} \rightarrow \mathrm{C}$

Char. 605: $\mathrm{C} \rightarrow \mathrm{A}$

Char. 611: $\mathrm{A} \rightarrow \mathrm{G}$

Char. 614: $\mathrm{C} \rightarrow \mathrm{T}$

Char. 617: $\mathrm{C} \rightarrow \mathrm{T}$

Char. 648: $\mathrm{A} \rightarrow \mathrm{C}$

Char. 779: $\mathrm{T} \rightarrow \mathrm{C}$

Char. 868: $\mathrm{T} \rightarrow \mathrm{A}$

Char. 891: $\mathrm{T} \rightarrow \mathrm{G}$

Char. 909: $\mathrm{G} \rightarrow \mathrm{T}$

Char. 910: $\mathrm{G} \rightarrow \mathrm{C}$

Char. 912: $\mathrm{C} \rightarrow \mathrm{T}$

Char. 971: $\mathrm{C} \rightarrow-$

Char. 1155: $\mathrm{C} \rightarrow \mathrm{T}$

Char. 1162: $\mathrm{G} \rightarrow \mathrm{A}$

Char. 1229: $-\rightarrow$ T

Char. 1235: $\mathrm{G} \rightarrow \mathrm{C}$

Char. 1336: $\mathrm{G} \rightarrow \mathrm{C}$

Char. 1359: $\mathrm{C} \rightarrow \mathrm{T}$

Char. 1360: $\mathrm{C} \rightarrow \mathrm{T}$

Char. 1365: $\mathrm{T} \rightarrow-$

Char. 1370: $\mathrm{T} \rightarrow \mathrm{C}$

Char. 1460: $\mathrm{A} \rightarrow \mathrm{G}$

Char. 1538: $-\rightarrow \mathrm{T}$

Char. 1565: $\mathrm{T} \rightarrow \mathrm{G}$

Char. 1618: $\mathrm{C} \rightarrow \mathrm{AG}$

Char. 1620: $\mathrm{C} \rightarrow-$

Char. 1639: $\mathrm{G} \rightarrow \mathrm{T}$

Char. 1666: $\mathrm{T} \rightarrow \mathrm{C}$

Char. 1710: $\mathrm{T} \rightarrow-$

Char. 1731: $\mathrm{T} \rightarrow \mathrm{C}$

Char. 1732: $\mathrm{C} \rightarrow \mathrm{T}$

Char. 1754: $\mathrm{C} \rightarrow-$

Char. 1768: $\mathrm{A} \rightarrow \mathrm{C}$

Char. 1777: $-\rightarrow$ A

Char. 1786: $-\rightarrow$ G

Char. 1873: $\mathrm{T} \rightarrow \mathrm{C}$

Char. 1947: $\mathrm{T} \rightarrow \mathrm{C}$

Char. 2135: $\mathrm{T} \rightarrow \mathrm{G}$

Char. 2422: $\mathrm{C} \rightarrow \mathrm{A}$

Char. 2427: A $\rightarrow$ C

Char. 2439: $\mathrm{G} \rightarrow \mathrm{T}$

Char. 2592: $\mathrm{A} \rightarrow \mathrm{G}$

Char. 2709: $\mathrm{G} \rightarrow \mathrm{C}$

Char. 2853: $\mathrm{C} \rightarrow \mathrm{T}$

Char. 2930: $\mathrm{T} \rightarrow \mathrm{A}$

Char. 3050: $\mathrm{C} \rightarrow \mathrm{A}$

Char. 3056: $\mathrm{C} \rightarrow \mathrm{T}$

Char. 3177: $\mathrm{G} \rightarrow \mathrm{C}$

Char. 3417: $\mathrm{G} \rightarrow \mathrm{A}$

Char. 3712: $\mathrm{G} \rightarrow \mathrm{A}$

Char. 3737: $-\rightarrow$ A

Char. 3738: - $\rightarrow$ A

Char. 3811: $\mathrm{G} \rightarrow \mathrm{A}$

Char. 3840: $\mathrm{T} \rightarrow \mathrm{C}$

Char. 3870: $\mathrm{C} \rightarrow \mathrm{T}$

Char. 4014: $\mathrm{G} \rightarrow \mathrm{T}$

Char. 4019: $\mathrm{C} \rightarrow \mathrm{G}$

Char. 4133: $\mathrm{T} \rightarrow \mathrm{A}$

Char. 4134: $\mathrm{C} \rightarrow \mathrm{A}$

Char. 4139: $-\rightarrow \mathrm{T}$

Char. 4215: $\mathrm{G} \rightarrow \mathrm{C}$

Char. 4219: $\mathrm{C} \rightarrow \mathrm{A}$

Char. 4480: $\mathrm{C} \rightarrow \mathrm{T}$

Char. 4487: $\mathrm{G} \rightarrow \mathrm{T}$

Char. 4504: $\mathrm{T} \rightarrow-$
Char. 4509: $\mathrm{T} \rightarrow \mathrm{G}$

Char. 4532: $\mathrm{G} \rightarrow \mathrm{A}$

Char. 4693: $-\rightarrow$ G

Char. 4696: $\mathrm{T} \rightarrow \mathrm{G}$

Char. 4759: $\mathrm{T} \rightarrow \mathrm{C}$

Char. 4774: $-\rightarrow \mathrm{T}$

Char. 4775: $-\rightarrow \mathrm{C}$

Char. 4793: $\mathrm{T} \rightarrow-$

Char. 4807: $\mathrm{T} \rightarrow \mathrm{A}$

Char. 5196: $\mathrm{T} \rightarrow \mathrm{C}$

$18 S$

Char. 5277: $\mathrm{T} \rightarrow-$ Char. 5420: $-\rightarrow$ C

Char. 5432: $-\rightarrow \mathrm{T}$

Char. 5463: - $\rightarrow$ G

Char. 5489: $-\rightarrow$ A

Char. 5490: $-\rightarrow$ A

Char. 5501: $-\rightarrow$ A

Char. 5549: $-\rightarrow \mathrm{G}$

Char. 5570: $\mathrm{T} \rightarrow \mathrm{C}$

Char. 5594: $\mathrm{C} \rightarrow-$

Char. 5600: $\mathrm{C} \rightarrow-$

Char. 5608: $\mathrm{G} \rightarrow \mathrm{T}$

Char. 5641: $\mathrm{T} \rightarrow \mathrm{G}$

Char. 5704: $\mathrm{C} \rightarrow \mathrm{T}$

Char. 6125: C $\rightarrow$ A

Char. 6126: $\mathrm{T} \rightarrow \mathrm{A}$

Char. 6165: $\mathrm{C} \rightarrow \mathrm{G}$

Char. 6193: $-\rightarrow$ C

Char. 6194: $\mathrm{A} \rightarrow \mathrm{G}$

Char. 6215: $\mathrm{T} \rightarrow \mathrm{G}$

Char. 6223: $\mathrm{T} \rightarrow \mathrm{A}$

Char. 6250: $\mathrm{G} \rightarrow \mathrm{T}$

Char. 6331: $-\rightarrow \mathrm{T}$

Char. 6335: $\mathrm{G} \rightarrow \mathrm{T}$

Char. 6351: $\mathrm{A} \rightarrow \mathrm{G}$

Char. 7077: $\mathrm{T} \rightarrow \mathrm{C}$

\section{COI}

Char. 7794: $\mathrm{C} \rightarrow \mathrm{T}$

Char. 7797: $\mathrm{G} \rightarrow \mathrm{A}$

Char. 7800: $\mathrm{T} \rightarrow \mathrm{C}$

Char. 7811: $\mathrm{T} \rightarrow \mathrm{A}$

Char. 7813: $\mathrm{A} \rightarrow \mathrm{T}$

Char. 7844: $\mathrm{A} \rightarrow \mathrm{T}$

Char. 7847: $\mathrm{A} \rightarrow \mathrm{T}$

Char. 7854: $\mathrm{G} \rightarrow \mathrm{A}$

Char. 7877: $\mathrm{T} \rightarrow \mathrm{A}$

Char. 7923: $\mathrm{A} \rightarrow \mathrm{G}$

Char. 7931: $\mathrm{T} \rightarrow \mathrm{A}$

Char. 7954: $\mathrm{G} \rightarrow \mathrm{T}$

Char. 7997: $\mathrm{A} \rightarrow \mathrm{T}$

Char. 8006: $\mathrm{A} \rightarrow \mathrm{T}$

Char. 8019: $\mathrm{T} \rightarrow \mathrm{A}$

Char. 8062: $\mathrm{C} \rightarrow \mathrm{T}$

Char. 8072: $\mathrm{T} \rightarrow \mathrm{C}$

Char. 8124: $\mathrm{T} \rightarrow \mathrm{A}$

Char. 8125: $\mathrm{C} \rightarrow \mathrm{G}$

Char. 8149: $\mathrm{C} \rightarrow \mathrm{T}$

Char. 8163: $\mathrm{A} \rightarrow \mathrm{G}$

Char. 8181: $\mathrm{T} \rightarrow \mathrm{A}$

Char. 8183: $\mathrm{A} \rightarrow \mathrm{T}$

Char. 8208: $\mathrm{G} \rightarrow \mathrm{T}$

Char. 8211: $\mathrm{A} \rightarrow \mathrm{T}$

Char. 8222: $\mathrm{T} \rightarrow \mathrm{A}$ 
Char. 8223: $\mathrm{A} \rightarrow \mathrm{G}$

Char. 8231: $\mathrm{T} \rightarrow \mathrm{A}$

Char. 8233: $\mathrm{T} \rightarrow \mathrm{A}$

Char. 8250: $\mathrm{A} \rightarrow \mathrm{C}$

Char. 8258: $\mathrm{G} \rightarrow \mathrm{T}$

Char. 8277: $\mathrm{A} \rightarrow \mathrm{T}$

Char. 8290: $\mathrm{G} \rightarrow \mathrm{A}$

Char. 8291: $\mathrm{T} \rightarrow \mathrm{C}$

Char. 8314: $\mathrm{A} \rightarrow \mathrm{T}$

Char. 8325: $\mathrm{C} \rightarrow \mathrm{G}$

Char. 8331: $\mathrm{C} \rightarrow \mathrm{G}$

Char. 8332: $\mathrm{T} \rightarrow \mathrm{C}$

Char. 8367: $\mathrm{C} \rightarrow \mathrm{T}$

Char. 8374: $\mathrm{A} \rightarrow \mathrm{T}$

Char. 8375: $\mathrm{C} \rightarrow \mathrm{T}$

Char. 8427: $\mathrm{A} \rightarrow \mathrm{T}$

Char. 8516: $\mathrm{A} \rightarrow \mathrm{G}$

Char. 8531: $\mathrm{C} \rightarrow \mathrm{T}$

Char. 8536: $\mathrm{G} \rightarrow \mathrm{C}$

Char. 8538: $\mathrm{G} \rightarrow \mathrm{A}$

Char. 8539: $\mathrm{G} \rightarrow \mathrm{A}$

Char. 8578: $\mathrm{G} \rightarrow \mathrm{T}$

Char. 8580: $\mathrm{T} \rightarrow \mathrm{A}$

Char. 8599: $\mathrm{T} \rightarrow \mathrm{A}$

Char. 8713: $\mathrm{A} \rightarrow \mathrm{G}$

Char. 8744: $\mathrm{T} \rightarrow \mathrm{G}$

Char. 8745: $\mathrm{C} \rightarrow \mathrm{G}$

Char. 8747: $\mathrm{C} \rightarrow \mathrm{A}$

Char. 8765: $\mathrm{C} \rightarrow \mathrm{A}$

Char. 8775: $\mathrm{A} \rightarrow \mathrm{C}$

Char. 8868: $\mathrm{C} \rightarrow \mathrm{T}$

\section{$12 S$}

Char. 8904: $\mathrm{G} \rightarrow \mathrm{T}$

Char. 8951: $\mathrm{T} \rightarrow \mathrm{A}$

Char. 8953: $\mathrm{A} \rightarrow \mathrm{T}$

Char. 8967: $\mathrm{A} \rightarrow \mathrm{G}$

Char. 8989: $-\rightarrow \mathrm{T}$

Char. 8997: $\mathrm{T} \rightarrow \mathrm{A}$

Char. 9017: $\mathrm{C} \rightarrow \mathrm{T}$

Char. 9098: $\mathrm{G} \rightarrow \mathrm{T}$

Char. 9138: $\mathrm{A} \rightarrow \mathrm{T}$

Char. 9140: $\mathrm{A} \rightarrow \mathrm{T}$

Char. 9157: $\mathrm{G} \rightarrow \mathrm{T}$

Char. 9175: $\mathrm{A} \rightarrow \mathrm{T}$

Char. 9186: $\mathrm{T} \rightarrow \mathrm{A}$

Char. 9189: $\mathrm{T} \rightarrow \mathrm{A}$

Char. 9247: $\mathrm{T} \rightarrow \mathrm{A}$

Char. 9274: $\mathrm{C} \rightarrow \mathrm{A}$

Char. 9277: $\mathrm{G} \rightarrow \mathrm{T}$

Char. 9278: $\mathrm{G} \rightarrow \mathrm{A}$

Char. 9279: $\mathrm{T} \rightarrow \mathrm{A}$

Char. 9300: $\mathrm{G} \rightarrow \mathrm{A}$

Char. 9306: $\mathrm{T} \rightarrow \mathrm{A}$

Char. 9309: $\mathrm{G} \rightarrow$ AC

Char. 9340: $\mathrm{A} \rightarrow \mathrm{T}$

Char. 9358: $\mathrm{T} \rightarrow-$

Char. 9455: $\mathrm{T} \rightarrow \mathrm{C}$

Char. 9545: $\mathrm{C} \rightarrow \mathrm{A}$

Char. 9546: $\mathrm{T} \rightarrow \mathrm{A}$

Char. 9548: $\mathrm{A} \rightarrow \mathrm{T}$

\section{$16 S$}

Char. 9592: $\mathrm{T} \rightarrow \mathrm{A}$

Char. 9607: $\mathrm{C} \rightarrow \mathrm{A}$

Char. 9610: $A \rightarrow G$
Char. 9629: A $\rightarrow-$

Char. 9679: $\mathrm{G} \rightarrow-$

Char. 9681: A $\rightarrow-$

Char. 9686: $\mathrm{G} \rightarrow-$

Char. 9689: $\mathrm{C} \rightarrow-$

Char. 9753: A $\rightarrow-$

Char. 9789: $-\rightarrow$ A

Char. 9888: $\mathrm{T} \rightarrow \mathrm{A}$

Char. 9909: $\mathrm{C} \rightarrow \mathrm{A}$

Char. 9910: $\mathrm{A} \rightarrow \mathrm{G}$

Char. 9967: $-\rightarrow \mathrm{T}$

Char. 10109: $\mathrm{C} \rightarrow \mathrm{T}$

Char. 10120: $\mathrm{G} \rightarrow \mathrm{A}$

Char. 10132: $\mathrm{A} \rightarrow \mathrm{T}$

Char. 10140: $\mathrm{G} \rightarrow \mathrm{T}$

Char. 10147: $\mathrm{T} \rightarrow-$

Char. 10148: $\mathrm{T} \rightarrow \mathrm{A}$

Char. 10160: $\mathrm{T} \rightarrow \mathrm{A}$

Char. 10172: $\mathrm{T} \rightarrow \mathrm{A}-$

Char. 10229: $\mathrm{T} \rightarrow-$

Char. 10258: $\mathrm{T} \rightarrow-$

Char. 10347: $\mathrm{T} \rightarrow \mathrm{C}$

Char. 10348: $\mathrm{G} \rightarrow \mathrm{T}$

Char. 10367: $\mathrm{T} \rightarrow \mathrm{A}$

Char. 10395: $\mathrm{A} \rightarrow \mathrm{T}$

Char. 10511: $\mathrm{A} \rightarrow \mathrm{T}$

\section{H3}

Char. 10558: $\mathrm{T} \rightarrow \mathrm{A}$

Char. 1238: $-\rightarrow \mathrm{G}$

Char. 1309: $\mathrm{T} \rightarrow \mathrm{G}$

Char. 1313: $\mathrm{G} \rightarrow \mathrm{C}$

Char. 1520: $\mathrm{C} \rightarrow \mathrm{T}$

Char. 1521: $\mathrm{A} \rightarrow \mathrm{G}$

Char. 1718: $\mathrm{G} \rightarrow-$

Char. 1748: $\mathrm{G} \rightarrow \mathrm{C}$

Char. 1922: $\mathrm{T} \rightarrow \mathrm{A}$

Char. 2368: $\mathrm{T} \rightarrow-$

Char. 3204: $\mathrm{T} \rightarrow \mathrm{C}$

Char. 3237: $-\rightarrow \mathrm{T}$

Char. 3346: $\mathrm{A} \rightarrow \mathrm{G}$

Char. 3432: $A \rightarrow G$

Char. 4779: $\mathrm{C} \rightarrow \mathrm{G}$

Char. 5338: $\mathrm{G} \rightarrow \mathrm{A}$

Char. 6194: $\mathrm{T} \rightarrow \mathrm{C}$

Char. 7080: $\mathrm{A} \rightarrow \mathrm{G}$

Char. 7083: $\mathrm{C} \rightarrow \mathrm{T}$

Char. 7956: $\mathrm{C} \rightarrow \mathrm{A}$

Char. 8240: $\mathrm{A} \rightarrow \mathrm{G}$

Char. 8595: $\mathrm{A} \rightarrow \mathrm{T}$

Char. 8700: $\mathrm{A} \rightarrow \mathrm{T}$

Char. 8734: $\mathrm{T} \rightarrow \mathrm{A}$

Char. 8753: $\mathrm{T} \rightarrow \mathrm{A}$

Char. 8865: $\mathrm{A} \rightarrow \mathrm{G}$

Char. 8963: $\mathrm{T} \rightarrow \mathrm{C}$

Char. 9247: $\mathrm{T} \rightarrow-$

Char. 9413: $-\rightarrow \mathrm{T}$

Char. 9429: A $\rightarrow-$

Char. 9459: $\mathrm{A} \rightarrow \mathrm{G}$

Char. 9542: $\mathrm{T} \rightarrow \mathrm{C}$

Char. 9564: $\mathrm{T} \rightarrow \mathrm{A}$

Char. 9587: $\mathrm{T} \rightarrow \mathrm{A}$

Char. 9603: $A \rightarrow$ G

Char. 9623: $-\rightarrow$ A

Char. 9653: $\mathrm{A} \rightarrow \mathrm{G}$

Char. 9657: A $\rightarrow \mathrm{T}$

Char. 9774: $\mathrm{C} \rightarrow \mathrm{T}$ 
Char. 9796: $\mathrm{A} \rightarrow \mathrm{T}$

Char. 9991: $\mathrm{T} \rightarrow-$

Char. 10010: $\mathrm{T} \rightarrow \mathrm{A}$

Char. 10071: $\mathrm{T} \rightarrow-$

Char. 10198: A $\rightarrow-$

Char. 10320: $\mathrm{T} \rightarrow \mathrm{A}$

Char. 10446: A $\rightarrow-$

Char. 10555: $\mathrm{A} \rightarrow \mathrm{G}$

Char. 10587: $\mathrm{T} \rightarrow \mathrm{C}$

Char. 10730: $\mathrm{G} \rightarrow \mathrm{T}$

Char. 10786: $\mathrm{C} \rightarrow \mathrm{G}$

\section{Ammotheids + Rhynchothoracidae group}

$28 S$

Char. 232: $\mathrm{G} \rightarrow-$

Char. 233: $\mathrm{C} \rightarrow \mathrm{A}$

Char. 257: $\mathrm{T} \rightarrow \mathrm{C}$

Char. 261: $\mathrm{G} \rightarrow \mathrm{C}$

Char. 329: $-\rightarrow \mathrm{G}$

Char. 338: $\mathrm{A} \rightarrow-$

Char. 643: $\mathrm{G} \rightarrow \mathrm{C}$

Char. 697: $\mathrm{A} \rightarrow \mathrm{G}$

Char. 903: $\mathrm{T} \rightarrow \mathrm{G}$

Char. 951: $\mathrm{C} \rightarrow-$

Char. 953: $\mathrm{T} \rightarrow-$

Char. 955: $\mathrm{C} \rightarrow-$

Char. 958: $\mathrm{T} \rightarrow-$

Char. 963: $\mathrm{C} \rightarrow-$

Char. 964: $\mathrm{C} \rightarrow-$

Char. 965: A $\rightarrow-$

Char. 969: $\mathrm{T} \rightarrow-$

Char. 971: $\mathrm{C} \rightarrow-$

Char. 973: $\mathrm{C} \rightarrow-$

Char. 977: $\mathrm{G} \rightarrow-$

Char. 980: $\mathrm{G} \rightarrow-$

Char. 981: $\mathrm{G} \rightarrow-$

Char. 984: $\mathrm{G} \rightarrow-$

Char. 987: $\mathrm{G} \rightarrow-$

Char. 988: AG $\rightarrow-$

Char. 989: $\mathrm{G} \rightarrow-$

Char. 992: $\mathrm{T} \rightarrow-$

Char. 993: T $\rightarrow-$

Char. 1064: $-\rightarrow$ A

Char. 1155: $\mathrm{C} \rightarrow \mathrm{T}$

Char. 1207: $\mathrm{T} \rightarrow-$

Char. 1228: $\mathrm{G} \rightarrow-$

Char. 1365: $\mathrm{T} \rightarrow \mathrm{C}$

Char. 1423: A $\rightarrow$ C

Char. 1431: $\mathrm{A} \rightarrow \mathrm{T}$

Char. 1457: $\mathrm{C} \rightarrow \mathrm{A}$

Char. 1495: $\mathrm{A} \rightarrow \mathrm{T}$

Char. 1502: $\mathrm{C} \rightarrow \mathrm{G}$

Char. 1557: $\mathrm{G} \rightarrow-$

Char. 1659: $\mathrm{G} \rightarrow \mathrm{T}$

Char. 1682: $\mathrm{T} \rightarrow \mathrm{A}$

Char. 1708: $-\rightarrow \mathrm{T}$

Char. 1760: $\mathrm{A} \rightarrow-$

Char. 2214: $\mathrm{C} \rightarrow \mathrm{A}$

Char. 3820: $\mathrm{T} \rightarrow \mathrm{C}$

Char. 3843: $\mathrm{T} \rightarrow \mathrm{A}$

Char. 3847: $\mathrm{T} \rightarrow \mathrm{C}$

Char. 4445: $\mathrm{C} \rightarrow \mathrm{T}$

Char. 4523: $\mathrm{G} \rightarrow \mathrm{C}$

Char. 4584: $\mathrm{G} \rightarrow \mathrm{C}$

Char. 4694: $-\rightarrow \mathrm{G}$
Char. 4796: $\mathrm{T} \rightarrow \mathrm{C}$

Char. 4797: $\mathrm{C} \rightarrow \mathrm{A}$

Char. 4807: $\mathrm{T} \rightarrow \mathrm{A}$

$18 S$

Char. 5644: $\mathrm{G} \rightarrow \mathrm{A}$

Char. 6162: $\mathrm{C} \rightarrow \mathrm{T}$

Char. 6175: $-\rightarrow \mathrm{T}$

Char. 6205: $\mathrm{C} \rightarrow \mathrm{G}$

Char. 7080: $\mathrm{G} \rightarrow \mathrm{T}$

Char. 7083: $\mathrm{T} \rightarrow \mathrm{C}$

$\mathrm{COI}$

Char. 7783: $\mathrm{A} \rightarrow \mathrm{T}$

Char. 7844: $\mathrm{A} \rightarrow \mathrm{T}$

Char. 7922: $\mathrm{T} \rightarrow \mathrm{A}$

Char. 7971: $\mathrm{G} \rightarrow \mathrm{A}$

Char. 7972: $\mathrm{A} \rightarrow \mathrm{T}$

Char. 7996: $\mathrm{A} \rightarrow \mathrm{T}$

Char. 8531: $\mathrm{C} \rightarrow \mathrm{G}$

Char. 8695: $\mathrm{G} \rightarrow \mathrm{A}$

$12 S$

Char. 9049: - $\rightarrow$ A

Char. 9302: $-\rightarrow$ A

Char. 9340: $\mathrm{A} \rightarrow \mathrm{T}$

Char. 9403: $\mathrm{A} \rightarrow \mathrm{T}$

Char. 9449: $\mathrm{A} \rightarrow \mathrm{G}$

Char. 9476: $\mathrm{T} \rightarrow \mathrm{A}$

Char. 9509: $\mathrm{A} \rightarrow \mathrm{T}$

$16 S$

Char. 9635: $-\rightarrow \mathrm{T}$

Char. 9653: $\mathrm{T} \rightarrow \mathrm{A}$

Char. 9826: $\mathrm{G} \rightarrow \mathrm{T}$

Char. 9850: $-\rightarrow \mathrm{T}$

Char. 9852: $\mathrm{C} \rightarrow \mathrm{T}$

Char. 9995: A $\rightarrow-$

Char. 10030: $-\rightarrow \mathrm{C}$

Char. 10057: $\mathrm{A} \rightarrow \mathrm{T}$

Char. 10094: $-\rightarrow$ A

Char. 10332: A $\rightarrow-$

Char. 10387: $\mathrm{G} \rightarrow \mathrm{T}$

Char. 10472: $\mathrm{G} \rightarrow \mathrm{A}$

Phoxichilidiids + Ammotheids

$28 S$

Char. 328: $\mathrm{T} \rightarrow \mathrm{C}$

Char. 335: $\mathrm{T} \rightarrow \mathrm{G}$

Char. 359: $\mathrm{G} \rightarrow \mathrm{T}$

Char. 582: $\mathrm{T} \rightarrow \mathrm{A}$

Char. 653: $\mathrm{C} \rightarrow \mathrm{T}$

Char. 1280: $-\rightarrow \mathrm{G}$

Char. 1493: A $\rightarrow-$

Char. 1656: $-\rightarrow \mathrm{G}$

Char. 1705: $-\rightarrow \mathrm{C}$

Char. 1821: $\mathrm{C} \rightarrow \mathrm{G}$

Char. 1897: $\mathrm{T} \rightarrow \mathrm{G}$

Char. 2144: $\mathrm{C} \rightarrow \mathrm{A}$

Char. 3811: $\mathrm{G} \rightarrow \mathrm{C}$

Char. 3840: $\mathrm{T} \rightarrow-$

Char. 4444: $\mathrm{C} \rightarrow \mathrm{T}$

Char. 4779: $-\rightarrow$ C 
$18 S$

Char. 5638: $\mathrm{T} \rightarrow-$

\section{COI}

Char. 7749: $\mathrm{A} \rightarrow \mathrm{T}$

Char. 8245: $\mathrm{A} \rightarrow \mathrm{T}$

Char. 8637: $\mathrm{A} \rightarrow \mathrm{T}$

Char. 8787: $\mathrm{T} \rightarrow \mathrm{G}$

\section{$12 S$}

Char. 8972: $\mathrm{T} \rightarrow \mathrm{C}$

Char. 9251: $-\rightarrow$ A

Char. 9305: $\mathrm{G} \rightarrow \mathrm{A}$

Char. 9322: $A \rightarrow G$

Char. 9438: $\mathrm{A} \rightarrow \mathrm{T}$

Char. 9495: $\mathrm{T} \rightarrow \mathrm{A}$

Char. 9514: $\mathrm{T} \rightarrow \mathrm{A}$

\section{$16 S$}

Char. 9581: $-\rightarrow \mathrm{T}$

Char. 9600: $\mathrm{A} \rightarrow \mathrm{T}$

Char. 10022: $\mathrm{T} \rightarrow \mathrm{A}$

Char. 10132: $\mathrm{A} \rightarrow \mathrm{T}$

Char. 10448: $-\rightarrow$ C

\section{H3}

Char. 10715: $\mathrm{C} \rightarrow \mathrm{T}$

Char. 10727: $\mathrm{A} \rightarrow \mathrm{G}$

Char. 10786: $\mathrm{G} \rightarrow \mathrm{T}$

Char. 10821: $\mathrm{T} \rightarrow \mathrm{C}$

\section{Pallenopsidae + (Phoxichilidiids + Ammotheids $)$}

\section{$28 S$}

Char. 234: $-\rightarrow \mathrm{T}$

Char. 545: $\mathrm{C} \rightarrow \mathrm{T}$

Char. 567: C $\rightarrow$ A

Char. 697: $-\rightarrow$ A

Char. 732: $-\rightarrow$ A

Char. 737: $\mathrm{T} \rightarrow \mathrm{G}$

Char. 824: $\mathrm{C} \rightarrow \mathrm{T}$

Char. 1076: $-\rightarrow \mathrm{T}$

Char. 1107: $-\rightarrow \mathrm{T}$

Char. 1109: $-\rightarrow \mathrm{T}$

Char. 1159: $-\rightarrow \mathrm{G}$

Char. 1164: $\mathrm{C} \rightarrow \mathrm{T}$

Char. 1196: $\mathrm{A} \rightarrow \mathrm{G}$

Char. 1220: $\mathrm{G} \rightarrow \mathrm{C}$

Char. 1278: $-\rightarrow \mathrm{C}$

Char. 1291: $\mathrm{G} \rightarrow \mathrm{C}$

Char. 1309: $\mathrm{C} \rightarrow \mathrm{T}$

Char. 1318: $\mathrm{T} \rightarrow \mathrm{C}$

Char. 1354: $\mathrm{G} \rightarrow \mathrm{T}$

Char. 1370: $\mathrm{T} \rightarrow \mathrm{A}$

Char. 1457: $\mathrm{T} \rightarrow \mathrm{C}$

Char. 1604: $-\rightarrow$ C

Char. 1615: $-\rightarrow \mathrm{T}$

Char. 1644: $\mathrm{C} \rightarrow \mathrm{G}$

Char. 1810: $\mathrm{G} \rightarrow \mathrm{C}$

Char. 2283: $\mathrm{G} \rightarrow \mathrm{C}$

Char. 2368: $\mathrm{C} \rightarrow \mathrm{G}$

Char. 3232: $\mathrm{A} \rightarrow \mathrm{G}$

Char. 3275: $\mathrm{T} \rightarrow \mathrm{C}$
Char. 3307: $\mathrm{G} \rightarrow \mathrm{C}$

Char. 3380: $-\rightarrow$ C

Char. 3708: $-\rightarrow$ A

Char. 3723: $\mathrm{G} \rightarrow \mathrm{T}$

Char. 3795: $\mathrm{A} \rightarrow \mathrm{T}$

Char. 3800: $\mathrm{C} \rightarrow \mathrm{G}$

Char. 4445: $\mathrm{A} \rightarrow \mathrm{C}$

Char. 4623: $\mathrm{A} \rightarrow \mathrm{G}$

Char. 4714: $-\rightarrow \mathrm{G}$

Char. 5246: $\mathrm{G} \rightarrow \mathrm{A}$

$18 S$

Char. 5424: $-\rightarrow$ C

Char. 5494: $-\rightarrow$ G

Char. 5579: $-\rightarrow \mathrm{C}$

Char. 5629: $-\rightarrow$ C

Char. 5641: $\mathrm{T} \rightarrow \mathrm{C}$

Char. 6196: $-\rightarrow$ C

Char. 7593: $\mathrm{G} \rightarrow \mathrm{A}$

\section{COI}

Char. 7819: $\mathrm{A} \rightarrow \mathrm{T}$

Char. 7822: $\mathrm{A} \rightarrow \mathrm{T}$

Char. 7838: $\mathrm{A} \rightarrow \mathrm{T}$

Char. 7841: $\mathrm{A} \rightarrow \mathrm{T}$

Char. 7960: $\mathrm{T} \rightarrow \mathrm{A}$

Char. 8253: $\mathrm{A} \rightarrow \mathrm{C}$

Char. 8283: $\mathrm{A} \rightarrow \mathrm{T}$

Char. 8331: $\mathrm{C} \rightarrow \mathrm{T}$

Char. 8552: A $\rightarrow \mathrm{T}$

Char. 8558: $\mathrm{A} \rightarrow \mathrm{T}$

Char. 8877: $\mathrm{A} \rightarrow \mathrm{T}$

$12 S$

Char. 8992: $\mathrm{C} \rightarrow \mathrm{T}$

Char. 9004: $\mathrm{G} \rightarrow \mathrm{A}$

Char. 9039: $-\rightarrow$ T

Char. 9067: $-\rightarrow$ AT

Char. 9309: $\mathrm{G} \rightarrow-$

Char. 9358: $\mathrm{T} \rightarrow \mathrm{A}$

Char. 9442: $\mathrm{T} \rightarrow \mathrm{A}$

\section{$16 S$}

Char. 9595: $\mathrm{T} \rightarrow \mathrm{A}$ Char. 9608: $\mathrm{G} \rightarrow \mathrm{T}$ Char. 9666: $\mathrm{T} \rightarrow \mathrm{A}$ Char. 9944: $\mathrm{T} \rightarrow-$ Char. 9951: $\mathrm{T} \rightarrow \mathrm{A}$ Char. 10075: $-\rightarrow$ A Char. 10107: $\mathrm{A} \rightarrow \mathrm{T}$ Char. 10124: $\mathrm{T} \rightarrow \mathrm{A}$ Char. 10198: A $\rightarrow$ T Char. 10282: $\mathrm{C} \rightarrow-$ Char. 10291: $\mathrm{A} \rightarrow \mathrm{T}$ Char. 10294: $\mathrm{A} \rightarrow \mathrm{T}$ Char. 10321: $\mathrm{G} \rightarrow \mathrm{A}$ Char. 10327: $\mathrm{T} \rightarrow \mathrm{A}$ Char. 10354: $A \rightarrow G$ Char. 10376: $\mathrm{G} \rightarrow \mathrm{A}$ Char. 10467: $\mathrm{T} \rightarrow \mathrm{A}$ Char. 10487: A $\rightarrow-$ Char. 10508: $-\rightarrow \mathrm{G}$

H3

Char. 10561: $\mathrm{C} \rightarrow \mathrm{T}$ 
Char. 10567: A $\rightarrow$ C Char. 10668: $\mathrm{C} \rightarrow \mathrm{A}$

Char. 10699: $\mathrm{G} \rightarrow \mathrm{A}$

Char. 10852: $\mathrm{C} \rightarrow \mathrm{T}$

Char. 10868: $\mathrm{C} \rightarrow \mathrm{T}$

Colossendeidae + (P. femoratum + Pycnogonidae $)$

\section{$28 S$}

Char. 179: $\mathrm{A} \rightarrow \mathrm{C}$

Char. 718: $\mathrm{A} \rightarrow \mathrm{T}$

Char. 744: $-\rightarrow$ C

Char. 805: - $\rightarrow$ C

Char. 912: $\mathrm{C} \rightarrow \mathrm{T}$

Char. 977: $\mathrm{G} \rightarrow \mathrm{A}$

Char. 1163: $\mathrm{T} \rightarrow$

Char. 1394: $\mathrm{T} \rightarrow \mathrm{A}$

Char. 1529: $-\rightarrow$ C

Char. 1565: $\mathrm{T} \rightarrow \mathrm{C}$

Char. 1628: $\mathrm{G} \rightarrow \mathrm{A}$

Char. 1733: $\mathrm{C} \rightarrow \mathrm{T}$

Char. 1751: $\mathrm{G} \rightarrow \mathrm{T}$

Char. 1857: $-\rightarrow \mathrm{G}$

Char. 1941: $-\rightarrow$ C

Char. 1943: - $\rightarrow$ A

Char. 2180: $\mathrm{G} \rightarrow \mathrm{A}$

Char. 2203: $\mathrm{G} \rightarrow \mathrm{A}$

Char. 2418: $\mathrm{G} \rightarrow \mathrm{A}$

Char. 3811: $\mathrm{G} \rightarrow \mathrm{C}$

Char. 3836: A $\rightarrow-$

Char. 4120: $\mathrm{G} \rightarrow \mathrm{T}$

Char. 4536: $\mathrm{G} \rightarrow-$

Char. 4742: $\mathrm{A} \rightarrow \mathrm{C}$

Char. 4746: $\mathrm{C} \rightarrow-$

$18 S$

Char. 5486: $-\rightarrow \mathrm{T}$

Char. 7363: $\mathrm{C} \rightarrow \mathrm{T}$
Char. 7642: $\mathrm{T} \rightarrow \mathrm{C}$

$\mathrm{COI}$

Char. 7822: $\mathrm{A} \rightarrow \mathrm{T}$

Char. 7854: $\mathrm{G} \rightarrow \mathrm{A}$

Char. 8027: $-\rightarrow$ A

Char. 8062: $\mathrm{C} \rightarrow \mathrm{T}$

Char. 8250: $\mathrm{A} \rightarrow \mathrm{T}$

Char. 8313: $\mathrm{A} \rightarrow \mathrm{T}$

Char. 8319: $\mathrm{T} \rightarrow \mathrm{C}$

Char. 8357: $\mathrm{T} \rightarrow \mathrm{A}$

$12 \mathrm{~S}$

Char. 8937: $\mathrm{A} \rightarrow \mathrm{G}$

Char. 9206: $-\rightarrow$ A

Char. 9434: $\mathrm{T} \rightarrow \mathrm{A}$

Char. 9460: $\mathrm{A} \rightarrow \mathrm{T}$

Char. 9472: $\mathrm{T} \rightarrow \mathrm{A}$

Char. 9513: $\mathrm{T} \rightarrow \mathrm{A}$

Char. 9525: $\mathrm{A} \rightarrow-$

$16 S$

Char. 9655: $\mathrm{T} \rightarrow \mathrm{A}$

Char. 9826: $\mathrm{G} \rightarrow \mathrm{A}$

Char. 9941: $-\rightarrow$ AT

Char. 9962: - $\rightarrow$ A

Char. 10022: $\mathrm{T} \rightarrow \mathrm{C}$

Char. 10101: $-\rightarrow \mathrm{T}$

Char. 10152: $\mathrm{A} \rightarrow \mathrm{T}$

Char. 10227: $\mathrm{T} \rightarrow-$

Char. 10291: A $\rightarrow \mathrm{T}$

H3

Char. 10665: A $\rightarrow$ C

Char. 10804: $\mathrm{T} \rightarrow \mathrm{A}$

Char. 10821: $\mathrm{T} \rightarrow \mathrm{G}$

Char. 10839: $\mathrm{G} \rightarrow \mathrm{A}$

Char. 10900: A $\rightarrow$ C 